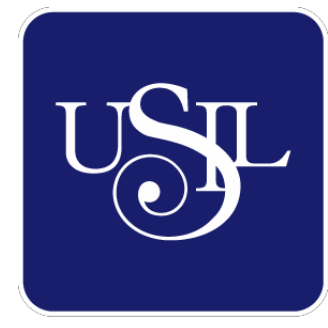

UNIVERSIDAD

SAN IGNACIO

DE LOYOLA

ESCUELA DE POSTGRADO

\title{
POLÍTICA PARA IMPULSAR EL DESARROLLO DEL DEPORTE DE ALTO RENDIMIENTO
}

Trabajo de Investigación para optar el Grado de:

CHRISTIAN EDISON DE LA TORRE CHOQUE

Maestro en Gestión Pública con Mención en Formación Práctica en Contratación Pública

\section{JONATHAN EMMANUEL OVIEDO MORE}

Maestro en Gestión Pública con Mención en Formación Práctica en Contratación Pública

\author{
Asesor: \\ Dr. Luis Fernando Peredo Rojas \\ Lima - Perú
}

2018 


\section{POLÍTICA PARA IMPULSAR EL DESARROLLO DEL DEPORTE DE ALTO RENDIMIENTO}




\begin{abstract}
Agradecemos a la Escuela de Post Grado de la Universidad San Ignacio de Loyola, que gracias a su excelente plana docente, nos brindó las herramientas necesarias para elaborar el presente Proyecto de investigación gerencial aplicado.
\end{abstract}

A nuestras familias, profesores, amigos y conocidos que gracias a su apoyo y confianza, permitieron que desarrollemos este proyecto.

Christian De la Torre y Jonathan Oviedo 


\section{RESUMEN EJECUTIVO}

La presente investigación tiene por objeto analizar el problema del bajo desempeño del deporte peruano en la alta competencia, la cual se desarrolló de manera cualitativa con revisión de bibliografías y a través de la metodología del marco lógico, para describir las causas y efectos más relevantes; de esta forma plantear una alternativa viable de solución, que permita mejorar el desempeño del deporte peruano en la alta competencia.

En tal sentido, en la investigación se ha podido evidenciar que el principal factor es el limitado apoyo y reconocimiento que existe por parte del Estado, para los deportistas con alto rendimiento deportivo; la falta de recursos, medios e incentivos necesarios y en general las condiciones en que se desarrolla este sistema, ha originado una desmotivación de nuestra juventud para llevar su talento a un nivel de alta competencia y en consecuencia esto ha repercutido en la indiferencia del sector privado y la sociedad en general.

Esta situación, nos ha llevado a formular lineamientos, que dan forma a una política pública que hemos denominado: "POLÍTICA PARA IMPULSAR EL DESARROLLO DEL DEPORTE DE ALTO RENDIMIENTO” esta iniciativa se justifica, toda vez que en nuestro país no se ha establecido una política para promover el desarrollo del deporte de alta competencia, que permita brindar las condiciones e incentivos necesarios a nuestros deportistas con alto rendimiento, que permita su valoración y reconocimiento por parte de la sociedad y el sector privado.

Esta valoración y reconocimiento, como iniciativa por parte del Estado es prioritaria, toda vez que estos deportistas dado el conjunto de valores que lo identifican, como su constancia, sacrificio y afán de superación, lo convierten en un referente muy valioso para nuestra sociedad, hasta el punto de poder inspirar patriotismo, fortalecer nuestra identidad cultural y a través de sus logros impulsar el pilar fundamental que es la masificación del deporte, que resulta nuestra principal arma contra los innumerables problemas sociales de nuestro país.

En ese sentido, esta política ha sido formulada y evaluada mediante el enfoque de valor público, planteado por Moore (1995), en su publicación Gestión Estratégica y creación de Valor en el sector público, donde se introdujo el concepto de valor público y el desarrollo de una estructura de razonamiento práctico como guía para el gestor público, que se podría resumir en 
concebir políticas con un enfoque estratégico que satisfaga tres pruebas; primero lo sustantivo, segundo lo legítimo y políticamente sostenible y tercero debe ser operativa y administrativamente viable, dichas pruebas al quedar satisfechas nos revelaría la acertada generación de valor público que se pretende alcanzar. (1995, p.11). 


\section{ÍNDICE}

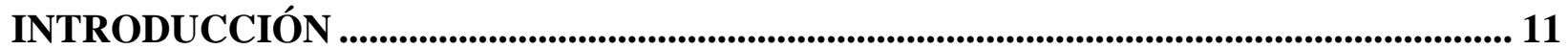

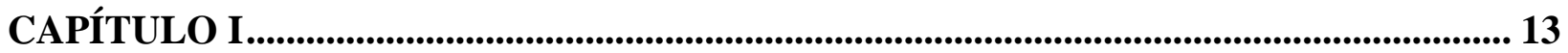

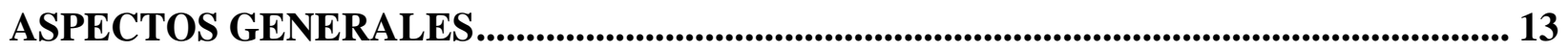

1. Aspectos generales .................................................................................................. 14

1.1. Importancia del deporte en el desarrollo de las sociedades............................................ 14

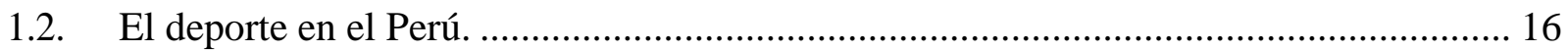

1.2.1 Descripción del proceso de captación, formación y desarrollo del Deportista orientado hacia la alta competencia (Juegos deportivos escolares, Programa de formación deportiva del IPD, Centros de Entrenamiento de Alto Rendimiento - CEAR). ....................................... 16

1.2.2 Marco conceptual (Deportistas Calificados y Calificados de Alto Nivel- Alto rendimiento, Alta competencia) …………………………………………………….... 21

1.2.3 Sistema de Estímulos y beneficios para el DC y DECAN ………………………....... 22

1.2.4 Desempeño del deporte peruano de alta competencia en eventos internacionales....... 24

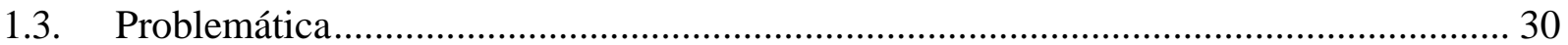

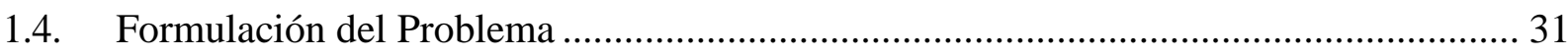

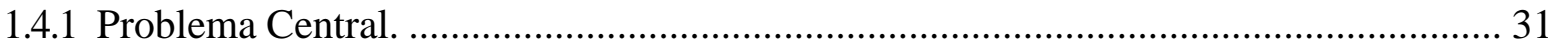

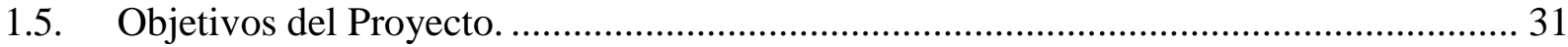

1.5.1 Objetivo General.................................................................................................. 31

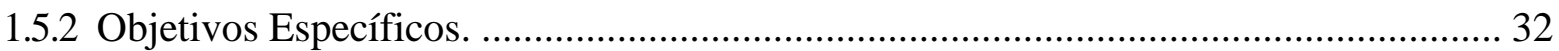

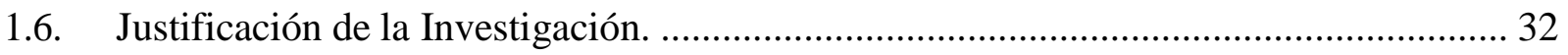

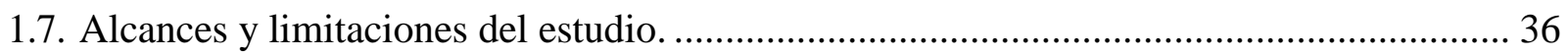

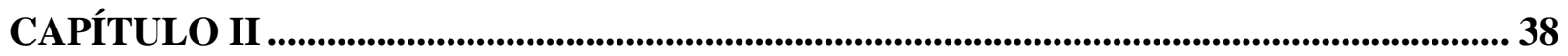

MARCO TEÓRICO

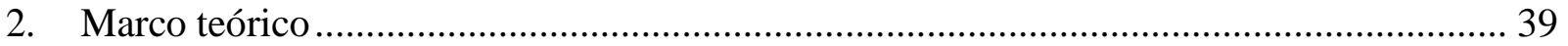

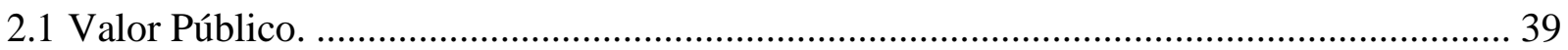

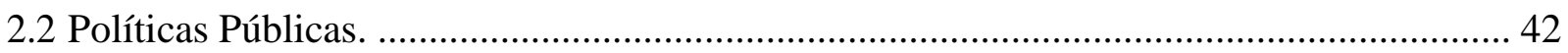

2.3 Ciclo de las Políticas Públicas........................................................................................... 46

2.4 Enfoque Integrado de Políticas Públicas.......................................................................... 49

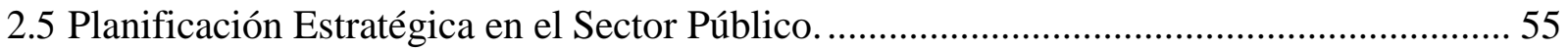

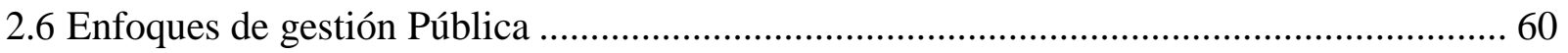

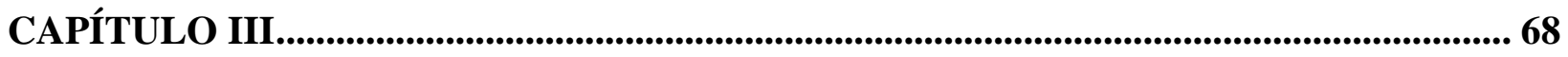

GENERACIÓN DE LA POLÍTICA PÚBLICA ......................................................................... 68 


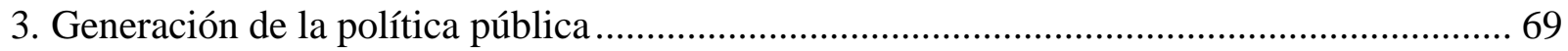

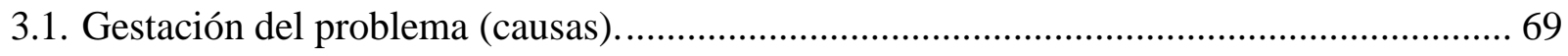

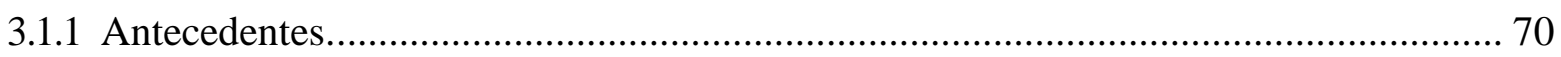

3.1.1.1 Políticas públicas para mejorar el deporte de alta competencia ................................. 70

3.1.1.2 Análisis comparativo del deporte de alta competencia en otros países ...................... 73

3.2. Diagnostico de la situación. ............................................................................................ 831

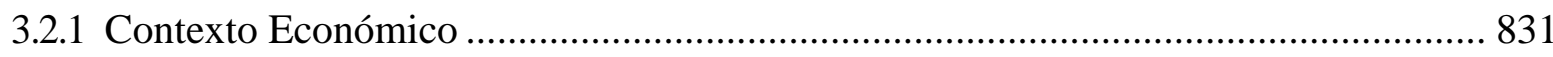

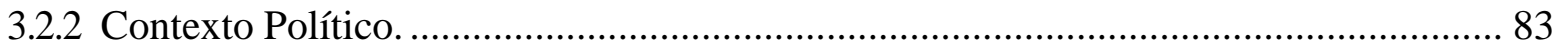

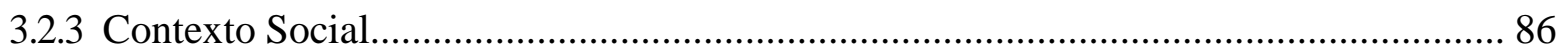

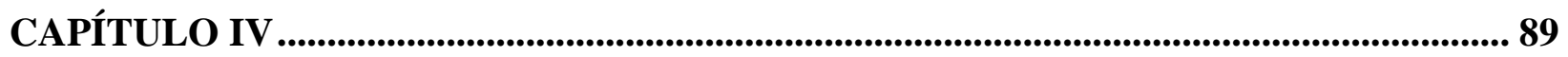

FORMULACIÓN DE LA POLÍTICA PÚBLICA......................................................................... 89

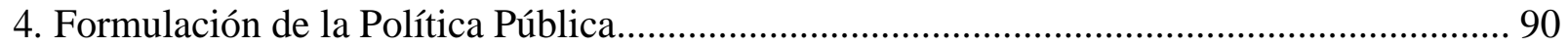

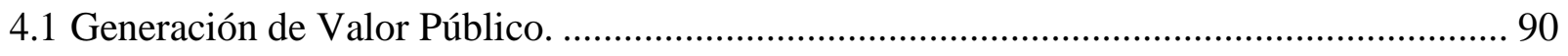

4.1.1 Dimensión Sustantiva de la Política ............................................................................ 90

4.1.2 Dimensión Operativa de la Política ........................................................................... 95

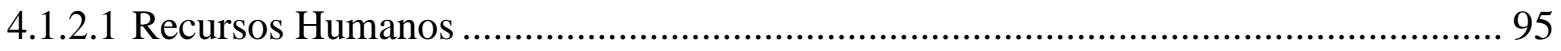

4.1.2.2 Recursos Logísticos ............................................................................................... 95

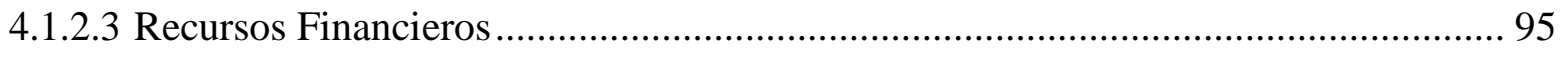

4.1.3 Dimensión Política de la Política......................................................................... 102

4.2 Enfoque Integrado de Políticas Públicas....................................................................... 113

4.2.1 Identificación de Políticas de Apoyo......................................................................... 113

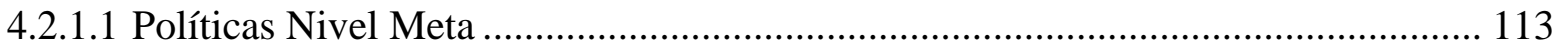

4.2.1.2 Políticas Nivel Macro ........................................................................................... 113

4.2.1.3 Políticas Nivel Meso....................................................................................... 114

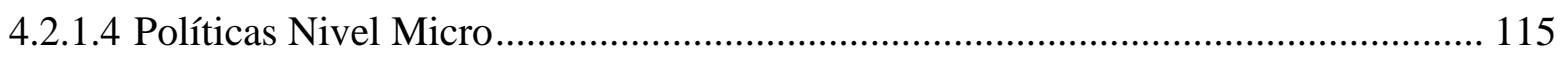

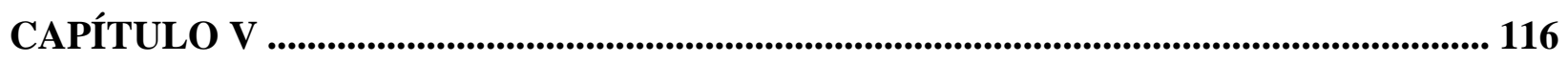

APLICACIÓN DE LA POLÍTICA EN UNA ENTIDAD PÚBLICA ...................................... 116

5. Aplicación de la Política en una Entidad Pública................................................................ 117

5.1 Planificación Estratégica de la Política con enfoque de Valor Público.............................. 117

5.1.1 Elaboración de la Gestión Estratégica de la Política .................................................... 120

5.1.1.1 Definición de Objetivo General.......................................................................... 121

5.1.1.2 Definición de Objetivos específicos ....................................................................... 121 
5.1.1.3 Elaboración de la Matriz Estratégica de Gestión........................................ 121

(Objetivos, Estrategias, Resultados, indicadores de medición y responsables) ................. 121

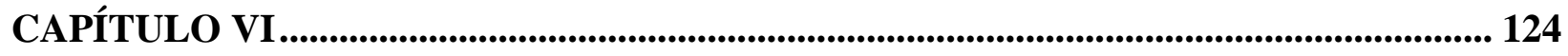

EVALUACIÓN DE LA POLÍTICA ............................................................................ 124

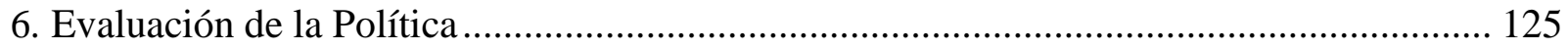

6.1 Análisis de la sostenibilidad de la Política ..................................................................... 125

6.2 Evaluación del impacto de la política ..................................................................... 128

6.3 Evaluación de las Autoridades de la Institución Pública de la Política Pública propuesta.

CAPÍTULO VII

CONCLUSIONES Y RECOMENDACIONES............................................................... 133

7. Conclusiones y recomendaciones........................................................................... 134

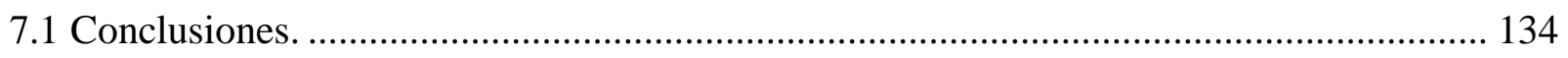

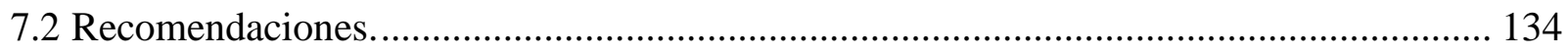




\section{ÍNDICE DE TABLAS}

Tabla 1 Microrregiones............................................... 17

Tabla 2 Cuadro resumen de beneficios e incentivos del programa de apoyo

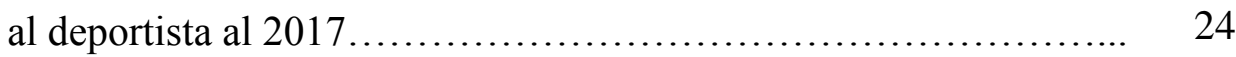

Tabla 3 Cuadro de medallas obtenidas por Perú en su participación histórica en los Juegos Olímpicos............................ 24

Tabla 4 Cuadro comparativo de preseas obtenidas por países latinoamericanos en los Juegos Olímpicos.......................... 25

Tabla 5 Gasto deportivo público - Perú................................. 26

Tabla 6 Medallas obtenidas por Perú en los Juegos Deportivos

Bolivarianos 1938-2001........................................ 27

Tabla 7 Medallas obtenidas en competencias internacionales 1978-2000... 27

Tabla $8 \quad$ Cantidad de DECAN a nivel nacional............................ 29

Tabla 9 Participación en los Juegos Olímpicos RÍO 2016................. 29

Tabla $10 \quad$ Tipos de políticas............................................ 43

Tabla 11 Ciclo de políticas públicas................................... 47

Tabla 12 Cuadro comparativo de Paradigmas................................ 63

Tabla 13 Cuadro comparativo del sistema de alto rendimiento peruano con el país de Cuba.................................................. 77

Tabla 14 Presupuesto en soles: becas de estudio.......................... 97

Tabla 15 Presupuesto en soles: becas de estudio - deportista de colegio gobiernos regionales......................................... 99

Tabla 16 Presupuesto del Instituto Peruano del Deporte. Año de ejecución 2017.

101

Tabla 17 Elaboración del Mapa Político (posicionamiento de actores)........ 107

Tabla 18 Elaboración de la Tipología de Intereses de los Grupos de Interés.. 108

Tabla 19 Análisis del Poder de los Grupos de Interés...................... 110

Tabla 20 Elaboración de Estrategias para reposicionamiento de actores...... 111

Tabla 21 Elaboración del Balance Político................................. 112

Tabla 22 Mapa estratégico del IPD 2016 - 2021........................... 118

Tabla 23 Elaboración de la Gestión Estratégica de la Política................ 120

Tabla 24 Elaboración de la Matriz Estratégica de Gestión.................... 122

Tabla $25 \quad$ Lista de entrevistados....................................... 126 
Tabla 26 Impacto en el tiempo........................................

Tabla 27 Evaluación de las Autoridades de la Institución Pública de la Política Pública propuesta.

\section{ÍNDICE DE FIGURAS}

Figura 1 Participación Peruana en los Juegos Sudamericanos escolares

Figura 2 Participación Peruana en los Juegos Sudamericanos escolares 2013........................................................ 19

Figura 3 Proceso de formación del talento deportivo...................... 19

Figura 4 Beneficios que ofrecen los CAR ............................ 21

Figura 5 Desempeño en la alta competencia. Instituto Peruano del deporte.. 28

Figura 6 Resultados deportivos comparados con Colombia................. 28

Figura 7 Política Nacional del Deporte - D.S. N003-2017-MINEDU....... 35

Figura 8 Triángulo de Moore, sobre la base de Moore (1995)................ 41

Figura 9 Niveles de intervención pública............................... 46

Figura 10 Ciclo de Políticas Públicas, sobre la base de Harguindéguy (2013) 46

Figura 11 Ciclo de políticas públicas................................... 48

Figura 12 Ventaja del ciclo de políticas públicas, sobre la base de Ejea(2006) 49

Figura 13 Factores determinantes de la competitividad sistémica............ 55

Figura 14 Evolución histórica de la legislación peruana deporte.............. 84 


\section{INTRODUCCIÓN}

Actualmente en el Perú, existe una cultura que hemos denominado como "frustración deportiva". ¿De dónde salió este término?, es la explicación a lo que hoy viven y han vivido muchas generaciones con relación al deporte profesional o de alto rendimiento, es el sueño que tiene todo deportista amateur, convertirse en un deportista profesional, pero que finalmente quedaría en un sueño inalcanzable. Estas generaciones de deportistas son los eslabones perdidos del talento deportivo. Pues de algo estamos seguros, es que todos ellos tienen algo en común y es que el deporte nunca fue una prioridad en sus vidas, sea ajeno o no a su voluntad.

Se dice que el talento deportivo no nace, por el contrario, se hace y claro con mucho esfuerzo y dedicación que se involucra desde muy temprana edad. Pero creemos que muchas generaciones en el Perú, crecimos con un modelo predefinido de nuestras vidas, este paradigma de vida consiste en terminar el colegio, para luego los que tienen la posibilidad económica, asistir a una Universidad o Instituto, obtener una profesión y de esa forma sostenerse económicamente. Pero al reflexionar sobre esto, nos preguntamos ¿Cuántos de estos futuros trabajadores, profesionales o no, hubieran podido ser deportistas de alto rendimiento y traer logros significativos al País? y ¿Por qué se perdieron o desistieron en su intento de llegar a ser deportistas profesionales? Esta última pregunta resulta nuestro punto de partida de la presente investigación.

Uno de los factores más importante que causa esta deserción de talentos, es el aspecto económico. La falta de beneficios sociales y la falta de políticas de apoyo a los deportistas, nos da como resultado que no resulta rentable ser un deportista de alto rendimiento en el Perú, claro está que en esta regla se encuentran exceptuados los futbolistas, que debido a su popularidad permite asegurar un mejor futuro para él y su familia.

Pero mientras tanto, para los deportistas que pertenecen a las 52 federaciones restantes, en muchos casos tienen que estar mendigando apoyo al privado, para poder siquiera participar en eventos deportivos. 
En este mismo orden de ideas, los gobiernos regionales y locales juegan un rol importante en el desarrollo del deporte orientado a la alta competencia, pues en este nivel, las bases del deporte deben cimentarse bajo una estructura lógica y escalonada, propiciando la masificación y formación deportiva que finalmente debe redundar en la promoción de deportistas a los centros de alto rendimiento y selecciones nacionales.

En ese sentido, con el presente proyecto de investigación se busca formular una política de incentivo para los Deportistas Calificados de Alto Nivel y Deportistas Calificados en edad escolar (Ganadores de los Juegos Deportivos Nacionales Escolares), a través de becas de estudio que les permita desarrollar capacidades y competencias alternativas al deporte, para de esta forma cuando pasen al retiro, cuenten con las herramientas necesarias para insertarse al mercado laboral y generar ingresos para su sustento económico. 


\section{CAPÍTULO I ASPECTOS GENERALES}




\section{Aspectos generales}

En el presente Capítulo se describe la problemática, donde previamente ha sido necesario abordar temas generales y conceptuales, la cual nos servirá más adelante para comprender el desarrollo del deporte de alta competencia en el Perú. Asimismo, el problema central en base a la metodología de la causalidad y los objetivos de nuestra investigación. También se describe la justificación y los alcances y limitaciones que se ha identificado para realizar el estudio.

Asimismo, en este capítulo se mostrará como es el proceso del desarrollo deportivo nacional y su arraigo en la sociedad, del mismo modo se evidenciará el panorama actual de los deportistas, los beneficios que perciben y una comparación con países del área.

\subsection{Importancia del deporte en el desarrollo de las sociedades.}

El Instituto Peruano del Deporte, menciona: "El deporte es un derecho de la persona, debe tenerse presente que el deporte no es un lujo, sino una inversión crucial en el presente y en el futuro, por lo que los países hoy lo reconocen como un derecho humano, un derecho del pueblo y como consecuencia un compromiso ineludible del Estado" (2011, p. 6).

El Instituto Peruano del Deporte, indica: "En el contexto del desarrollo, el deporte abarca todas las formas de actividad corporal que contribuyen al bienestar físico, equilibrio mental y al intercambio social, independientemente si se trata de deporte organizado o no" $(2011$, p. 6).

El Instituto Peruano del Deporte, señala: "El deporte, reconocido como actividad universal mundialmente extendida, está adquiriendo cada vez mayor importancia en nuestras sociedades y en su desarrollo, convirtiéndose en un fenómeno sociocultural que trasciende el ámbito estricto de las instalaciones deportivas, los estadios y los demás lugares en que se practica” (2011, p. 8).

El desarrollo de deporte en nuestra sociedad es importante, ya que no solo beneficia a las personas en estado físico, sino que crea hábitos en los jóvenes que previenen el uso de drogas, alcohol y otras sustancias que perjudican el estado de salud y emocional a las personas. 
En el Perú, a través de la Ley de Promoción y Desarrollo del Deporte, en su Artículo $2^{\circ}$ define al Deporte como:

La actividad física que se promueve como un factor importante para la recreación, mejora de la salud, renovación y desarrollo de las potencialidades físicas y mentales del ser humano, mediante la participación y sana competencia en todas sus disciplinas deportivas, recreativas y de educación física. (2010, p. 3).

Asimismo, el artículo 26 de la Declaración Universal de los Derechos humanos de las Naciones Unidas, señala:

La educación tendrá por objeto el pleno desarrollo de la personalidad humana y el fortalecimiento del respeto a los derechos humanos y a las libertades fundamentales; favorecerá la comprensión, la tolerancia y la amistada entre todas las naciones y todos los grupos étnicos o religiosos, y promoverá el desarrollo de las actividades de la Naciones Unidas para el mantenimiento de la paz. (1948, p. 4).

En ese sentido el deporte es considerado un derecho humano, en consecuencia, un derecho fundamental tal como los describe el artículo 14 de la Constitución Política del Perú. 


\subsection{El deporte en el Perú.}

1.2.1 Descripción del proceso de captación, formación y desarrollo del Deportista orientado hacia la alta competencia (Juegos deportivos escolares, Programa de formación deportiva del IPD, Centros de Entrenamiento de Alto Rendimiento CEAR).

Deporte escolar - Juegos deportivos nacionales

Según el MINEDU:

Los Juegos Deportivos Escolares Nacionales (JDEN), se desarrollan de forma descentralizada a nivel nacional, teniendo a las instituciones educativas - II. EE., Unidades de Gestión Educativa Local - UGEL y Direcciones o Gerencias Regionales de Educación o las que hagan sus veces - DRE o GRE, como instancias educativas que organizan, promueven y desarrollan los juegos en su jurisdicción. (2018, p. 4). 


\section{Conformación de las microrregiones}

Tabla 1.

Microrregiones.

\begin{tabular}{|c|c|c|}
\hline \multirow{4}{*}{$\begin{array}{l}\text { MACROREGION } \\
\mathrm{N}^{\circ} 1\end{array}$} & \multirow{4}{*}{$\begin{array}{c}\text { SEDE TARAPOTO / } \\
\text { MOYOBAMBA / RIOJA } \\
\text { (DRE SEDE SAN MARTIN) }\end{array}$} & Lambayeque \\
\hline & & Amazonas \\
\hline & & Loreto \\
\hline & & San Martin \\
\hline \multirow{5}{*}{$\begin{array}{l}\text { MACROREGION } \\
\mathrm{N}^{\circ} 2\end{array}$} & \multirow{5}{*}{$\begin{array}{l}\text { SEDE OXAPAMPA } \\
\text { (DRE SEDE PASCO) }\end{array}$} & Junín \\
\hline & & Pasco \\
\hline & & Huancavelica \\
\hline & & Huánuco \\
\hline & & Ucayali \\
\hline \multirow{4}{*}{$\begin{array}{l}\text { MACROREGION } \\
\mathrm{N}^{\circ} 3\end{array}$} & \multirow{4}{*}{$\begin{array}{c}\text { SEDE AREQUIPA } \\
\text { (DRE SEDE AREQUIPA) }\end{array}$} & Apurímac \\
\hline & & Arequipa \\
\hline & & Ayacucho \\
\hline & & Ica \\
\hline \multirow{5}{*}{$\begin{array}{l}\text { MACROREGION } \\
\mathrm{N}^{\circ} 4\end{array}$} & \multirow{5}{*}{$\begin{array}{c}\text { SEDE TRUJILLO } \\
\text { (DRE SEDE LA LIBERTAD) }\end{array}$} & Ancash \\
\hline & & Cajamarca \\
\hline & & La Libertad \\
\hline & & Piura \\
\hline & & Tumbes \\
\hline \multirow{6}{*}{$\begin{array}{l}\text { MACROREGION } \\
\mathrm{N}^{\circ} 5\end{array}$} & \multirow{6}{*}{$\begin{array}{c}\text { SEDE LIMA } \\
\text { METROPOLITANA } \\
\text { (DRE SEDE LIMA } \\
\text { METROPOLITANA) }\end{array}$} & Callao \\
\hline & & Lima Metropolitana \\
\hline & & Lima Provincias \\
\hline & & ADCA \\
\hline & & ADECOPA \\
\hline & & ADECORE \\
\hline
\end{tabular}

Fuente: Ministerio de Educación, 2017, p.6.

Nota: Adaptado de "Bases de lo Juegos Deportivos Escolares Nacionales 2017". 
Según la Resolución Viceministerial № 059-2018-MINEDU, las etapas de desarrollo son las siguientes:

\section{De las etapas de desarrollo}
A) Etapa Institución Educativa-Intersecciones.
B) Etapa UGEL-Interinstituciones
C) Etapa Regional-INTERUGEL.
D) Etapa Macrorregional-Interregional.
E) Etapa Nacional.
F) Etapa Sudamericana En esta etapa - clasifican los ganadores de la Etapa Nacional de los Juegos Deportivos Escolares Nacionales. (2018, p. 7).

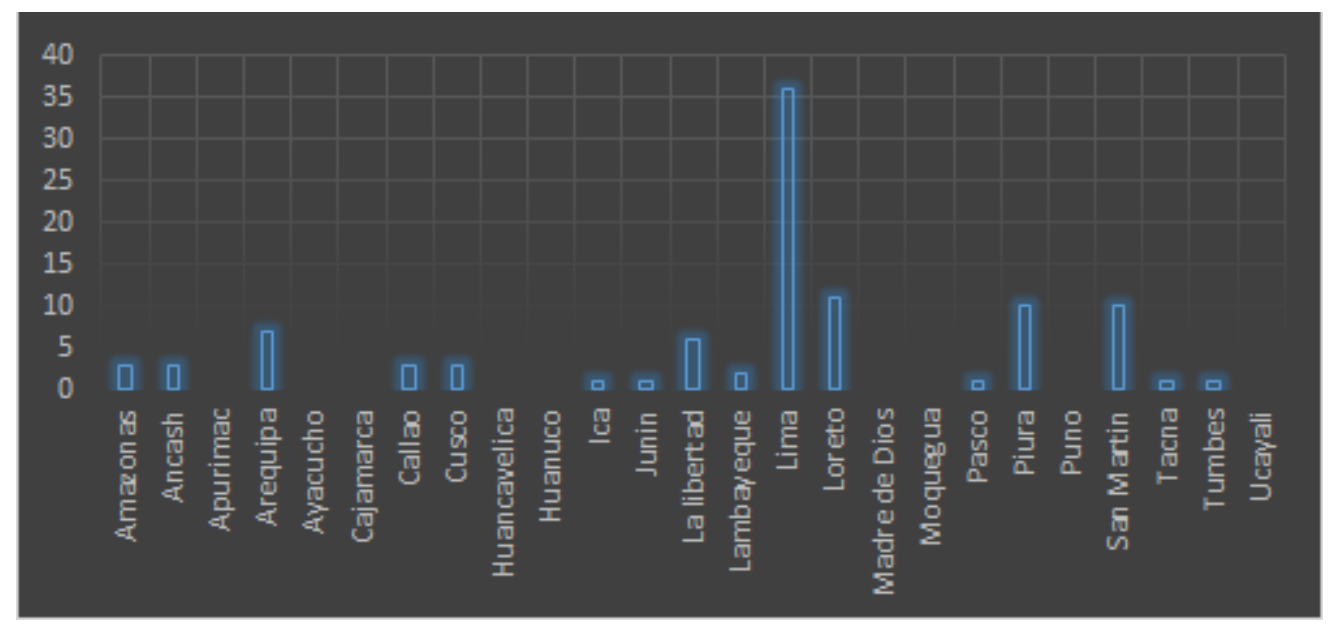

Figura 1. Participación Peruana en los Juegos Sudamericanos escolares 2013. Elaboración propia. 


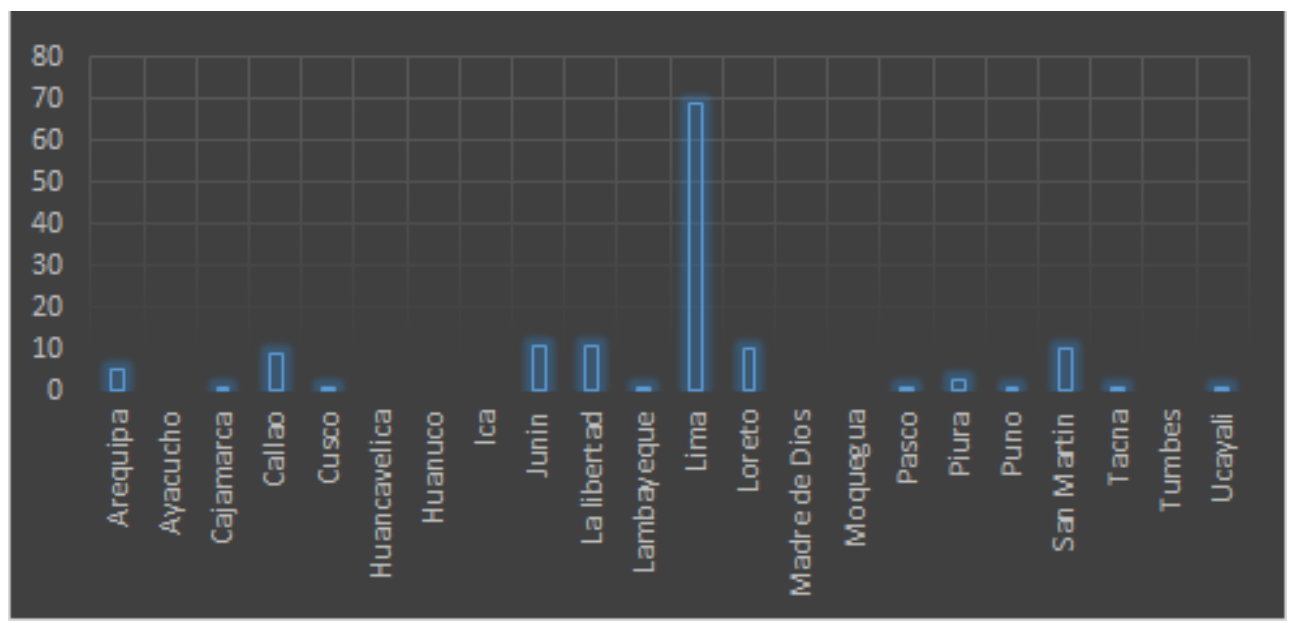

Figura 2. Participación Peruana en los Juegos Sudamericanos escolares 2013. Elaboración propia.

\section{Programa de formación deportiva}

El Programa de Formación Deportiva del IPD, se desarrolla a nivel nacional, sus principales objetivos son:

- Mejorar el nivel competitivo internacional de los deportistas peruanos de acorde con las exigencias actuales.

- Mejorar el nivel básico (gesto técnico) y físico de los deportistas del PFDR.

Este programa articula con el MINEDU, a través de la Dirección de Educación Física y Deporte, donde captan los talentos deportivos para formarlos y posteriormente derivarlos a los Centros de Alto Rendimiento (CEAR) y/o Federaciones Deportivas Nacionales, tal como se muestra en el siguiente gráfico:

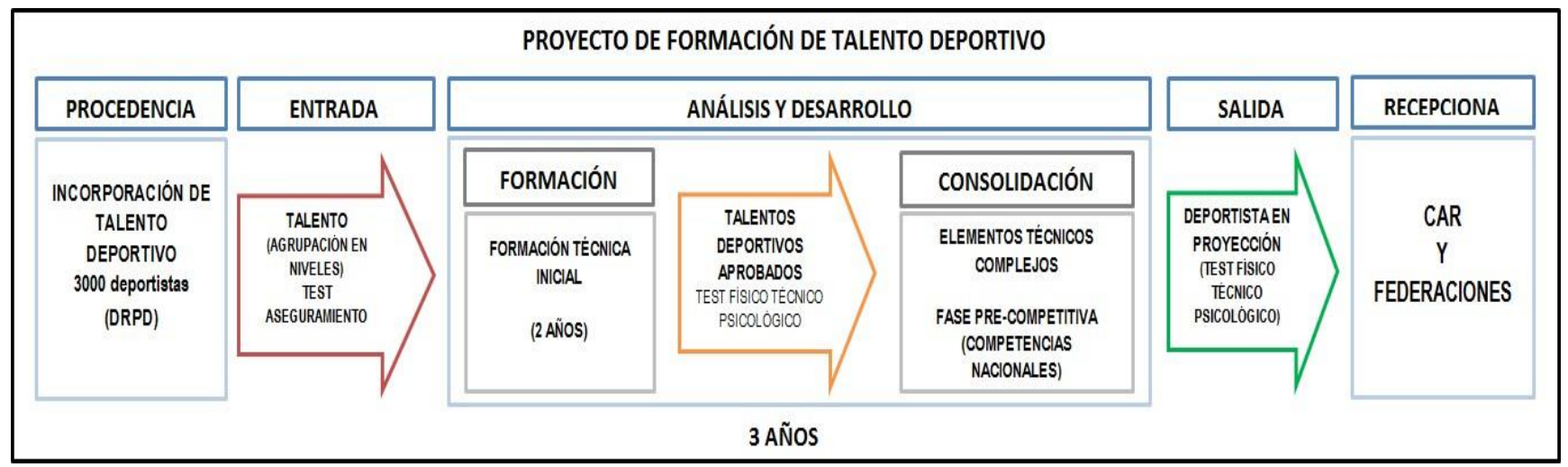

Figura 3. Proceso de formación del talento deportivo.

Fuente: Instituto Peruano del Deporte. 


\section{Los centros de alto rendimiento deportivo}

Según el Instituto Peruano del Deporte: Los CAR son centros de formación de para brindar la "formación integral a los deportistas de alto rendimiento y con proyección, buscando su desarrollo personal, profesional y logros en el deporte competitivo" (2018, s.p.), actualmente se encuentran en 7 regiones del Perú, Arequipa, Ancash, Loreto, Lambayeque, Ica, Cusco y Junín.

Según el Instituto Peruano del Deporte:

Su objetivo es reclutar deportistas talentos con proyección al alto rendimiento en las disciplinas. Esta formación integral conlleva un equipo multidisciplinario de soporte (administrativos, técnicos, nutricionistas, psicólogos, fisioterapeutas, médicos, asistentes sociales, asistencia académica) así como los servicios integrales para su desarrollo, con el fin de resultados deportivos cada vez mejores. (2018, s.p.).

A partir de los 11 años en adelante, los niños y adolescentes que tengan la aprobación de los padres o apoderados, podrán formar parte de estos Centros, que cuentan con un área de Psicología y Bienestar Social donde se trabaja en aspectos clínicos, asimismo otro aspecto, según el Instituto Peruano del Deporte: "Es el educacional y social bajo una óptica analítica comunitaria, a partir de la cual, se consideran factores sociales y ambientales a fin de realizar acciones orientadas al mejoramiento de las condiciones de vida de los deportistas" (2018, s.p.). 


\section{Beneficios / Servicios CAR}

Servicios Especializados

- Alojamiento

- Alimentación diaria (Internos: todos los dias / Externos: Parcialmente)

- Asistencia Técnico - Metodológica.,

- Sala de internet

- Tv-cable

- Juegos

- Lavanderia.

- Gimnasio

- Medicamentos mensuales

- Movilidad local mensual

- Zapatillas de entrenamiento

- Atención de pasajes y alojamiento para eventos deportivos

Figura 4. Beneficios que ofrecen los CAR. Fuente: Instituto Peruano del Deporte.

\subsubsection{Marco conceptual (Deportistas Calificados y Calificados de Alto Nivel-Alto rendimiento, Alta competencia).}

\section{DEPORTISTA CALIFICADO DE ALTO NIVEL (DECAN)}

Según el Instituto Peruano del Deporte, manual de indicaciones metodológicas define al DECAN como:

Aquel deportista que representa al país en eventos internacionales oficiales (Juegos de Órbita Olímpica o Campeonatos del calendario de las Federaciones Internacionales) y que obtiene resultados en ese nivel dentro de las categorías de competencia oficiales establecidas por las Federaciones internacionales y el COP (en todos los casos la antigüedad del resultado no debe ser mayor a dos años. (2016, s.p.). 


\section{DEPORTISTA CALIFICADO (DC)}

Según el manual de indicaciones metodológicas del IPD define al DC como:

El deportista afiliado y reconocido por la Federación Deportiva Nacional, el Instituto Peruano del Deporte y el Comité Olímpico Peruano, que obtiene el primer, segundo o tercer lugar en competencias nacionales y participación sin resultados en competencias internacionales oficiales. (2016, s.p.).

\section{ALTO RENDIMIENTO DEPORTIVO.}

Billat, define el alto rendimiento deportivo como "la máxima expresión de las capacidades del deportista y que estas conllevan a la obtención de importantes resultados deportivos" (2002, p.16).

\section{ALTA COMPETENCIA DEPORTIVA.}

La alta competencia deportiva es básicamente el óptimo desenvolvimiento que tienen los deportistas en competencias de altas exigencias.

\subsubsection{Sistema de Estímulos y beneficios para el DC y DECAN.}

El IPD cuenta con el Programa Apoyo al Deportista - PAD I del IPD, es el programa que beneficia a deportistas calificados de alto nivel (DECAN), por medio de la entrega de subvenciones económicas, pólizas de seguro y premios. Cabe resaltar que para ingresar a este programa, los atletas cuentan con marcas a nivel sudamericano, panamericano y mundial.

Al respecto, los Deportistas Calificados de Alto Nivel - DECAN, el IPD le ofrece un programa de Apoyo al Deportista (PAD II) que consiste en ofrecer un seguro médico y una subvención económica para complementar su preparación, esta oscila entre $\$ 500$ y $\$ 1,200.00$ 
USD. El otorgamiento y mantención de este beneficio se da en función a los resultados deportivos que obtenga el deportista, en cuanto deje de obtener resultados, automáticamente se le corta el apoyo.

Para el 2015 el IPD, según su Memoria Anual:

Brindo apoyo directo a un total de 666 deportistas, categorizados de acuerdo a su rendimiento deportivo, mediante la entrega de diversos beneficios (vales económicos, vales alimentarios, efectivo, seguro médico y premios). A través del apoyo se busca cubrir las principales necesidades de los deportistas de alto nivel, con miras a asegurar su adecuada preparación y el fortalecimiento de su nivel competitivo. Para el año 2015, se utilizó una inversión de S/.14 179 109, incrementándose en 19\% con respecto al año 2014 y 44\% respecto al año 2013. (2015, p. 37).

Cabe mencionar que el Programa de Apoyo al deportista (2017), se aplica sólo para algunos deportistas dependiendo de sus resultados. Por el momento hay 503 deportistas en el PAD I que son parte de los Deportistas calificados, 75 en el PAD II que son los Deportistas calificados de alto nivel y 28 en el PAD III que corresponde al grupo de maratonistas. 
Tabla 2.

Cuadro resumen de beneficios e incentivos del programa de apoyo al deportista al 2017.

\begin{tabular}{|l|c|c|c|c|}
\hline Beneficios vs Programa & $\begin{array}{l}\text { Población } \\
\text { beneficiaria }\end{array}$ & $\begin{array}{l}\text { Seguro médico } \\
\text { privado }\end{array}$ & $\begin{array}{l}\text { Subvención económica } \\
\text { preparación deportiva }\end{array}$ & $\begin{array}{l}\text { Seguro de accidentes } \\
\text { personales en caso de } \\
\text { fallecimiento, accidentes o/y } \\
\text { invalidez }\end{array}$ \\
\hline PAD I - DC & 503 & SÍ & La subvención oscila & Sí \\
\cline { 1 - 3 } PAD II - DECAN & 75 & SÍ & & Sí \\
\cline { 1 - 3 } PAD III - & \multirow{2}{*}{28} & SÍ & & Sí \\
\hline
\end{tabular}

Elaboración propia.

\subsubsection{Desempeño del deporte peruano de alta competencia en eventos internacionales.}

El indicador más confiable, en relación al mejor resultado que se espera de un deportista de alto nivel, se podría medir en referencia a los logros o preseas obtenidos en los eventos deportivos internacionales de alta competencia, uno de ellos el más importante es sin duda los Juegos Olímpicos, en donde participan atletas de diversas partes del mundo y que reúne a más de 200 naciones participantes.

Para tal efecto, haciendo un recuento de la participación de nuestros deportistas de alto nivel en los Juegos Olímpicos a lo largo de nuestra historia deportiva, solamente en 4 oportunidades se ha logrado conseguir estas valiosas preseas. En el siguiente cuadro se detalla los autores de estas hazañas.

Tabla 3.

Cuadro de medallas obtenidas por Perú en su participación histórica en los Juegos Olímpicos.

\begin{tabular}{|l|l|l|l|}
\hline \multicolumn{1}{|c|}{ Nombre } & \multicolumn{1}{c|}{ Disciplina } & \multicolumn{1}{c|}{ Evento } & Presea \\
\hline Edwin Vásquez Cam & Tiro (pistola libre 50 mt) & Londres 1948 & Oro \\
\hline Francisco Boza & Tiro (fosa olímpica) & Los Ángeles 1984 & Plata \\
\hline Combinado & Vóley & Seúl 1988 & Plata \\
\hline Juan Giha & Tiro & Barcelona 1992 & Bronce \\
\hline
\end{tabular}

Elaboración propia. 
Si analizamos estas cifras en comparación con nuestros países vecinos podemos observar que tenemos problemas muy serios con respecto al deporte de alto rendimiento. Solo obtener 4 preseas refleja la lamentable situación.

Tabla 4.

Cuadro comparativo de preseas obtenidas por países latinoamericanos en los Juegos Olímpicos.

\begin{tabular}{|l|l|l|l|l|}
\hline \multicolumn{1}{|c|}{ PAIS } & \multicolumn{1}{|c|}{ ORO } & PLATA & \multicolumn{1}{c|}{ BRONCE } & \multicolumn{1}{c|}{ TOTAL } \\
\hline Cuba & 72 & 67 & 69 & 208 \\
\hline Brasil & 23 & 30 & 55 & 108 \\
\hline Argentina & 18 & 24 & 28 & 70 \\
\hline México & 13 & 21 & 28 & 62 \\
\hline República Dominicana & 3 & 2 & 1 & 6 \\
\hline Chile & 2 & 7 & 4 & 13 \\
\hline Colombia & 2 & 6 & 11 & 19 \\
\hline Venezuela & 2 & 2 & 8 & 12 \\
\hline Uruguay & 2 & 2 & 6 & 10 \\
\hline Perú & 1 & 3 & & 4 \\
\hline Costa Rica & 1 & 1 & 2 & 4 \\
\hline Ecuador & 1 & 1 & & 2 \\
\hline Panamá & 1 & & 2 & 3 \\
\hline Puerto Rico & & 2 & 6 & 8 \\
\hline Haití & & 1 & 1 & 2 \\
\hline Guatemala & & 1 & & 1 \\
\hline Paraguay & 1 & & & \\
\hline $\begin{array}{l}\text { Bolivia, El Salvador, } \\
\text { Honduras y Nicaragua no } \\
\text { tienen medallas. }\end{array}$ & & & & \\
\hline
\end{tabular}

Fuente: En diario La Opinión, 2016.

Tal como nos revela los cuadros anteriores, desde 1992 el deporte de alto rendimiento no ha obtenido ningún logro importante a nivel de Juegos Olímpicos, por lo que se evidencia que existe un carente apoyo y una falta de incentivos a los deportistas calificados de alto nivel (DECAN), por parte de los gobiernos predecesores, que eventualmente marcarían la diferencia para que puedan alcanzar su más alto rendimiento de competencia.

Asimismo, como se puede apreciar en el cuadro anterior los países de Cuba, Brasil, Argentina y México, presentan una cantidad notable de medallas, que los diferencia y los coloca muy por encima de los demás países latinoamericanos. 
También, en la última edición de los Juegos Olímpicos Río 2016, nuestros compatriotas no lograron obtener resultados de importancia, logrando ubicarse en el puesto 88. Estos resultados no son alentadores lo que nos hace reflexionar si efectivamente ¿se están haciendo bien las cosas? ¿Faltan políticas públicas que impulsen el desarrollo del deporte?

Queda el compromiso del estado para asumir responsablemente las necesidades económicas en el sector deportivo, a través del financiamiento de los recursos económicos con el fin de cumplir los objetivos. Ya que en las últimas décadas el apoyo económico ha sido desalentador, tal como se observa en la tabla 5. (Navarro, de la revista digital Efedeportes, 2002).

Tabla 5

Gasto deportivo público - Perú.

\begin{tabular}{|c|c|c|}
\hline ANO & $\begin{array}{c}\text { GDP } \\
\text { USAS de 1994* }\end{array}$ & $\begin{array}{c}\text { GDP / PBI } \\
\text { (Por 100) }\end{array}$ \\
\hline 1950 & 687,733 & 0.007 \\
1955 & 485,960 & 0.004 \\
1960 & 867,647 & 0.005 \\
1965 & $6,272,305$ & 0.027 \\
1970 & $8,523,353$ & 0.030 \\
1977 & $11,236,268$ & 0.030 \\
1980 & $7,580,754$ & 0.018 \\
1986 & 46918,909 & 0.105 \\
1990 & $5,334,573$ & 0.014 \\
1995 & $7,710,699$ & 0.016 \\
2000 & $10.162,035$ & 0.018 \\
\hline
\end{tabular}

Fuente: EFDEPORTES, 2018.

Por otro lado, según Navarro, de la revista digital Efedeportes, indica:

En un contexto de crisis económica y explosión demográfica, han provocado en las últimas décadas, entre otros síntomas: i) El reducido surgimiento de clubes deportivos sólidos y económicamente solventes; ii) El restringido surgimiento de talentos deportivos con buena formación, resultado del paulatino y persistente deterioro de la calidad y cobertura de la educación física y del deporte escolar, aficionado y competitivo; iii) La limitada capacidad del sistema de acumular infraestructura y equipamiento en buenas condiciones, o de fomentar la formación 
de personal especializado y la investigación científica para potenciar las capacidades de los deportistas calificados. (2002, s.p.).

Tabla 6.

Medallas obtenidas por Perú en los Juegos Deportivos Bolivarianos 1938-2001.

\begin{tabular}{|c|c|c|c|}
\hline ANO & \multicolumn{2}{|c|}{ T O I I } & MEDALLAS POR \\
\cline { 2 - 4 } & DEPORTISTAS & MEDALLAS & DEPORTSTA \\
\hline 1938 & 97 & 62 & 0.6 \\
1947 & 246 & 160 & 0.7 \\
1951 & 189 & 104 & 0.6 \\
1961 & 103 & 41 & 0.4 \\
1965 & 177 & 80 & 0.5 \\
1970 & 153 & 96 & 0.6 \\
1973 & 249 & 88 & 0.4 \\
1977 & 158 & 95 & 0.6 \\
1981 & 183 & 90 & 0.5 \\
1985 & 181 & 106 & 0.6 \\
1989 & 114 & 109 & 1.0 \\
1993 & 181 & 131 & 0.7 \\
1997 & 407 & 209 & 0.5 \\
2001 & 186 & 107 & 0.6 \\
\hline
\end{tabular}

Fuente: EFDEPORTES, 2018.

De las cifras mostradas en el cuadro anterior, se puede deducir que los resultados no son los esperados y ello se manifiesta también en que el ámbito deportivo internacional no se cuenta con la competitividad necesaria. En la tabla 6 se muestra que la cantidad de medallas obtenidas han sido menores a 1 a excepción del año 1989.

Tabla 7.

Medallas obtenidas en competencias internacionales 1978-2000.

\begin{tabular}{|c|c|c|c|c|}
\hline ANOO & EYENTMOS & 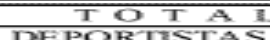 & MEDAISA = & MEDALLASPOR \\
\hline 1978 & 94 & DEPTor & 333 & 63 \\
\hline 1979 & 110 & 8066 & 176 & $a .2$ \\
\hline 1980 & 123 & 1.172 & 187 & 0.2 \\
\hline 1981 & 139 & 1311 & 392 & 0.3 \\
\hline 1982 & 153 & 1443 & 421 & 03 \\
\hline 1983 & 160 & 2009 & 286 & 01 \\
\hline 1984 & 173 & 2189 & 426 & 0.2 \\
\hline 1985 & 222 & 2731 & 593 & a. 2 \\
\hline 1986 & 327 & 5,002 & 455 & a. 1 \\
\hline 1987 & 415 & 6,676 & 564 & a. 1 \\
\hline 1988 & 279 & 4918 & 355 & a. 1 \\
\hline 1989 & 302 & 6,544 & 493 & a. 1 \\
\hline 15990 & 341 & 7,632 & 611 & a. 1 \\
\hline 1991 & 277 & 5,593 & 399 & a. 1 \\
\hline 1992 & 225 & 10,345 & 381 & 0,0 \\
\hline 1593 & 51 & $x 2$ & 205 & 0.3 \\
\hline $\begin{array}{l}1994 \\
1995\end{array}$ & 123 & & $\begin{array}{l}216 \\
143\end{array}$ & \\
\hline 1996 & 68 & & 187 & \\
\hline 19997 & 317 & 12,311 & 258 & 0.0 \\
\hline 1908 & 149 & 3,382 & 318 & a. 1 \\
\hline 1999 & 130 & 11,226 & 529 & 00 \\
\hline 2000 & 2005 & 3.495 & 513 & 0.1 \\
\hline
\end{tabular}

Fuente: EFDEPORTES, 2018. 
Durante las últimas décadas, el rendimiento de los deportistas de alta competencia ha ido decayendo notablemente en nuestro País, siendo nuestra mejor participación en el Circuito Olímpico de 1992, decayendo notablemente en cada competición hasta la actualidad.

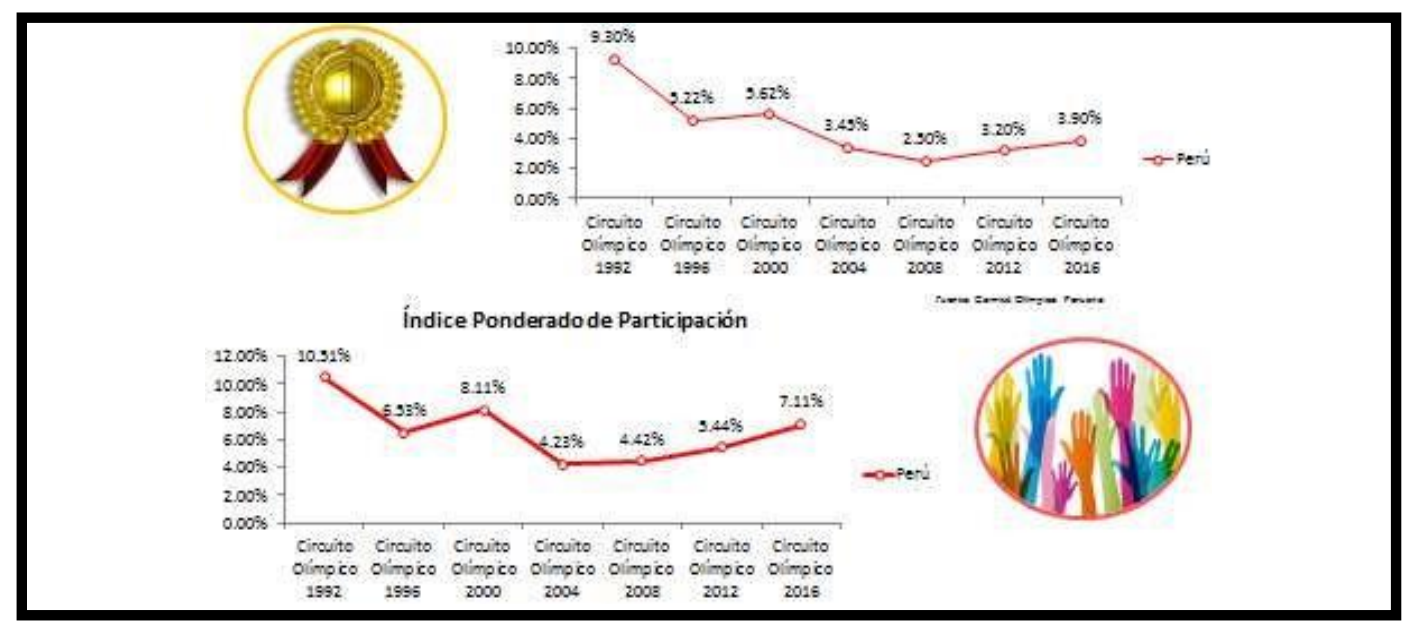

Figura 5. Desempeño en la alta competencia. Instituto Peruano del deporte.

Fuente: Instituto Peruano del Deporte, 2017.

A la par haciendo un comparativo con nuestro similar País de Colombia, se aprecia en el gráfico, que su rendimiento deportivo ha ido incrementando notablemente.

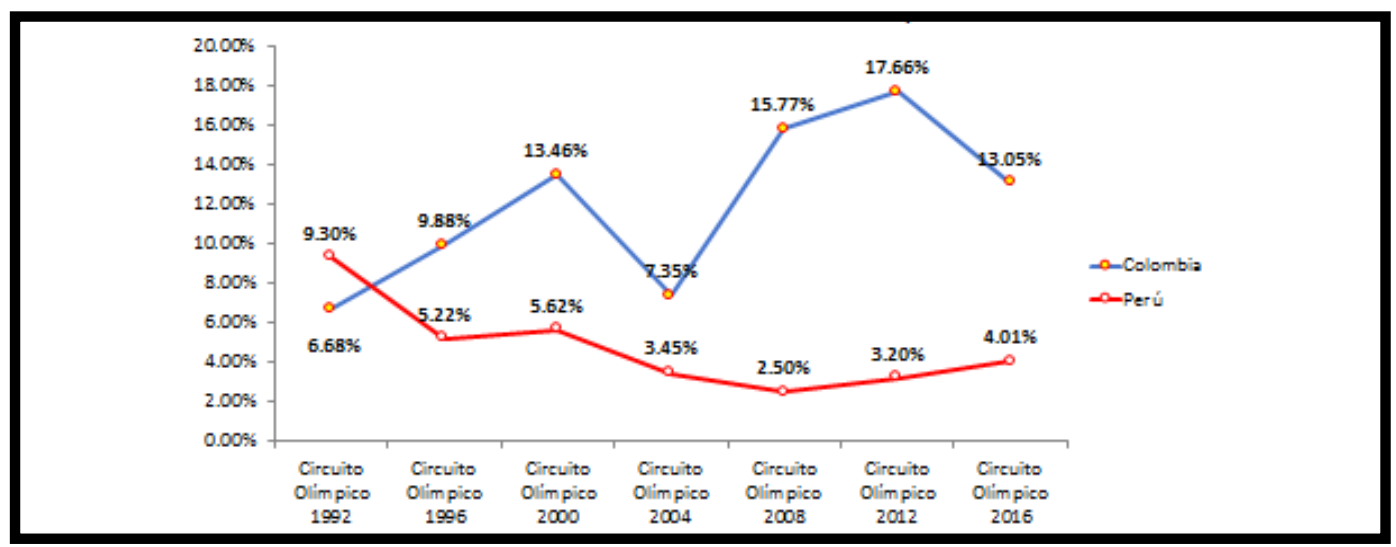

Figura 6. Resultados deportivos comparados con Colombia

Fuente: Instituto Peruano del Deporte, 2017.

A continuación, mostraremos la cantidad de DECAN que figuran registrados en el Sistema Integral Deportivo Nacional - SISDENA IPD. 
Tabla 8.

\section{Cantidad de DECAN a nivel nacional.}

\begin{tabular}{|c|c|c|c|}
\hline \multicolumn{4}{|c|}{ DEPORTISTAS CALIFICADOS DE ALTO NIVEL } \\
\hline $\mathbf{N}^{\circ}$ & FEDERACIÓN & DAMAS & VARONES \\
\hline 1 & Actividades Sub. Acuáticas & 1 & 4 \\
\hline 2 & Aero deportiva & 0 & 0 \\
\hline 3 & Ajedrez & 16 & 16 \\
\hline 4 & Amateur de Sambo & 1 & 1 \\
\hline 5 & Asociación Paralímpica del Perú & 7 & 10 \\
\hline 6 & Atletismo & 72 & 65 \\
\hline 7 & Automovilismo & 0 & 0 \\
\hline 8 & Bádminton & 37 & 26 \\
\hline 9 & Basketball & 0 & 10 \\
\hline 10 & Béisbol & 0 & 20 \\
\hline 11 & Billar & 0 & 14 \\
\hline 12 & Bochas & 1 & 6 \\
\hline 13 & Bowling & 0 & 8 \\
\hline 14 & Boxeo & 2 & 4 \\
\hline 15 & Canotaje & 0 & 0 \\
\hline 16 & Ciclismo & 0 & 6 \\
\hline 17 & Deportes Ecuestre & 3 & 2 \\
\hline 18 & Esgrima & 6 & 5 \\
\hline 19 & Esquí Acuático & 4 & 4 \\
\hline 20 & Fisicocultur ismo y Fitnes & 5 & 17 \\
\hline 21 & Futbol & 0 & 0 \\
\hline 22 & Gimna sia & 39 & 13 \\
\hline 23 & Golf & 9 & 8 \\
\hline 24 & Handball & 12 & 0 \\
\hline 25 & Hockey & 10 & 4 \\
\hline 26 & Jiu Jitsu & 0 & 1 \\
\hline 27 & Judo & 9 & 16 \\
\hline
\end{tabular}

\begin{tabular}{|c|c|c|c|}
\hline \multicolumn{4}{|c|}{ DEPORTISTAS CALIFICADOS DE ALTO NIVEL } \\
\hline $\mathbf{N}^{0}$ & FEDERACIÓN & DAMAS & VARONES \\
\hline 28 & Karate & 24 & 16 \\
\hline 29 & Kartismo & 0 & 1 \\
\hline 30 & Kick Boxing y Deportes de Contacto & 0 & 6 \\
\hline 31 & Kung Fu & 4 & 12 \\
\hline 32 & Levantamiento de Pesas & 18 & 12 \\
\hline 33 & Levantamiento de Potencia & 0 & 18 \\
\hline 34 & Lucha Amateur & 12 & 20 \\
\hline 35 & Motociclismo & 0 & 3 \\
\hline 36 & Motonáutica & 2 & 12 \\
\hline 37 & Muay Thai & 5 & 13 \\
\hline 38 & Natación & 24 & 18 \\
\hline 39 & Paleta Frontón & 2 & 4 \\
\hline 40 & Personas con Discapacidad Física & 11 & 11 \\
\hline 41 & Remo & 7 & 12 \\
\hline 42 & Rugby & 7 & 18 \\
\hline 43 & Softbol & 12 & 0 \\
\hline 44 & Squash Racket & 0 & 5 \\
\hline 45 & Tabla & 9 & 16 \\
\hline 46 & Tae kwon do & 14 & 21 \\
\hline 47 & Tenis de Campo & 14 & 20 \\
\hline 48 & Tiro & 6 & 20 \\
\hline 49 & Tiro con Arco & 0 & 1 \\
\hline 50 & Triatlón & 0 & 1 \\
\hline 51 & Vela & 14 & 13 \\
\hline 52 & Voleibol & 20 & 0 \\
\hline & Sub Total & 439 & 533 \\
\hline & TOTAL & & 72 \\
\hline
\end{tabular}

Fuente: Elaboración propia en base a información del Instituto Peruano del Deporte, 2017.

A simple vista parece que 972 Deportistas Calificados de Alto Nivel en el Perú, es una cifra interesante y que debería representar un alto nivel de desarrollo del deporte y de resultados deportivos, pero haciendo un análisis de participación de países sudamericanos en os últimos Juegos Olímpicos “Río 2016” nos arroja lo siguiente:

Tabla 9.

Participación en los Juegos Olímpicos RÍO 2016.

\begin{tabular}{|l|c|}
\hline PAÍS & PARTICIPANTES \\
\hline BRASIL & 465 \\
\hline ARGENTINA & 215 \\
\hline COLOMBIA & 148 \\
\hline VENEZUELA & 86 \\
\hline CHILE & 42 \\
\hline ECUADOR & 38 \\
\hline PERÚ & 29 \\
\hline URUGUAY & 17 \\
\hline BOLIVIA & 12 \\
\hline PARAGUAY & 11 \\
\hline
\end{tabular}

Fuente: Instituto Peruano del Deporte, 2017. 
Entonces, este cuadro nos lleva a un análisis simple, de 972 DECAN solo podemos clasificar a 29 deportistas a unos Juegos Olímpicos (siendo esta cifra la participación más numerosa en la historia del Perú en las últimas décadas) entonces, cuántos deportistas Calificados de Alto Nivel debe tener Brasil para clasificar a 465 Deportistas a unos Juegos Olímpicos o Argentina que clasifica a 215 deportistas.

Definitivamente, la cantidad de deportistas que tiene el Perú es insuficiente para obtener resultados, y es que muy pocos se animan a esta actividad debido al poco apoyo del gobierno y temor a quedar en el abandono luego de culminar su ciclo competitivo.

\subsection{Problemática.}

Resulta evidente, de acuerdo a las estadísticas descritas previamente, sobre el bajo desempeño de nuestros deportistas de alto nivel en eventos internacionales, que existe un notable problema en nuestro deporte nacional. Solo a lo largo de nuestra historia deportiva se ha podido alcanzar 4 logros a nivel olímpico, lo cual resulta lamentable si nos comparamos con otros países a nivel suramericano y mundial.

El principal protagonista de este escenario son nuestros deportistas de alto nivel, de tal manera que se les exige que entreguen todo de ellos para que nos den esos anhelados triunfos y medallas, pero sin embargo nos preguntamos si ellos reciben todos los recursos, medios y herramientas necesarias que les permita llegar a su más alto rendimiento. Solo al darle una mirada rápida a los estímulos e incentivos que reciben, el cual no cubre ni al 30\% de nuestros deportistas y con una subvención que en promedio no alcanza el sueldo mínimo, resulta más que lamentable. Además, a ello se suman las deserciones de deportistas porque deciden estudiar una carrera profesional que los respalde a futuro.

$\mathrm{Al}$ respecto, nos preguntamos ¿Con estos incentivos es posible exigir un alto rendimiento? ¿Es obligación del deportista participar en estos eventos y exigir su mayor compromiso? A nuestro criterio sería deshonesto exigir este compromiso para quienes tienen necesidades tan igual como 
cualquier otra persona o trabajador, ya que el alto rendimiento requiere de una dedicación exclusiva que alcanza hasta las 8 horas diarias, incluidas las horas necesarias de recuperación.

En esa misma línea, no solo dedican horas sino años valiosos de su juventud, ya que la mayoría de disciplinas culminan su ciclo competitivo a los 30 años, por lo que ellos mismos tienen que asegurar su futuro buscando oportunidades en otro ámbito profesional, teniendo que costear sus propios estudios y a la par tener que conseguir un trabajo que le permita cubrir sus necesidades básicas.

Entonces ¿Se encuentran realmente valorados y reconocidos nuestros deportistas? La respuesta puede ser amplia y variada, pero de lo que si estamos seguros es que en el alto rendimiento deportivo no estamos obteniendo los resultados esperados, y esta situación es muchas veces asociada a la ausencia de políticas públicas a favor del deporte.

\subsection{Formulación del Problema.}

¿CUÁLES SON LOS FACTORES O CAUSAS LIMITANTES QUE CONDICIONAN EL BAJO DESEMPEÑO DE LOS DEPORTISTAS PERUANOS DE ALTO RENDIMIENTO EN LA ALTA COMPETENCIA?

\subsubsection{Problema Central.}

"Limitado apoyo y reconocimiento al deportista orientado al deporte de alta competencia".

\subsection{Objetivos del Proyecto.}

Para la presente investigación se han establecidos los siguientes objetivos:

\subsubsection{Objetivo General.}

Realizar una investigación con la finalidad de impulsar el desarrollo del deporte de alta 
competencia a nivel nacional a través de una política pública con valor público, que promueva el apoyo y reconocimiento a los deportistas orientados al alto rendimiento deportivo.

\subsubsection{Objetivos Específicos.}

- Implementar un sistema de incentivos extrínsecos, basado en becas de estudio con énfasis en carreras ligadas al deporte, para el desarrollo integral del deportista calificado en edad escolar, que resulten campeones Nacionales, comprendidos entre los 15 a 17 años y Deportistas Calificados de alto nivel en edades comprendidas entre 18 y 29 años.

- Articular el SISDEN, empoderando a los Gobiernos Regionales y Locales conjuntamente con las federaciones, en la implementación (12) de un programa de becas de estudio y apoyo al deportista con orientación en carrera profesionales ligadas al deporte.

- Contar con profesionales en carreras ligadas al deporte para impulsar el desarrollo del deporte de alta competencia.

- Promover el apoyo e interés del sector privado para la promoción del deporte de alta competencia.

\subsection{Justificación de la Investigación.}

En nuestro país no se ha establecido una política para promover el deporte de alta competencia, si bien es cierto en la Política Nacional del Deporte esto se establece como uno de los objetivos estratégicos, está carece de elementos estratégicos para impulsar su desarrollo y sostenibilidad, que permita articular a los actores del Sistema Deportivo Nacional (SISDEN) y contribuir a la visión de producir deportistas de alto rendimiento, que sean valorados por la sociedad. 
El deportista de alto rendimiento tiene el poder de alcanzar e incentivar el patriotismo, fortalecer nuestra identidad cultural, en un ídolo hasta el punto de denominarlos héroes nacionales. El conjunto de los valores que lo identifican; como su constancia, sacrificio y su afán de superación, lo convierten en un referente muy valioso para nuestra juventud. Ahora, según El Peruano. Además, los logros de estos deportistas son el pilar fundamental para impulsar la masificación a través de la práctica como aficionados de algún deporte.

En tal sentido, la alta competencia, requiere de un compromiso y una dedicación exclusiva, que se desarrolla entre los 15 a 30 años, generalmente dependiendo de la disciplina, debiendo darle todas las herramientas necesarias, acompañado de una formación integral, para que al finalizar su ciclo competitivo puedan integrarse al mercado laboral y sostenerse económicamente. Sobre este punto las Universidades juegan un rol muy importante, pero que por el momento resulta incipiente.

Por otro lado, la captación y formación de los talentos es limitada, ya que la base para tener tanto buenos deportistas como personas, son los Capacitadores, los cuales actualmente se carece ampliamente tanto en profesionales, técnicos como en agentes deportivos.

Por último, la realidad del nivel socioeconómico de nuestro país es muy diversa y con altos índices de inequidad, lo que redunda en pocas oportunidades para que nuestros jóvenes se desarrollen y mantengan en la alta competencia deportiva, la falta de apoyo y reconocimiento a estos origina que nuestra juventud decline su voluntad por continuar en el deporte de alta competencia y busquen un camino diferente que les brinde el reconocimiento y sustento para la vida. En ese sentido es necesario determinar cuáles serían los factores que contribuyan a reducir el bajo desempeño y la falta de deportistas alto rendimiento.

Según el IPD, indica en su propuesta del Plan Nacional del Deporte 2011 - 2030 menciona los siguientes ejes estratégicos:

- Eje Estratégico No 1: Masificación del Deporte

- Eje Estratégico No 2: Desarrollo del Deporte Afiliado. (2011, p. 73). 
Objetivos específicos:

- Primer Objetivo Específico: Lograr la Masificación del Deporte en el Marco de la Concepción del Desarrollo Humano Para Lograr el Bienestar y La Paz.

- Segundo Objetivo Específico: Promover la Participación Regular y Permanente de los Estudiantes en Actividades de Educación Física Recreativas y Deportivas.

- Tercer objetivo estratégico: Elevar el Nivel Competitivo de los Deportistas de Alto Nivel. (Plan Nacional del Deporte 2011 - 2030, 2011).

El deporte, contribuye sustancialmente al mejoramiento de la aptitud física, al equilibrio psicológico y a fortalecer las relaciones interpersonales, definitivamente es importante para mejorar aspectos como la salud y estado físico brindando auto dependencia y seguridad en el quehacer diario.

El deporte nutre, fortalece y educa a la sociedad, por lo tanto, es un pilar fundamental para su desarrollo, puesto que actúa de manera transversal en sus diferentes ámbitos de intervención, logrando generar impactos favorables en la sociedad. 


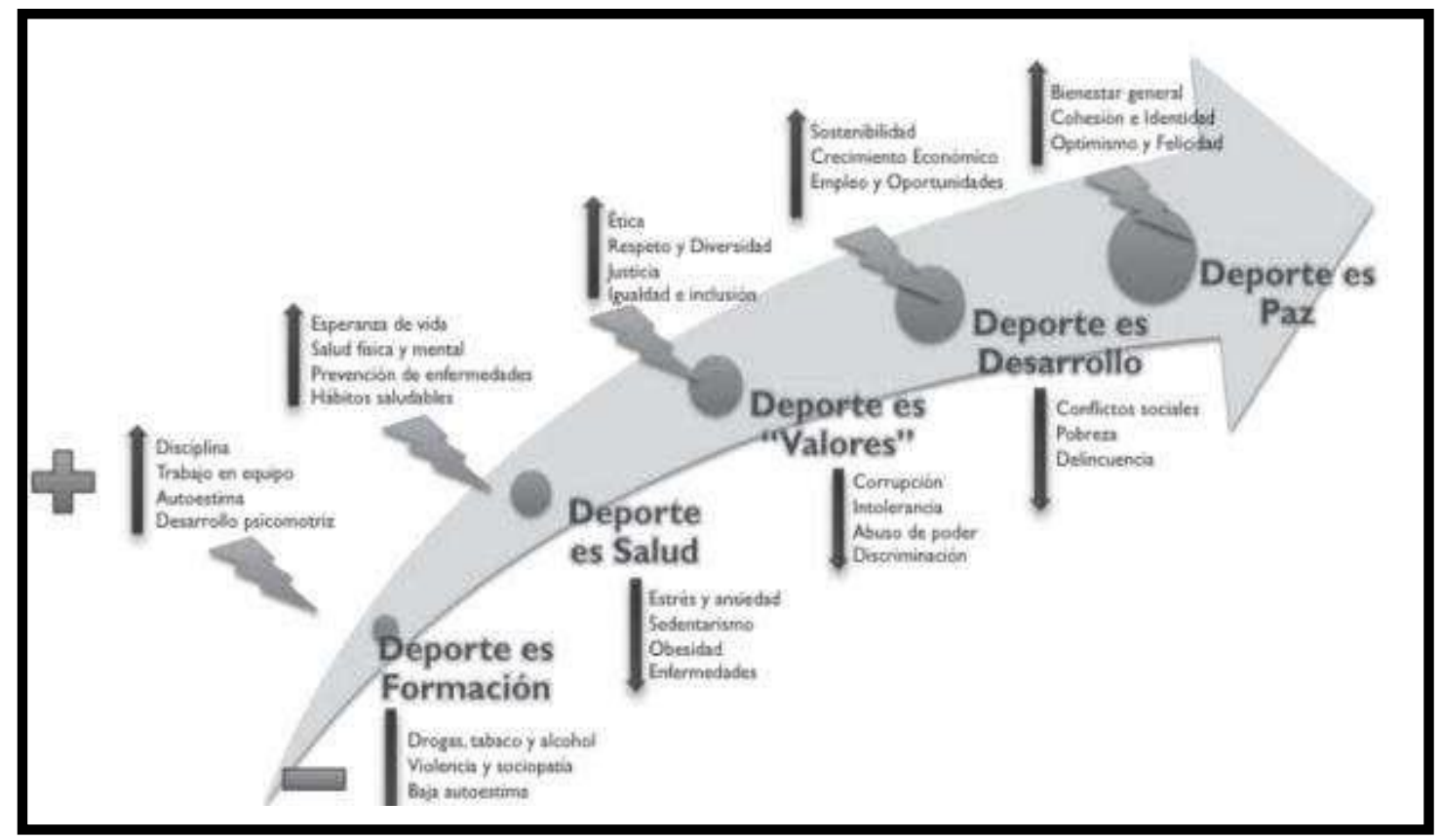

Figura 7. Política Nacional del Deporte - D.S. N003-2017-MINEDU.

Fuente: Instituto Peruano del Deporte, 2017.

Lyra y Welty Peachey, citado por EL Peruano, definen deporte para el desarrollo como:

Para que la salud pública genere una influencia positiva en las personas es necesario tener en cuenta la inclusión social de poblaciones vulnerables, el desarrollo económico de regiones y estados, sobretodo el fomento de intercambio cultural y resolución de conflictos. (2017, p. s.p.).

El deporte de alto rendimiento favorece en el crecimiento de una sociedad potencialmente activa y saludable, puesto que, al tener referentes nacionales con altos resultados deportivos en la órbita internacional, automáticamente se convierte en un estilo y/o moda que las demás personas querrán imitar, logrando de esta manera incentivar y promover la práctica deportiva.

A través de esta política se pretende impulsar el desarrollo del deporte de alto rendimiento, con intervención directa en los deportistas Calificados de Alto Nivel y Deportistas Calificados en edad escolar que hayan ocupado el primer puesto en los Juegos Escolares Nacionales, a través de 
estímulos que garanticen la longevidad del deportista, así como también que potencie la formación profesional en carreras ligadas al deporte, de esta manera se cubrirá una brecha muy importante que es el déficit de profesionales en las diferentes áreas del deporte.

Asimismo, a través de la formación profesional, se pretende incrementar el número de profesionales que sumen en el desarrollo deportivo de sus respectivas regiones y de esta manera se logre elevar el nivel competitivo regional lo que finalmente redundará en canteras de deportistas preparados para el alto rendimiento deportivo.

Otro aspecto relevante es que los deportistas Calificados de Alto Nivel que dedican gran parte de su vida al deporte y en representar al Perú en competencias internacionales, podrán contar con un respaldo profesional, que les servirá como herramienta que los sustentará una vez que se retiren de la alta competencia y de esta manera también contribuirán en el desarrollo del deporte desde una óptica profesional-científica.

\subsection{Alcances y limitaciones del estudio.}

- El presente estudio es de alcance nacional y dirigido a los deportistas calificados en edad escolar, Campeones Nacionales, en la categoría (C) entre 15 a 17 años y Deportistas Calificados de alto nivel en edades comprendidas entre 18 y 30 años.

- Podrán acceder a este beneficio aquellos DECAN que como mínimo tengan 1 Ciclo Olímpico de actividad de deportiva/competitiva y haber participado en al menos 2 eventos deportivos.

- Se podrá acceder a las becas por única vez y solo para una carrera profesional

- Para mantener el beneficio el DECAN deberá cumplir con al menos 2 Ciclos Olímpicos de actividad deportiva/competitiva y participar en al menos 2 eventos deportivos por cada Ciclo Olímpico.

- Los DECAN que decidan estudiar carreras ligadas al deporte y/o educación física, finalizando la carrera contarán con beneficios para su inserción laboral.

- Por otro lado, el nivel de información a utilizar para el presente PGA se basa en información secundaria. La información primaria será obtenida a través de encuestas a 
los mismos actores relacionados con la política.

- La cobertura a la población beneficiaria se encuentra limitada, por no ser de alcance de los deportistas calificados de alto nivel que se encuentran en retiro. 


\section{CAPÍTULO II MARCO TEÓRICO}




\section{Marco teórico}

Para poder entender la situación actual del deporte con relación a la reglamentación, normatividad, funcionamiento, entre otros temas que son determinantes para el funcionamiento del deporte peruano, es necesario tener el marco conceptual, donde se explica y describe todo lo relacionado a las políticas públicas, cuándo y cómo se genera valor público, los diferentes enfoques y cómo lo defines los diferentes autores.

\subsection{Valor público.}

\section{Definiendo la palabra VALOR:}

El diccionario de la Real Academia ofrece la acepción de esta palabra como:

El grado de aptitud o_utilidad de las cosas, para lograr satisfacer las necesidades: Valor es un concepto amplio que puede referirse a la importancia, el precio o la utilidad de algo; a una cualidad, una virtud o un talento personal; al coraje o el descaro de una persona, así como a un bien o a la validez de una cosa. Como tal, proviene del latín valor, valōris. Significados. (2017, s.p.).

Vía Definición ABC, explica que "el valor es una cualidad que le otorga a las cosas, hechos o personas una estimación ética o estética según corresponderá en cada caso y que podrá ser positiva o negativa" (2017, s.p.).

El valor público es aquella acción que está orientada a responder y resolver las necesidades de la población, debiendo estar presente en todos los niveles de gobierno. a fin de profundizar más en el conocimiento del valor público, procederemos a citar autores que describen el valor público desde sus propias perspectivas. 
El valor público tiene ver con el grado de utilidad o el valor que los ciudadanos otorguen a las actividades o servicios que les ofrece es Estado. Estos servicios generados por el Estado, deben ser proveídos eficientemente y confiables; asimismo la principal característica ha de ser que es lo realmente el público necesita.

Gómez cita a Kelly y Muers, "El concepto de valor público provee entonces una medida con la cual se puede evaluar el desarrollo de las políticas y las instituciones públicas, la forma en que toman las decisiones, distribuyen los recursos y seleccionan los sistemas adecuados para generar los bienes" (2012, s.p.).

La creación de valor público presenta una mayor complejidad a la de retomar y definir cuáles son las preferencias individuales que mejor representan las necesidades de la sociedad, o bien, la selección de una determinada política pública. El gobierno puede generar valor público cuando realiza una adecuada selección de las preferencias ciudadanas, cuando hace una correcta definición sobre los bienes o servicios que mejor respondan al interés público y la oportuna elección de políticas que permita proveerlos, - la cual no deberá responder solamente a criterios de eficiencia, es decir bajo el criterio costo-beneficio, ya que no es lo único que genera valor (Gómez cita a Bozeman, 2002; Jackson, 2001; Kelly y Muers, 2002; Moore, 1995).

Por otro lado, la idea de Valor Público remite al valor creado por el Estado a través de servicios, leyes, regulaciones y otras acciones (Riega-Virú, 2017).

Pero también, se crea valor sobre todo a través de transacciones individuales con los ciudadanos, garantizando sus derechos, satisfaciendo sus demandas y, prestándoles servicios de calidad (Moreno, M., 2009).

\section{Según Carrillo:}

Asimismo, el valor público, en la gestión pública de cualquier Estado Democrático, no es otra cosa que producir más valor, garantizando mayor y mejor vida de sus ciudadanos beneficiarios. Pues ellos aportan, tributan, pagan impuestos y nos 
delegan temporalmente autoridad con responsabilidad en las ánforas cada hay elecciones ciudadanas o somos designados designamos en algún cargo público. (2012, p. 4).

Mark Moore, plantea que para generar valor público y este sea sostenible en el tiempo, se debe tener en cuenta 3 dimensiones (Sustantiva, Política y Operativa), y estas deben guardar armonía mutua.

Dimensión sustantiva: conocer la problemática que aqueja a la población, los antecedentes y el impacto.

Dimensión política: se conocen los principales actores que intervienen en la puesta en marcha de la política pública, y se evalúa a través de un mapa político cuáles son los actores a favor y en contra.

Dimensión operativa: los recursos con los que se contarán para la implementación de la política pública. (1995, p. 16).

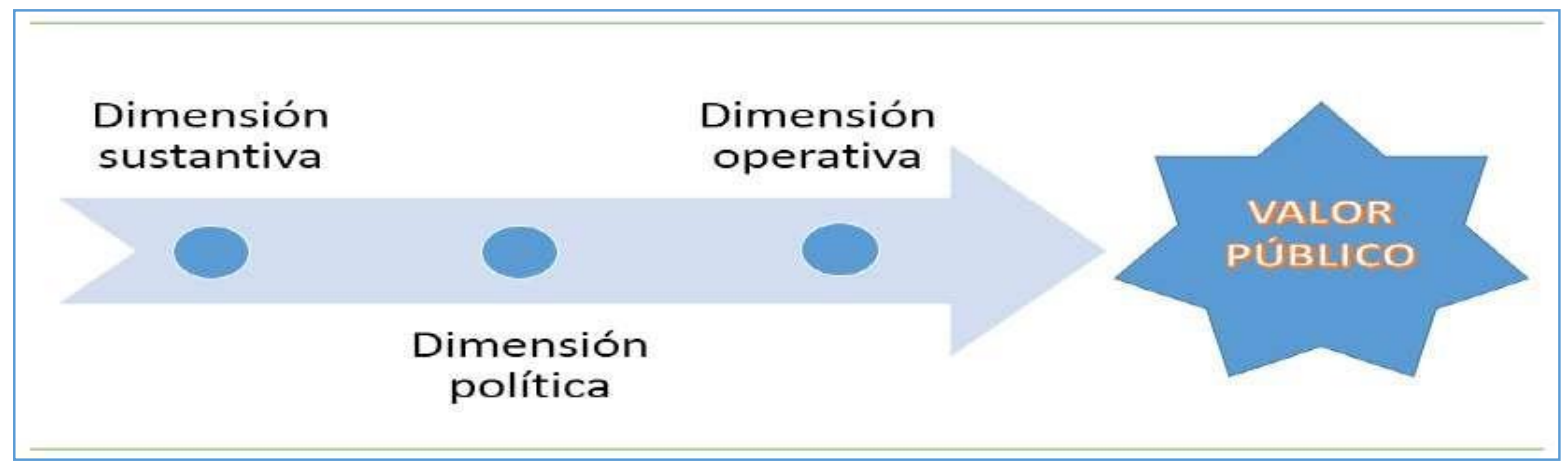

Figura 8.Triángulo de Moore, sobre la base de Moore (1995).

Fuente: Creating Public Value: Strategic Management in Government, 1995. 
Muchas políticas públicas luego de 3 ó 4 años de haberse promulgado o cada cambio de gobierno, tienden a desaparecer. Por ello, es importante conocer y desarrollar correctamente cada una de estas dimensiones, porque de ello dependerá la sostenibilidad de la política pública en el tiempo.

Zuñiga cita Kelly y Muers, indican: "El valor público, para que tenga un verdadero valor, no solo debe guiarse de la preferencia de los ciudadanos, sino que es tal cual si los ciudadanos están dispuestos a renunciar a algo a cambio de aquello" (2003, s.p.).

Entonces, podemos concluir en que el valor público hace referencia al valor creado por el Estado a través de la calidad y eficiencia de los servicios que presta a la ciudadanía, de esta manera brindando bienestar y calidad de vida a población.

Es responsabilidad del Estado buscar la satisfacción y la calidad de vida de sus ciudadanos, garantizando políticas públicas que respondan a las necesidades de la población, que tengan como soporte primigenio la transparencia y mecanismos eficientes de rendición y de fácil acceso a la población.

\subsection{Políticas públicas.}

Hablar de políticas públicas es referirnos a todas aquellas regulaciones y/o acciones que implementan los diferentes niveles de gobierno a fin de brindar un mejor servicio al ciudadano.

En este sentido, es preciso conocer las definiciones que plantean los diferentes autores; el término política debe poder incluir lo que intencionalmente persigue y lo que realmente ocurre como resultado de la intención (Aguilar, 1992).

Winchester cita al Banco Mundial "Una política es un plan para alcanzar un objetivo de interés público” (2011, p. 5). 
Por otro lado, Winchester, sostiene que:

Es un conjunto de actividades (programas, estrategias, procedimientos, leyes, reglamentos) dirigido hacia un objetivo general. Estas actividades frecuentemente se acumulan durante años. Asimismo, Aguilar, menciona: "El curso intencional de acción que sigue un actor o un conjunto de actores al tratar un problema o asunto de interés". (1992, p. 5).

En opinión de Sojo, una política pública es toda acción de gobierno encaminada a atender o resolver un problema de interés público.

Molina y Cabrera, citados por Segeplan; resaltan que "Las políticas públicas son procesos de construcción colectiva de iniciativas, decisiones y acciones, respaldadas y legitimadas por el Estado, para dar respuesta a problemas socialmente reconocidos, en un contexto económico, político, social y cultural particular" $(2015$, p. 16).

Aguilar, citado por Lima, indica: "El concepto de política presta atención a lo que de hecho se efectúa y lleva a cabo, más que a lo que se propone y quiere" (1993, s.p.). Distingue también la política de una decisión, que es la mera elección entre alternativas" (Anderson, 1984: 3) citado por (Aguilar 1992) hechura de políticas públicas.

Por su parte Harguindéguy 2013, define las políticas públicas como "Programas desarrollados por autoridades públicas" (2013, s.p.).

Tabla 10.

Tipos de políticas.

\begin{tabular}{|l|l|l|}
\hline & $\begin{array}{l}\text { COERCIÓN PÚBLICA SOBRE LOS } \\
\text { AFECTADOS }\end{array}$ & $\begin{array}{l}\text { COERCIÓN PÚBLICA SOBRE EL } \\
\text { ENTORNO DE LOS AFECTADOS }\end{array}$ \\
\hline COERCIÓN PÚBLICA INDIRECTA & Políticas distributivas & Políticas Constitutivas \\
\hline COERCIÓN PÚBLICA DIRECTA & Políticas Reglamentarias & Políticas Redistributivas \\
\hline
\end{tabular}

Nota: recuperado de Lowi (1964, 677-755; citado en Mény y Thoenig, 1989). 
Ruiz y Cárdenas, definen las políticas públicas como "El conjunto de actividades de las instituciones de gobierno, actuando directamente o a través de agentes, y que van dirigidas a tener una influencia determinada sobre la vida de los ciudadanos" (2003, p.12.).

PETERS, B. G. American Public Policy, Franklin Wats Pubs., Nueva York En este sentido las Políticas Públicas deben ser consideradas como un "procesos decisional”, y estas deben llevarse a cabo a lo largo de un plazo de tiempo y deben ser sostenibles (1982, p, 5).

Ejea, define las políticas públicas como estrategias de acción encaminadas a resolver problemas públicos a partir del interés y la opinión de los grupos sociales afectados (2006, p. 8).

Del mismo modo, Tamayo, sostiene que "Las políticas públicas son conjuntos de objetivos, decisiones y acciones que lleva a cabo un gobierno para solucionar los problemas que en un momento dado los ciudadanos y el propio gobierno consideran prioritarios" (1997, p.2).

De esta manera, Delgado, citado por la Junta de Comunidades de Castilla-La Mancha de Administraciones públicas, plantea 3 principales tipos de políticas públicas:

- Políticas sustantivas y procedimentales. Las políticas sustantivas tienen que ver con lo que el gobierno va a hacer, como construir autopistas, abonar un subsidio por desempleo o prohibir la venta de alcohol a menores de edad.

- Políticas distributivas, regulatorias, autorregulatorias y redistributivas. Las políticas pueden ser clasificadas en función de su efecto sobre la sociedad y de las relaciones entre los actores involucrados en su formación.

- Políticas materiales y simbólicas. También podemos clasificar las políticas públicas en función del tipo de beneficio que suponen para sus beneficiarios. 
Uno de los enfoques para la formulación y ejecución de políticas públicas se basa en decisiones colectivas que parten de la elección racional, en la cual, las partes involucradas - tanto gerentes públicos como ejecutores de política, usuarios, ciudadanos y sociedad civil en general- buscan la maximización de sus beneficios. (2009, p.4).

En este sentido, uno de los aspectos que deben tener en cuenta los formuladores y decisores de políticas públicas son los incentivos como marco institucional para la decisión y la acción. Es este marco institucional, implica la maximización de beneficios en la medida que los individuos toman un curso de acción según sus preferencias y creencias sobre el entorno, con el fin de obtener el mayor beneficio: comportamiento racional.

Segeplan Guatemala, plantea que existen 5 fases para la formulación de políticas públicas:

Fase I: Identificación del problema.

Fase II: Identificación y formulación de soluciones.

Fase III: Toma de decisión.

Fase IV: Implementación (trabajo sobre terreno).

Fase V: Evaluación. (2015, p.38).

El Departamento Nacional de Planeamiento de Colombia, plantea 05 niveles de intervención pública: 


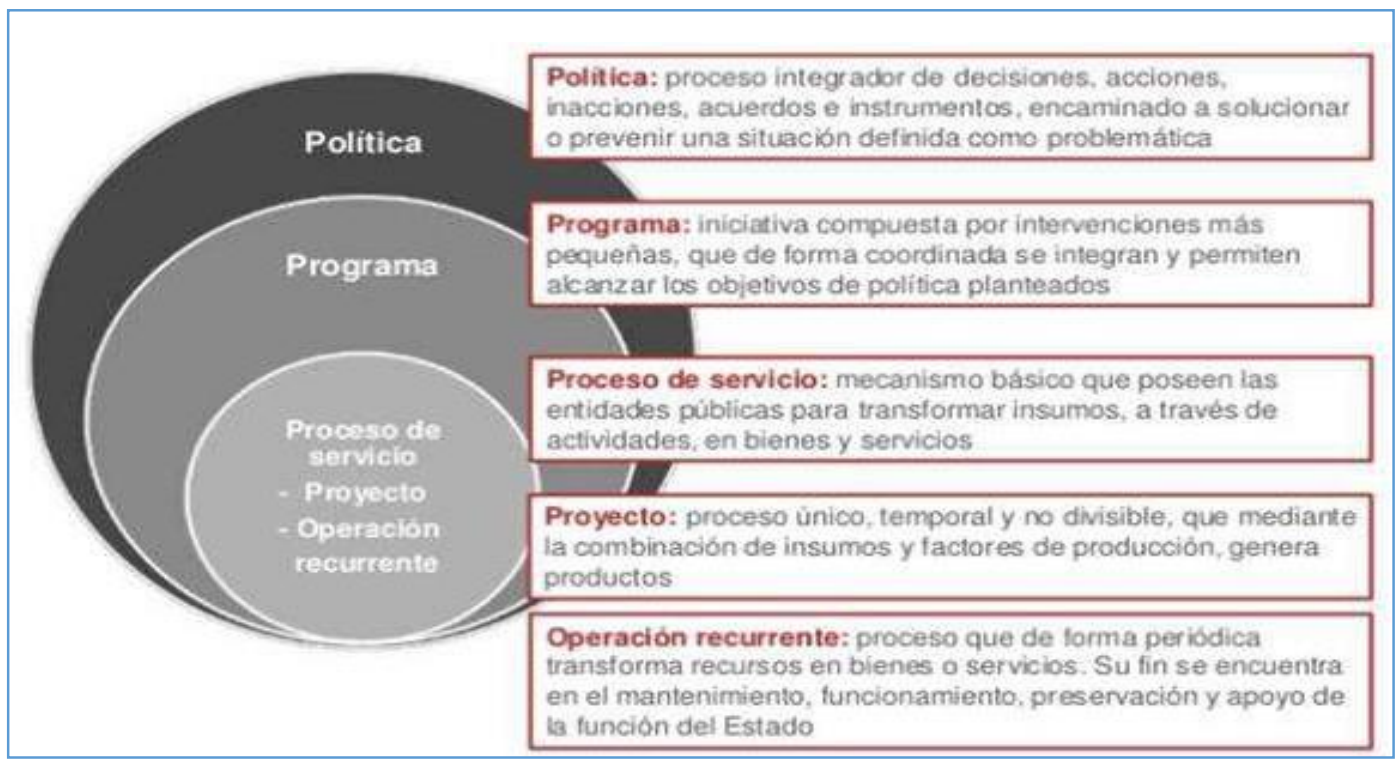

Figura 9. Niveles de intervención pública.

Fuente: Departamento Nacional de Planeación, 2015.

\subsection{Ciclo de las políticas públicas.}

El ciclo de políticas públicas hace referencia al conjunto de etapas y/o fases que en las cuales demandan de decisiones y acciones, bajo este contexto citamos a Harguindéguy (2013) quien sostiene que el ciclo de políticas públicas "se trata de dividir el proceso de adopción de un programa público en fases para poder entender (y mejorar) cada una de ellas.

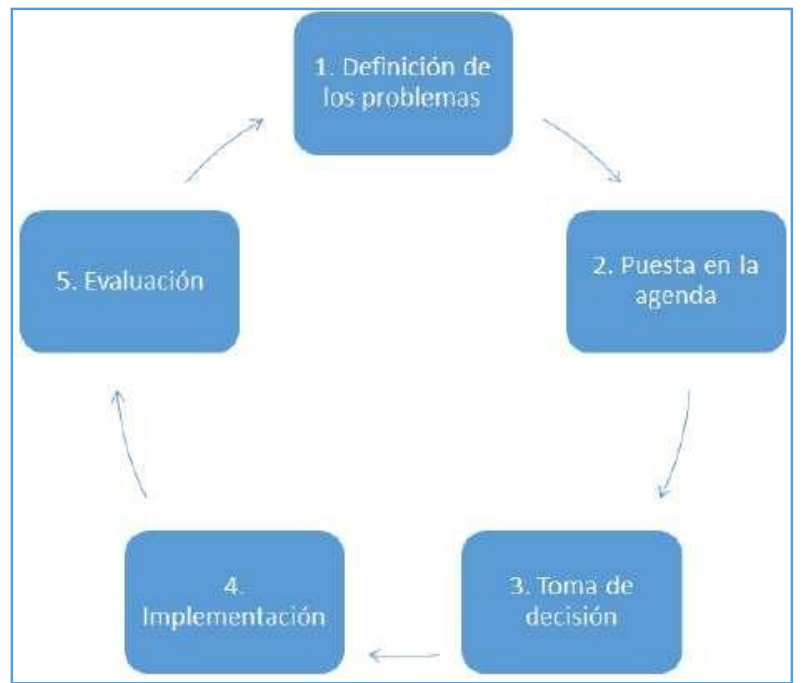

Figura 10. Ciclo de Políticas Públicas, sobre

la base de Harguindéguy (2013).

Elaboración propia. 
Por su parte, Delgado citado por la Junta de Comunidades de Castilla-La Mancha de Administraciones públicas precisa que "Las principales fases del ciclo de las políticas públicas son las siguientes: 1) la identificación y definición de problemas; 2) la formulación de políticas; 3 ) la adopción de la decisión; 4) la implantación; 5) la evaluación” (2009, p.6).

Asimismo, Lasswell citado por Harguindéguy 2013, sostiene que el ciclo de políticas públicas se divide en 7 etapas: 1) "Inteligencia" (Se estudia el problema en profundidad), 2) “Recomendación” (Se sopesa cada alternativa), 3) "Prescripción” (Se crea una regla general), 4) "Innovación" (Se espera que modifique algunos comportamientos), 5) "Aplicación” (Puesta en obra de la política), 6) “Terminación” (Se acaba) 7), "Evaluación” (Se calcula si ha sido eficaz y cómo mejorarla) (1956, p.8).

Corzo, sostiene, que el ciclo de políticas públicas se divide en 4 etapas, según muestra en el siguiente gráfico:

Tabla 11.

Ciclo de políticas públicas.

\begin{tabular}{|c|c|c|c|}
\hline Gestación & Diseño & Implementación & $\begin{array}{c}\text { Evaluación de } \\
\text { impacto }\end{array}$ \\
\hline $\begin{array}{l}\text { D Surgimionto o } \\
\text { identificación de } \\
\text { problemas públicos. } \\
\text { Inclusión en la } \\
\text { agenda de gobierno. }\end{array}$ & $\begin{array}{l}\text { Análisis del problema. } \\
\text { Análisis de soluciones. } \\
\text { Análisis de factibilidad. } \\
\text { Recomendación de } \\
\text { politica pública. } \\
\text { Plan do acción de } \\
\text { politica pública. }\end{array}$ & $\begin{array}{l}3 \\
\text { Decisión. } \\
\text { Presupuestación. } \\
\text { Legislación. } \\
\text { Ejecución en agencias } \\
\text { gubernamentales. }\end{array}$ & $\begin{array}{l}\text { Evaluación de los } \\
\text { efectos de la politica } \\
\text { pública. }\end{array}$ \\
\hline \multirow[t]{2}{*}{$\begin{array}{c}\text { Posibilidad de } \\
\text { evaluación en } \\
\text { las etapas } 2,3 \text { y } 4\end{array}$} & $\begin{array}{l}\text { Evaluación } \\
\text { ex-ante }\end{array}$ & $\begin{array}{l}\text { Evaluación } \\
\text { concomitante }\end{array}$ & $\begin{array}{l}\text { Evaluación } \\
\text { ex-post }\end{array}$ \\
\hline & $\begin{array}{l}\text { Objeto de análisis } \\
\text { de este libra. }\end{array}$ & & \\
\hline
\end{tabular}

Nota. Tomado de diseño de políticas públicas. Corzo (2013).

Fuente: Corzo, Diseño de políticas públicas, 2013. 
En el mismo orden de ideas, Segeplan 2015, plantea 3 momentos y 5 fases del ciclo de políticas públicas:

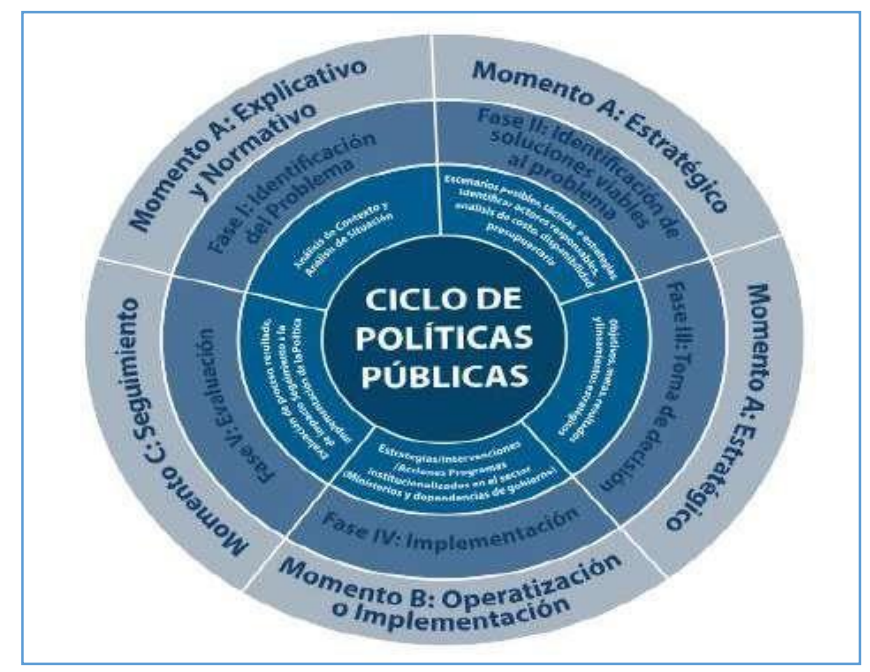

Figura 11. Ciclo de políticas públicas. Fuente: Segeplan 2015.

Las ventajas de llevar un ciclo de políticas públicas podemos citarlas atendiendo a Del Castillo y Mendez y Knoepfel y otros, citados por Ejea (2006). 


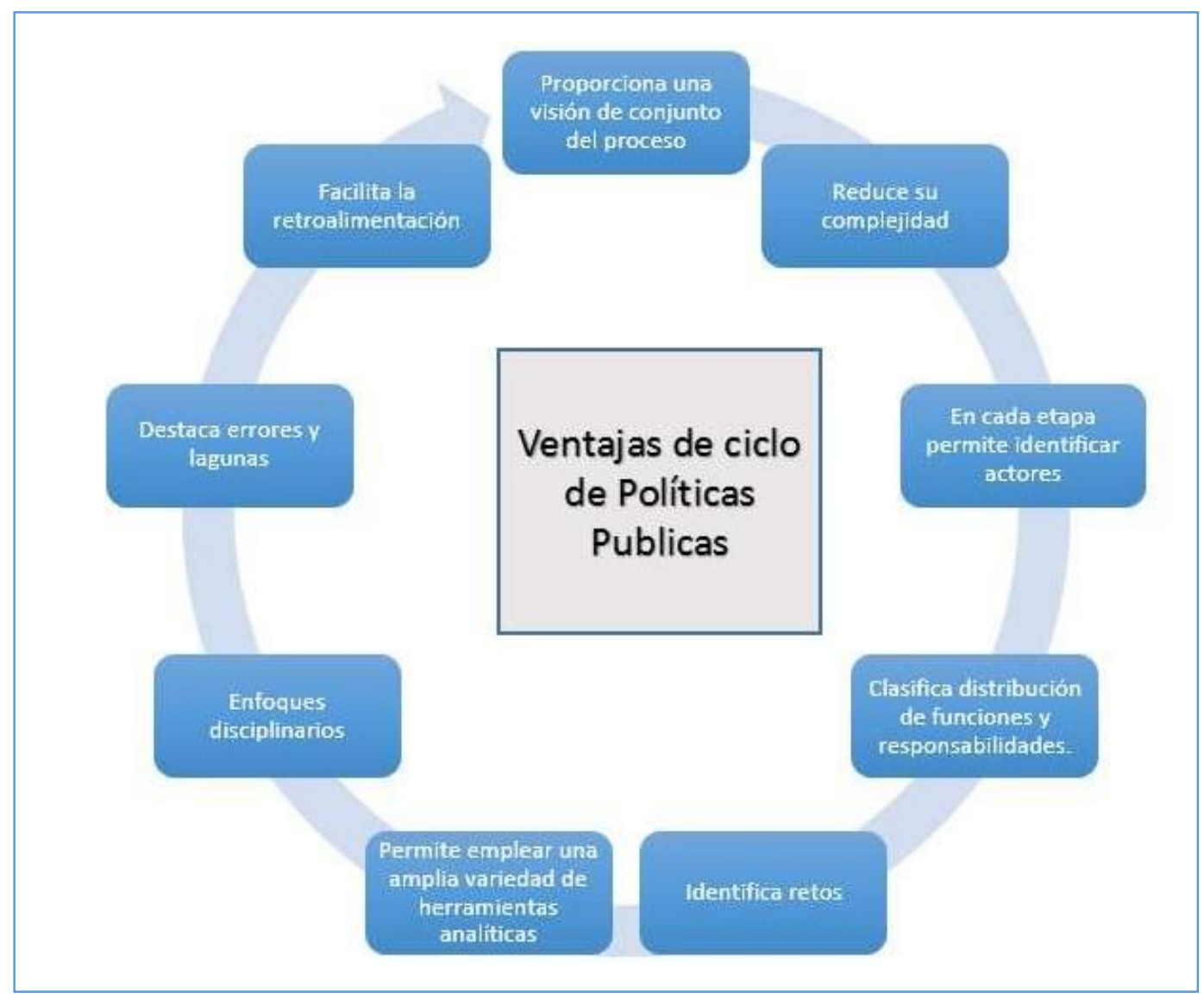

Figura 12. Ventaja del ciclo de políticas públicas, sobre la base de Ejea (2006). Elaboración propia.

\subsection{Enfoque integrado de políticas públicas.}

Las políticas públicas, son las intervenciones que se conciben como solución a determinados problemas y necesidades sociales, en ese sentido resulta necesario sistematizar e integrar estas intervenciones, para obtener el máximo beneficio y lograr el objetivo por las que fueran concebidas.

Estas intervenciones son las estrategias para superar las debilidades de las naciones, por lo que resulta necesario contar con un Estado fortalecido, moderno y transparente que promueva la integración entre Estado, sociedad y empresa, para lograr el desarrollo de las naciones.

El Banco Mundial introdujo la noción de buena gobernanza a fines de los 80, precisando que es necesario contar a nivel nacional con una regulación pública transparente y servicios 
públicos que funcionen con eficiencia, para alcanzar un crecimiento liderado por el mercado. Este concepto sirvió de inspiración para los Estados para iniciar una reforma institucional.

En la publicación de la revista 85 de la CEPAL, “Gobernanza Sistémica y Desarrollo en América Latina" por Von, se propone un marco conceptual para la evaluar la trayectoria de reforma institucional para la modernización del Estado y la cooperación para el desarrollo, a través del enfoque de buena gobernanza y el de competitividad sistémica (2005, p. 35).

Siguiendo esta publicación, este enfoque precisa que la competitividad sistémica engloba las funciones que los Estados deben asumir para promover un desarrollo de amplia base y cómo deben interactuar mercado y Estado para combinar sus fortalezas y superar sus debilidades, a efectos de lograr un nuevo equilibrio de poderes entre estos. En este enfoque se distingue cuatro niveles de interacción: el nivel meta, macro, meso y micro.

\section{El enfoque de competitividad sistémica}

Según Esser, Hillebrand, Messner y Meyer, señalan:

El concepto de competitividad sistémica parte de un fenómeno observado en muchos países en desarrollo, que se refiere a la inexistencia o insuficiencia de un entorno empresarial eficaz para alcanzar la competitividad estructural. Cada vez se acepta más que la creación de un entorno sustentador con el esfuerzo colectivo de las empresas, las asociaciones, el Estado y otros actores sociales, puede conducir a un desarrollo más acelerado de las ventajas competitivas. (1996, p.40). 
Aguilar, señala tres niveles:

EL NIVEL MICRO: A nivel micro, se identifican factores que condicionan el comportamiento de la empresa, como productividad, los costos, los esquemas de organización, la innovación con tecnologías, la gestión empresarial, el tamaño de empresa, etc.

EL NIVEL MACRO: Se refiere a las variables macroeconómicas y su estabilización, para poder competir en el mercado mundial, pues su inestabilidad no permite operar eficientemente el mercado nacional y limita el crecimiento de la economía.

EL NIVEL META: Forma parte integral de los otros niveles, y se refiere a la capacidad de organización por parte de todos los actores, para canalizar los conocimientos sociales, que permitan a su vez regular y conducir correctamente, tanto a nivel macro como micro los intereses del futuro.

EL NIVEL MESO: Dentro de este nivel es considerado el desarrollo de políticas que fomenten la formación de estructuras y apoyo específico hacia aquellas industrias o empresas líderes en el mercado nacional, así como también formar y apoyar aquellas empresas que consideren que puede alcanzar a los líderes o la formación de competidores. (2018, s.p.).

Oszlak y Donnell, definen a las Políticas Publicas como "Un conjunto de acciones que manifiestan una determinada modalidad de intervención del Estado en relación a una cuestión que concita atención, interés y movilización de otros actores de la sociedad” (1981,p.14).

Por otro lado, está integridad en las políticas no solo requiere un enfoque sistémico como fuera denominado anteriormente como gobernanza sistémica para alcanzar la competitividad de los países, a nuestro parecer requiere de elementos tanto de integración, coherencia y/o coordinación, para que todas estas intervenciones puedan converger en el tiempo y de forma conjunta lograr los objetivos por las que fueran concebidas. 
Bajo esta reflexión, la publicación del CEPAL $\mathrm{N}^{\circ}$ 76, Integración coherencia y coordinación de políticas públicas sectoriales, nos revela "Las debilidades que existen para que las políticas públicas se integren y convergen como un todo para alcanzar los objetivos y metas del desarrollo sostenible" (Lerda, 1996).

Es una realidad observar que las políticas por lo general no se encuentran integradas, por dar un ejemplo las políticas sectoriales muchas veces no obedecen algún orden con las políticas macro, inclusive en ciertos casos caen en un conflicto.

Es necesario mencionar que otros autores analizan la concepción de las políticas públicas bajo otro enfoque sistémico, tal es el caso de Ortigueira en su paper "Un enfoque sistémico de las políticas públicas"; donde se plantea una concepción sistémica de las políticas públicas vinculadas a cualquier organización. Desde este enfoque ilumina diversas cuestiones de gran orden teórico y práctico del denominado "Sistema de Políticas Públicas", como son sus límites, relaciones externas e internas y sus problemas epistemológicos. Otras consideraciones importantes incluyen los estados y modos de representación, las propiedades externas e internas y los aspectos de carácter dinámico (2013, s.p.).

Ortigueira, señala Dentro del Sistema de Políticas Públicas (SPP) cada política concreta constituye un "subsistema" formado, a su vez, por elementos que se relacionan. Cada uno de estos elementos se caracteriza por el consumo de recursos y/o tiempo para ser ejecutado. Los elementos no son otra cosa que las acciones que habrán de llevarse a cabo para conseguir que la política culmine su objetivo. Estos subsistemas pueden configurarse, preferentemente, como sistemas multifuncionales de modificación física, de acción, de observación y de proceso de información (2013, s.p.).

A modo de interpretación, se puede precisar que las políticas públicas se relacionan entre sí, ya que se apoyan una sobre otras para ser ejecutadas, comparten recursos, siendo uno de los factores que las distingue o identifica es el predominio en el volumen de recursos. 
Además, las políticas públicas, en relación con ciertos problemas planteados, pueden recibir tres tipos de calificativo: 1) funcionales, cuando favorecen la resolución del problema; 2) disfuncionales, cuando entorpecen o retardan la resolución del problema; 3) afuncionales cuando no tienen incidencia positiva o negativa alguna sobre el problema.

La identidad de una política pública está en función de la estructura o sistema planteado a la hora de expresar la "Situación Futura Deseada" para la Entidad, particularmente al nivel de las metas. Son estas metas las que determinan la nomenclatura de las políticas.

A pesar de que la identidad atribuida a las políticas públicas conecta con una función más o menos "específica" de las mismas, la realidad revela la existencia de otras funciones simultáneas. Queremos hacer resaltar que políticas públicas poseen en la mayor parte de los casos un carácter multifuncional. Así, por ejemplo, una "Política Deportiva", podría interpretarse, en parte, como una "Política de Salud" en su orientación de "medicina preventiva".

En efecto, los recursos que se destinan al deporte se transforman en una especie de "vacuna mental" en contra de una lacra social tan perjudicial como la drogadicción (alcohol, tabaco, etc.).Y, simultáneamente, en una "Política de Seguridad", por cuanto la práctica deportiva, en razón de los valores y comportamientos inculcados, beneficia a esta política al frenar la delincuencia. También la "Política Deportiva" cumple una función educativa (conocimiento), una función cultural (principios, valores, creencias, ritos, mitos, lenguaje, etc.) y una función económica (movimiento de dinero, empleo, prensa, radio, TV, etc.). Y en otro orden de cosas es fácil advertir cómo la "Política Medioambiental" tiene una incidencia muy clara sobre la "Política Deportiva" (practicantes de la actividad deportiva), la "Política de Salud" y la "Política de Promoción Económica". Sobre esta última política también inciden la Política de Salud, la Política de Seguridad y la Política Urbanística. La "Política de Promoción Económica" interacciona con la "Política económica", etc., etc.

Por último, este autor señala que debido al carácter relativo que posee cualquier política pública, esto nos llevaría a una consideración de rangos a lo que nosotros llamaríamos como una jerarquización, esto quiere decir de qué podríamos hablar de macro políticas, de políticas y sub 
políticas.

Por otro lado, retomando el enfoque de competitividad sistémica la cual nos servirá como modelo para nuestro objeto de estudio, la revista de la CEPAL $N^{\circ} 59$ profundiza este enfoque y lo lleva a otro nivel, precisando en resumidas cuentas que para la concepción de políticas públicas eficientes es necesaria su interacción en todos los niveles de factores determinantes, para de esta forma crear ventajas competitivas que redundará en una consolidación del modelo económico y por lo tanto en un mayor desarrollo para el país.

En ese sentido, también señala que no se pueden elaborar un número ilimitado de políticas o elementos de competitividad a partir de un conjunto dado de factores determinantes de la competitividad sistémica, dejando en evidencia además que los países más competitivos poseen:

i) en el nivel meta, estructuras básicas de organización jurídica, política y económica, capacidad social de organización e integración, y capacidad de los actores para la interacción estratégica;

ii) un contexto macro que exige mayor eficacia de las empresas;

iii) un nivel meso estructurado donde el Estado y los actores sociales desarrollan políticas de apoyo específico, fomentan la formación de estructuras y articulan los procesos de aprendizaje a nivel de la sociedad, y

iv) en el nivel micro un gran número de empresas que buscan simultáneamente la eficiencia, calidad, flexibilidad y rapidez de reacción, estando muchas de ellas articuladas en redes de colaboración recíproca. (1996, p.42). 
ORAFICO :

Factores determinantes de la competitividad sistémica

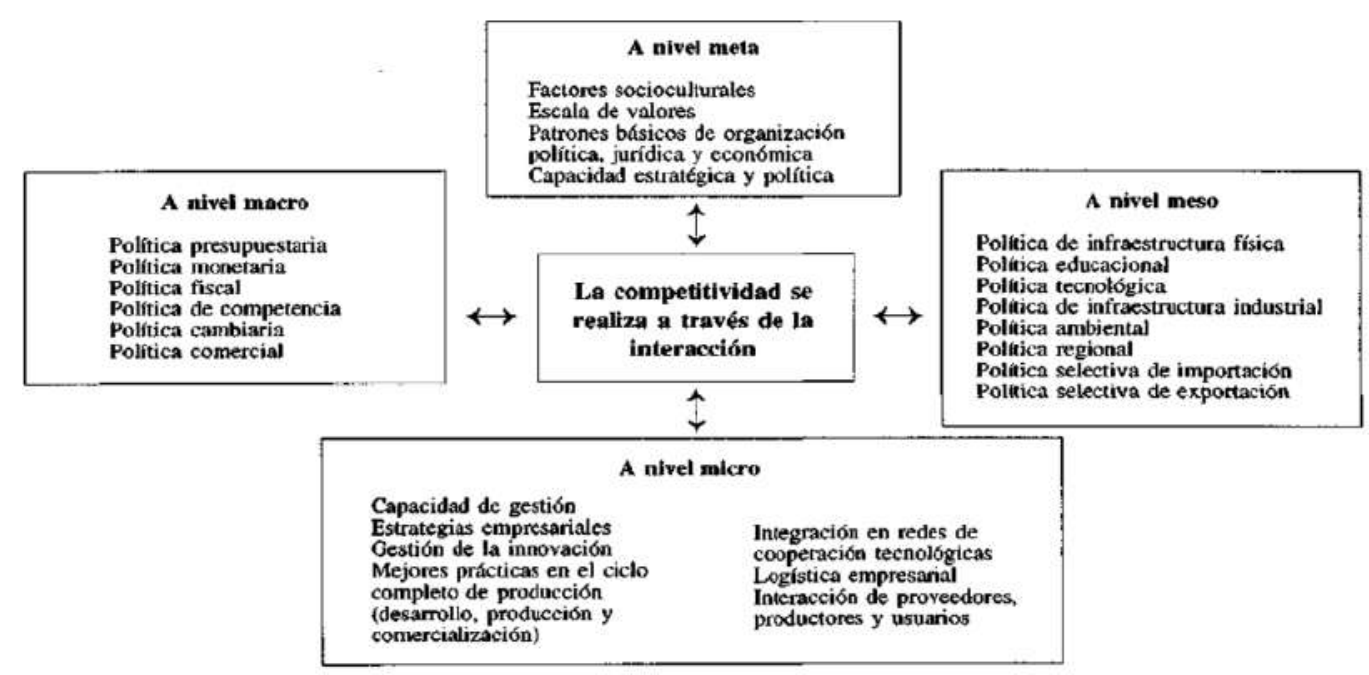

Figura 13. Factores determinantes de la competitividad sistémica. Fuente: CEPAL, 1996.

\subsection{Planificación estratégica en el sector público.}

Según el Instituto para la Democracia y la Asistencia Electoral:

La planificación en general, es un proceso que define objetivos, metas, estrategias y acciones para lograr resultados deseados en el futuro y encaminados a cambiar la situación actual. Para ello se requiere de determinadas metodologías y técnicas y la participación consciente de un conjunto de actores (institucionales e individuales) con responsabilidad o interés en cambiar el estado negativo o carencias de las cosas. (2008, p.31).

Según el Instituto para la Democracia y la Asistencia Electoral:

También es un proceso para decidir de antemano qué tipo de esfuerzos de planeación debe hacerse, cuándo y cómo debe realizarse, quién lo llevará a cabo, y qué se busca con los resultados. La planificación desde el Estado tiene como marco 
y objeto la promoción del desarrollo integral, sostenible e inclusivo, a partir de generar oportunidades para el bienestar de la población. (2008, p.31).

Según el Instituto para la Democracia y la Asistencia Electoral:

En este acápite se tratan a continuación los diferentes aspectos relacionados al planeamiento estatal. Es conveniente señalar que la situación de la planificación del Estado es precaria y sumamente débil. Los planes con los que cuentan las entidades gubernamentales dejan mucho que desear y en la práctica son poco útiles para conducir la acción gubernamental. Se los elabora más que nada para cumplir con la normatividad, evitarse problemas con los entes de control, pero que, como instrumentos de gestión, tienen un papel muy limitado, pues la gestión ésta más orientada por los presupuestos, que muy poco o casi nada están articulados a los planes. No se tiene definida una metodología mínima estándar, ni de contenidos, ni los alcances que deben tenerse en cuenta para la formulación y gestión de los planes de responsabilidad estatal. Se dice y exige, que los diferentes planes sectoriales, institucionales $y$ territoriales deben articularse sectorial y de manera intergubernamental, pero no se sabe cómo, no se tiene una metodología. (2008, p.31).

El programa de Desarrollo de Capacidades para el Fortalecimiento de las Organizaciones Políticas, es el ente rector del sistema nacional de planeamiento estratégico es el CEPLAN (Centro Nacional de Planeamiento Estratégico), es el organismo técnico especializado que ejerce la función de órgano rector, orientador y de coordinación del Sistema Nacional de Planeamiento Estratégico. Está adscrito a la Presidencia del Consejo de Ministros. Los órganos del Sistema Nacional de Planeamiento Estratégico mantienen una relación técnica y funcional con el CEPLAN en las 
materias de su competencia. El CEPLAN se estructura y funciona según un modelo de organización flexible y de gestión horizontal, basado fundamentalmente en la constitución de comités multidisciplinarios a cargo de coordinadores.

El Sistema Nacional de Planeamiento Estratégico se define como el conjunto articulado e integrado de órganos, subsistemas y relaciones funcionales, existentes en las diferentes instituciones gubernamentales relacionados a la planificación estatal, con la de finalidad es coordinar y viabilizar el proceso de planeamiento estratégico nacional, para promover y orientar el desarrollo armónico y sostenido del país. El Sistema Nacional de Planeamiento Estratégico está integrado por:

- El Centro Nacional de Planeamiento Estratégico, como órgano rector del Sistema;

- Los órganos del gobierno nacional, con salvaguarda de su autonomía, de los demás poderes del Estado, de los organismos constitucionales autónomos y de los gobiernos regionales y locales con responsabilidades y competencias en el planeamiento estratégico; - El Foro del Acuerdo Nacional, como instancia de concertación de la planificación estratégica nacional cuando su intervención es solicitada, en su orden, por el Presidente del Consejo de Ministros o el Presidente del Consejo Directivo del CEPLAN.

Los objetivos del Sistema Nacional de Planeamiento Estratégico son:

- Constituirse en el espacio institucionalizado para la definición concertada de una visión de futuro compartida y de los objetivos y planes estratégicos para el desarrollo nacional armónico, sustentable, sostenido y descentralizado del país.

- Articular, integrar y concertar la elaboración del Plan Estratégico de Desarrollo Nacional y los planes nacionales, sectoriales, institucionales y descentralizados.

- Definir las orientaciones, los métodos, los procesos y los instrumentos para el planeamiento estratégico.

- Promover y articular los programas de fortalecimiento de capacidades para el planeamiento estratégico.

- Desarrollar los procesos y las acciones para el monitoreo de la gestión para resultados de mediano y largo plazo, en coordinación con el Consejo Nacional de Competitividad, basada en los diferentes instrumentos de planeamiento estratégico y con orientación hacia 
la promoción de la modernización administrativa y el logro de estándares de eficiencia al servicio del ciudadano

- Promover la mejora de los índices de competitividad del país para aprovechar las oportunidades que la dinámica internacional ofrece en el Política Económica, Planeamiento, Desarrollo Regional y Local.

Según el Instituto Peruano del Deporte, indica en su propuesta del Plan Nacional del Deporte 2011 - 2030: "se constituye como el instrumento fundamental para orientar la promoción y desarrollo del deporte nacional para un periodo de largo alcance de 20 años del cual se desprenden los correspondientes planes regionales del deporte y municipales, así como de las organizaciones deportivas en general" $(2011$, p.2). Asimismo, este programa fue utilizado como base para el desarrollo de nuestra investigación.

Este SISTEMA NACIONAL DEL DEPORTE 2011-2030, por iniciativa del Instituto Nacional del Deporte, donde se desarrolló talleres de orientación, se trabajaron con las macro regiones; pero en resumidas cuentas tuvo un arduo trabajo de campo, para realizar un diagnóstico y determinar la visión y objetivos del deporte en el Perú. En ese sentido, este instrumento define como misión: "El Sistema Deportivo Nacional, con sus organismos e instituciones que la conforman, disponen de una organización moderna con personal altamente calificado, que asegura una eficiente gestión y servicio de calidad y proporciona las condiciones técnicas, infraestructura y recursos necesarios para la práctica regular y masiva de la educación física, recreación y deporte de la población nacional” y como visión: “La población del país tiene vida sana, física, mental y social, con altos niveles de actividad física de carácter inclusivo, y logros deportivos internacionales destacados, alcanzados como resultado de una cultura orientada al mejoramiento de su calidad de vida en el marco de la política de desarrollo humano" (2011, p.75). 
Es así, que este documento de gestión, NACIONAL DEL DEPORTE 2011-2030, plantea como el Objetivo Estratégico General: "Promover entre la población del país un estilo de vida saludable mediante la práctica, regular, masiva y con valores, del deporte, la educación física, y recreación, en el marco de la concepción del deporte como parte de la estrategia del desarrollo nacional" $(2011,72)$.

Según el IPD, indica en su propuesta del Nacional del Deporte 2011 - 2030:

Para el establecimiento de los objetivos específicos y metas, se han definido en primer lugar, como grandes marcos de acción, tres ejes estratégicos, los mismos que se indican a continuación:

- Eje Estratégico No 1: Masificación del Deporte

- Eje Estratégico No 2: Desarrollo del Deporte Afiliado

- Eje Estratégico $\mathrm{N}^{\mathrm{o}}$ 3: Fortalecimiento de Capacidades

Consideramos que el Eje Estratégico $\mathrm{N}^{\mathrm{o}}$ 1: Masificación del Deporte y Eje Estratégico $\mathrm{N}^{\circ}$ 2: Desarrollo del Deporte Afiliado, guardan relación con el presente estudio.

Eje Estratégico $\mathbf{N}^{\mathbf{0}}$ 1: Masificación del Deporte, se ubica básicamente la promoción y el desarrollo de la educación física, recreación y deportes orientada a la población en su conjunto: en el ámbito estudiantil (pre-escolar, primaria, secundaria y universitaria) y comunidad en general (jóvenes, adultos, adulto mayor y personas con capacidades diferentes). (IPD, 2008). 
Eje Estratégico $\mathbf{N}^{\mathbf{0}}$ 2: Desarrollo del Deporte Afiliado, este eje que tiene cuatro objetivos específicos, está referido al deporte de competencia y se orienta a superar la problemática que la caracteriza de ser de limitada trascendencia a nivel internacional, regional y local. (IPD, 2008).

En ese sentido, nuestra propuesta de política pública, se encuentra alienada y comparte la visión los dos ejes estratégicos, por lo que es factible relacionarlo con los objetivos específicos planteados en ambos ejes.

Según el Instituto Peruano del Deporte, indica en su propuesta del Plan Nacional del Deporte 2011 - 2030, puntualizando en los objetivos específicos alineados a la propuesta de política pública materia de esta investigación, consideramos los siguientes:

- Primer Objetivo Específico: Lograr la Masificación del Deporte en el Marco de la Concepción del Desarrollo Humano Para Lograr el Bienestar y La Paz

- Segundo Objetivo Específico: Promover la Participación Regular y Permanente de los Estudiantes en Actividades de Educación Física Recreativas y Deportivas Tercer objetivo estratégico: Elevar el Nivel Competitivo de los Deportistas de Alto Nivel. (2008, p.74).

\subsection{Enfoques de gestión Pública.}

La Gestión Pública se define como la especialidad que se enfoca en la correcta y eficiente administración de los recursos del Estado, a fin de satisfacer las necesidades de la ciudadanía e impulsar el desarrollo del país. Se dirige a profesionales de diversas áreas que desean desempeñarse en el sector público, asimismo, según el Instituto para la Democracia y la Asistencia 
Electoral "se entiende por administración pública, en su enfoque procedimental, a todas las instituciones y organismos públicos y privados que prestan servicios públicos” (2008, p.14).

Su evolución partiendo desde el modelo burocrático, planteado por Weber citado por Wong, Sociólogo Alemán, quien definió el concepto de burocracia, como "Una forma de organización humana, basada en las normas impersonales y la racionalidad, que garantiza la máxima eficiencia posible en el logro de sus objetivos” (2012, s.p.).

Esta teoría administrativa, presupone un modelo de gestión que fuera rápidamente adaptado en la administración pública, por sus definidas características fue el paradigma inspirador de todo movimiento internacional de reforma administrativa de los años 50 y 60 . La racionalidad legal gerencial burocrática, que ya había presidido la construcción histórica de los estados liberales del derecho, fue también el modelo que inspiró, tras la segunda guerra mundial, tanto la construcción institucional de los Estados en desarrollo como la de los grandes servicios nacionales del bienestar, característicos del Estado Social. (IPD, indica en su propuesta del Plan Nacional del Deporte 2011 - 2030, 2008).

Weber concebía la burocracia como “...la forma de organización a través de la cual opera el sistema de dominación política nacional o legal. El tipo de sistema que da sentido a la burocracia se contrapone a los sistemas de dominación carismática y tradicional, que no son racionales porque no se basan en la obediencia a la norma legal". La denominación legal o racional del modelo weberiano, articulada a través de la burocracia se basaba en:

a. La definición del interés público desde la perspectiva fundamentalmente "administrativista" esto implicaba reclutar, desarrollar y conservar expertos en el campo de la administración, la ingeniería y el trabajo social.

b. El logro de resultados en función de las especialidades de los expertos y bajo una fuerte orientación de inversión pública. 
c. La legitimación de la selección de los expertos y funcionarios no electos en un Estado administrativo.

d. La aplicación de sus conocimientos y normas profesionales a los problemas existentes en sus campos de especialización.

El modelo burocrático se caracterizó por la búsqueda de la eficiencia, siguiendo patrones y normas lineales, donde los funcionarios cumplen a cabalidad lo estipulado si opción a modificaciones durante el proceso, en este sentido, el desempeño del funcionario público se basaba en la obligatoriedad y no en la misión.

\section{MODELO POST BUROCRÁTICO}

A diferencia del anterior, el modelo post burocrático, que da origen al Estado contractual o gestión por resultados, que se inicia aproximadamente en los primeros años de los 90, enfatiza más bien en el beneficio que la sociedad percibe del accionar público. (Instituto Peruano del Deporte, indica en su propuesta del Plan Nacional del Deporte 2011 - 2030, 2008).

Los resultados no se miden en términos de insumos y procedimientos, sino en términos de cambios de distinta escala que se dan en el entorno - interno y externo - de la organización pública. No descuida el desarrollo normativo, pero le preocupa más la ejecución que el apego a las normas. Para ello agenda temas cruciales para la gestión, como las políticas de incentivo al talento y

ejecución, los estándares de calidad y el desempeño, etc. (Instituto Peruano del Deporte, indica en su propuesta del Plan Nacional del Deporte 2011 - 2030, 2008).

La post burocracia asume que las estructuras internas así como su optimización permanente, son necesarias, pero totalmente insuficientes para concretar resultados; que los procedimientos clave deben ser reformados pero no sólo en la perspectiva de optimizar el control sino el servicio a la ciudadanía, que los recursos financieros deben primordialmente ser aplicados de manera directa y vinculante con los resultados y que los sistemas de información y gestión del conocimiento son muy necesarios pero enfocados de manera estratégica. (Instituto Peruano del 
Deporte, indica en su propuesta del Plan Nacional del Deporte 2011 - 2030, 2008).

La corriente posburocrática privilegia el proceso de dirección estratégica. Implica un esfuerzo aún considerable en la dimensión operativa bajo principios de calidad total en procedimientos, talento humano y servicios, con la hipótesis que sólo es posible alcanzar resultados valiosos para la comunidad con conocimientos y capacidades técnicas, organizacionales y políticas dentro de las estructuras. (IPD, indica en su propuesta del Plan Nacional del Deporte $2011-2030,2008)$.

Tabla 12.

Cuadro comparativo de Paradigmas.

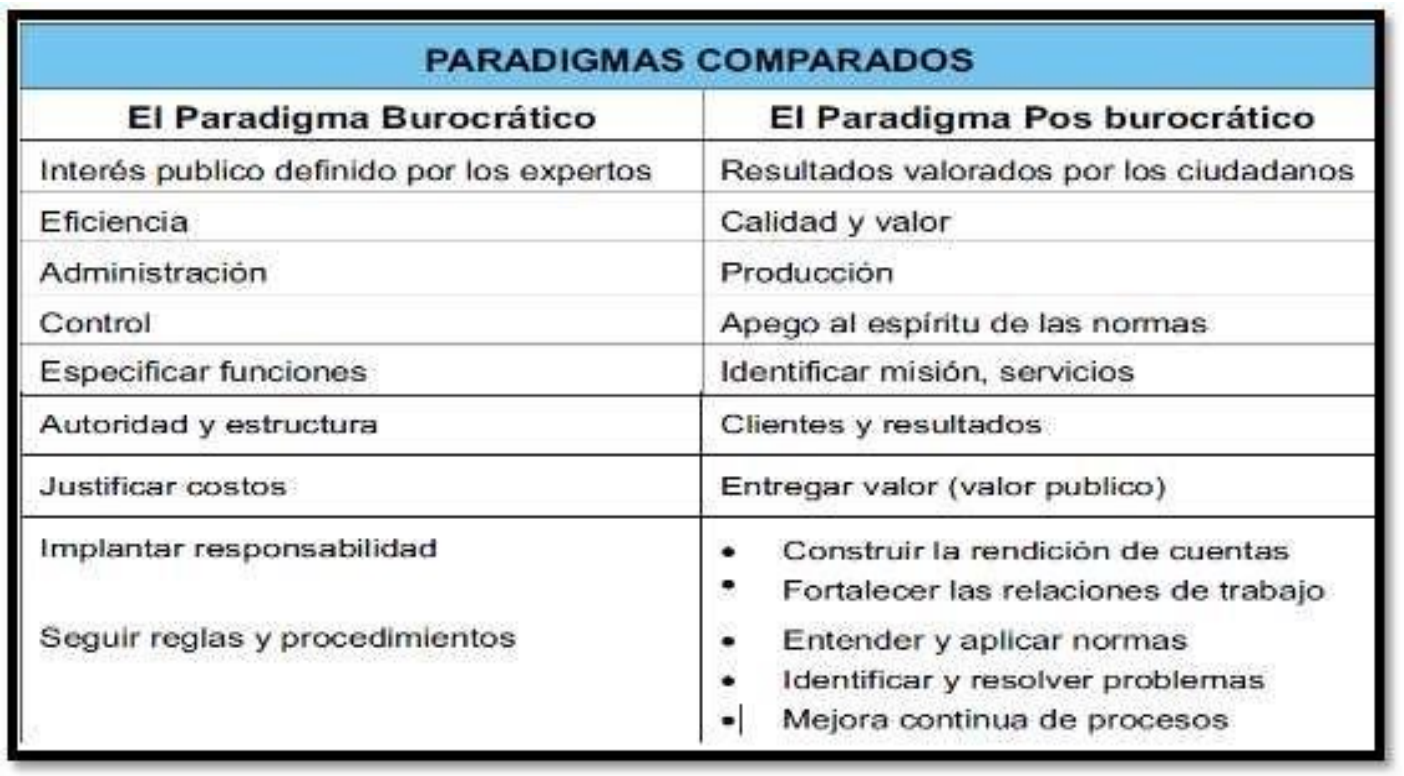

Fuente: (Instituto Peruano del Deporte, indica en su propuesta del Plan Nacional del Deporte 2011 - 2030, 2008).

\section{MODELO DE LA NUEVA GESTIÓN PÚBLICA}

La NGP busca cubrir las principales necesidades de los ciudadanos a través de una gestión pública eficiente y eficaz. Para este enfoque, es necesario la implementación y/o ejecución de programas, proyectos, entre otros, que sean ágiles, transparentes y sobre todo que involucre la participación activa del ciudadano. La NGP propone incorporar ciertos elementos utilizados en la gestión privada a la gestión pública, buscando en todo momento mejoras continuas vinculen más 
al ciudadano con la administración pública.

Arizaga, indica:

En la NGP los directivos públicos elegidos deben resolver la ambigüedad, la incertidumbre y el conflicto alrededor de las políticas públicas, a fin de describir de antemano lo que quieren que logren sus funcionarios en un lapso determinado; las funciones de formulación de políticas y las de operaciones deberían asignarse a organizaciones diferentes, con entidades operativas encabezadas por funcionarios versados en la gestión, mientras que los sistemas administrativos centralizados deberían reformarse a fin de trasladar obligaciones, autoridad y responsabilidad a los niveles más cercanos al ciudadano. (2017, p. 18).

Asimismo, también menciona, Arizaga:

En síntesis, la Nueva Gestión Pública está fundamentada sobre:

a. La formulación estratégica de políticas de desarrollo y gestión.

b. La gradual eliminación del modelo burocrático hacia una GESTIÓN POR RESULTADOS.

c. La creación del valor público.

d. El desarrollo de las instituciones y dimensionamiento adecuado del Estado

e. El mejoramiento de las conquistas macroeconómicas y la equidad social. (2017, p. 198). 
Según Arizaga:

La nueva gestión pública, tiene dos estadios. En su etapa de desarrollo vigente, la del Desarrollo Contractual, a diferencia del enfoque tradicional, un gobierno es eficiente no solamente gracias a los instrumentos administrativos que crea o utiliza sino debido a su posicionamiento en la escena política. Al estar el Estado compuesto por actores que tienen intereses, la eficiencia sólo podrá garantizarse si genera (el Estado) reglas del juego que liberen la acción de los actores sociales en todo su potencial y permiten controlar a los actores políticos y gubernamentales para dirigir sus esfuerzos hacia los resultados y no hacia su propia agenda política. (2017, p. 19).

Según Arizaga: "De esta manera, la responsabilidad de la nueva gerencia pública está ligada a la eficacia y eficiencia de su gestión y no sólo al cumplimiento de sus mandatos. Se propone separar el diseño de políticas públicas de su administración, reemplazar la burocracia y autoridad tradicional del gobierno por competencia e incentivos" (2017, p. 19).

Arizaga, señala:

En esta perspectiva, enfrenta desafíos buscando lograr metas y resultados transparentes dando la suficiente flexibilidad a los administradores del gobierno para determinar cómo alcanzarlas. La administración pública como prestadora de servicios para los ciudadanos no podrá liberarse de la responsabilidad de prestar éstos de manera eficiente y efectiva, sin buscar la generación de utilidades como fin último. (2017, p. 19). 
En el libro de Moore, "Denominado Gestión Estratégica y creación de valor en el sector público es elaborado bajo la situación de la Gestión Pública en los Estados Unidos, en los años 90. Donde el autor señala un nuevo modelo de directivo público, el cual contribuye a que el sector público genere valor" (1995, p. 9).

Para Moore, "el sector público crea valor a través de los bienes y servicios que el privado no puede producir, fundamentalmente crea valor en la manera en que produce dichos bienes, es decir a través del diálogo comunitario, la participación social y el respeto a los valores constitucionales y democráticos" (1995, p. 19).

En este libro el autor se centra en los directivos públicos, como el medio para mejorar la Gestión Pública, pero resalta que no es el único medio existiendo otros caminos como la reforma institucional. Una de las limitaciones que considero de este libro, es que se encuentra diseñado en el entorno político del siglo XX y desarrollado bajo un contexto basado en la democracia. El reto de la organización pública, consiste en hacerlas más eficientes, reducir costes y adaptarlas a las demandas políticas cambiantes.

La definición conceptual del éxito gerencial es aumentar el valor público producido por las organizaciones públicas tanto a corto como a largo plazo, en ese sentido no existe un modelo que nos garantice el éxito gerencial y mucho menos cómo medir este. En comparación al sector privado el éxito gerencial se puede medir a través de indicadores. Asimismo, es preciso señalar que el éxito gerencial no solo se debe a un modelo en específico existen otros factores.

\section{Para Moore:}

La evidencia del estudio considera tres puntos:

a) La importancia crucial de tener un propósito.

b) La necesidad de reconocer la gestión política como la función clave de la gestión pública.

c) La necesidad de redefinir nuestras imágenes de la gestión operativa para prestar mayor atención a la innovación de varios tipos. (1995, p. 19). 
Sin embargo, el autor afirma que este estudio ha sido elaborado en base a la información proporcionada por los directivos tanto exitosos como no exitosos, por lo que a modo de conclusión lo que nos muestra el libro el modo en que los gestores públicos deberían gerenciar, definiendo la metodología de cómo diagnosticar e intervenir.

\section{MODELO DE GOBERNANZA}

La gobernanza es entendida como el ejercicio de la autoridad política, económica y administrativa para gerenciar los asuntos de un país, mediante la promoción de relaciones interactivas entre el Estado, el sector privado y la sociedad civil, y la institucionalización de conceptos como transparencia, rendición de cuentas, debido proceso, probidad y eficiencia. 


\section{CAPÍTULO III \\ GENERACIÓN DE LA POLÍTICA PÚBLICA}




\section{Generación de la política pública}

\subsection{Gestación del problema (causas).}

Resulta evidente, de acuerdo a las estadísticas descritas en el Capítulo I, sobre el bajo desempeño de nuestros deportistas de alta competencia en eventos internacionales, que existe un notable problema en nuestro deporte nacional, sin ir muy lejos en la última edición de los Juegos Olímpicos Río 2016, nuestros compatriotas no alcanzaron resultados alentadores, tal es el caso que se ubicaron en el puesto 88 .

Esta situación deja en evidencia una vez más que el deporte peruano carece de políticas solidas que impulsen su desarrollo, que tengan como principal eje estratégico, las garantías necesarias para el desarrollo integral del deportista, la cual solo es posible a través de su formación profesional, que llevada de la mano con su experiencia y conocimientos empíricos sobre el deporte de alta rendimiento, podría ser aprovechada para sacar a flote nuestro deporte nacional.

La formación de profesionales en las distintas ramas que ofrece el deporte, entre las cuales podemos mencionar; Administración deportiva, psicología deportiva, entrenamiento deportivo, marketing deportivo, entre otros, es lo que el país necesita, ya que con una buena base de profesionales orientados al deporte, sin duda empezará el cambio para un país con cultura deportiva, especialmente con potenciales talentos deportivos orientados al deporte de alto rendimiento y definitivamente con un alto grado de investigación en el deporte. En Perú, no existen estadísticas con relación a la cantidad de profesionales orientados al deporte, pero tomando los comentarios de los mismos deportistas, indican que carecen de equipos de profesionales multidisciplinarios que contribuyan en la preparación del atleta, así como también en el desarrollo del deporte en general.

Los estímulos si bien es cierto no es materia fundamental que condiciona el rendimiento deportivo en los deportistas, pero genera un bienestar intrínseco que finalmente redunda positivamente en el deportista, la ausencia de ello genera cierto grado de desmotivación e incluso llega a la deserción debido a que no se sienten reconocidos ni mucho menos motivados. 


\subsubsection{Antecedentes.}

Vaquero, en su investigación denominada "MOTIVACIÓN, INCENTIVOS Y RENDIMIENTO. ESTUDIO DE UN CASO EN HOCKEY SOBRE CÉSPED, hace mención de cuán importante es para el deportista recibir incentivos como parte de una motivación extrínseca el cual se complementa con la motivación intrínseca que muchas veces es la parte más desarrollada en los atletas (autoconfianza, preparación Psicológica, determinación) pero que ambos guardan una estrecha relación y deben ser atendidos de una manera óptima a fin de garantizar el cumplimiento de los objetivos planteados. (2005, p. 271).

\subsubsection{Políticas públicas para mejorar el deporte de alta competencia}

En el portal FDEPORTES, menciona: “legislación deportiva de los últimos decenios, en general, ha reflejado los ideales de los gobernantes respecto al deporte en tanto medio educativo y de salud, cauce del tiempo libre, etc. orientado a masificar su práctica buscando forjar un país con una población sana y fuerte en valores morales, con una elite de deportistas calificados que lo prestigie internacionalmente, etc" (2002, s.p.).

En tal sentido, el deporte siendo de alto rendimiento, profesional o no, es una práctica del día a día, que debe estar presente siempre en nuestras vidas para nuestro desarrollo físico y mental. Su masificación y la infraestructura necesaria para su práctica, es política de Estado donde últimamente se han visto cambios y mejoras para nuestro deporte nacional. Actualmente se vienen generando políticas públicas que fortalezcan la práctica de la educación física, masificación deportiva, alto rendimiento capacitación y asociaciones deportivas. 
$\mathrm{Al}$ respecto, al realizar un diagnóstico sobre las Políticas y Planes dictadas para mejorar el Deporte de Alto Nivel donde se valore y reconozca a nuestros deportistas, encontramos que en el Plan Nacional del Deporte 2011 - 2030 se ha establecido como Eje Estratégico $\mathbf{N}^{\mathbf{0}}$ 2: “EI desarrollo del Deporte Afiliado" que tiene como Tercer objetivo estratégico: "Elevar el Nivel Competitivo de los Deportistas de Alto Nivel".

En la Política Nacional del deporte tiene como objetivos lo siguiente: "Incrementar el número de deportistas de alta competencia y mejorar consistentemente nuestro desempeño en las competiciones internacionales".

Si bien es cierto, los gobiernos han establecido como objetivos mejorar y aumentar la competitividad de los deportistas a través de las políticas y planes que se han descrito anteriormente, actualmente se mantiene un deuda con respecto a mejorar sus condiciones, estímulos e incentivos de los deportistas, si analizamos los actuales beneficios y estímulos que reciben nuestros deportistas, los cuales han sido descritos en el Capítulo I, solo tenemos al Programa de Apoyo al deportista que cubre solo a un 30\% de la población actual de deportistas calificados, calificados de alto nivel y maratonistas, que consiste en un incentivo económico menor que en la mayoría de casos no supera la RMV y solo es para cubrir solo gastos de su entrenamiento deportivo, además de un seguro de salud y contra accidentes.

Por otro lado, también cuentan con el beneficio para cursar estudios superiores e insertarse en el mercado laboral, de acuerdo a la Ley $\mathbf{N}^{\circ} \mathbf{2 7 6 7 4}$ "Ley que establece el acceso de deportistas de alto nivel a la Administración Pública "y su reglamento el Decreto Supremo No 089-2003PCM, condicionado de acuerdo a los logros deportivos obtenidos a nivel internacional y solo por el tiempo que es reconocido como Deportistas de alto Nivel, el cual solo es por un tiempo límite que muchas veces no supera el año, donde se considera un bonificación en el proceso de admisión que se configura por niveles que van desde el $20 \%$ hasta el $4 \%$, lo que no asegura cursar los estudios o intentarse al mercado laboral. 
Sin embargo, el IPD ha mantenido su compromiso con los deportistas gestionando Oficios para que también sean reconocidos los deportistas calificados. En ese sentido del total de solicitudes atendidas solo un $80 \%$ han podido integrarse a las respectivas Instituciones Educativas.

El Plan de Fortalecimiento de la Educación Física y el Deporte Escolar al 2021, lográndose el incremento de la Educación Física de 2 a 5 horas en el de nivel inicial a secundaria. Asimismo, la participación en competencias deportivas nacionales e internacionales a nivel interescolar.

Otra iniciativa que forma parte de este compromiso por mejorar el deporte nacional, se encuentra la Ley N ${ }^{\circ} 30476$ - Ley que Regula los Programas Deportivos de Alta Competencia en las Universidades (PRODAC), que hasta el momento no se ha implementado y cuyo fin es regular los Programas Deportivos de Alta Competencia en las universidades tanto públicas como privadas. Esta norma dispone que las Universidades privadas otorguen un número de becas integrales, becas al 100\% y becas al 50\% y sostener un Programa Deportivo de Alta Competencia para al menos 3 disciplinas deportivas a su elección.

Otra norma muy importante para obtener financiamiento y patrocinar a los deportistas, es la Ley No 30479 - Ley de Mecenazgo Deportivo. Esta norma consiste en regular las donaciones por parte del privado, para financiar actividades relacionadas al deporte, donde se incluye infraestructura deportiva, programas de gestión deportiva, contrataciones y pago de subvenciones a deportistas calificados y entrenadores, investigación en deporte y medicina deportiva, subvenciones en viajes entre otros. Estas donaciones tienen un beneficio tributario que consiste en deducir como gasto a las donaciones hasta un 10\% de la renta neta (El Peruano, 2017).

Finalmente, está la Ley 30474 - Ley de Organizaciones Deportivas. Esta ley regula todas las organizaciones deportivas; juntas directivas, funciones de los clubes, ligas, federaciones, entre otros (El Peruano, 2017). 
Por lo que es evidente el limitado apoyo y reconocimiento que reciben nuestros deportistas, lo que origina el abandono y falta de compromiso, por lo que son orientados a dedicarse a otras actividades que les permita asegurar su futuro profesional y por ende el futuro de sus familias.

\subsubsection{Análisis comparativo del deporte de alta competencia en otros países}

A continuación, se describe los diferentes estímulos y beneficios que perciben los deportistas de alto rendimiento en el mundo.

\section{a. COLOMBIA.}

Los deportistas colombianas son cobijados por la ley 181 de 1995, denominada Ley del Deporte, que los beneficia con diferentes estímulos. Los atletas son reconocidos por Coldeportes como medallistas en campeonatos nacionales, internacionales, olímpicos o mundiales tendrán derecho a seguro de vida, invalidez, seguridad social en salud, auxilio funerario, entre otros. El tema económico, no es simplemente que se otorgue plata al deportista. La norma establece que al atleta hay que rodearlo en otros aspectos como lo laboral, social, salud, educación.

Bajo el Programa Deportista Excelencia que promueve Coldeportes, los deportistas que obtienen altos logros internacionales se les concede, según la categoría, un salario por 12 meses. Los Altius son los que reciben más: 6 salarios mínimos legales mensuales, y si llegan a ser campeones mundiales en mayores o medallistas olímpicos tendrán derecho a un incentivo llamado Gloria del Deporte Colombiano, que se los dan a partir de que cumplan 52 años y que equivale a una pensión de cuatro salarios mínimos legales mensuales.

\section{b. BRASIL}

Una de las principales iniciativas del Plan Brasil Medallas fue implantar la Beca Atleta Podio, instituida por Ley N 12.395 , del 16 de marzo de 2011. La Beca Podio es una nueva categoría del programa Beca Atleta, con la finalidad de apoyar atletas con posibilidades de disputar finales y medallas olímpicas y paralímpicas. Las becas varían entre $R \$ 5$ mil y $R \$$ 
15 mil. Para ser contemplado, el atleta debe atender a criterios definidos en la ley, como estar situado entre los 20 mejores del ranking mundial o en la prueba específica de la modalidad. Luego de cumplir con los criterios y haber sido indicado por su confederación deportiva, en conjunto con el_Comité Olímpico de Brasil (COB), o por el_Comité

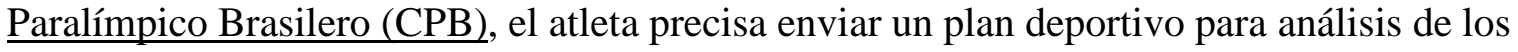
miembros del COB (o CPB), de la confederación y del Ministerio del Deporte. Luego de aprobado en todas las frentes, se publica el nombre del contemplado en el Diario (Boletín) Oficial. Una vez aprobado el atleta, pasa a tener derecho al beneficio durante 12 meses y solamente al finalizar dicho plazo se realiza la reevaluación de su permanencia.

Los atletas paralímpicos fueron los primeros en enviar los planes deportivos para análisis y se convirtieron en los primeros aprobados. Así, el 2 de agosto de 2013, la presidenta Dilma Rousseff recibió a una delegación de atletas del CPB en el Palacio del Planalto, en Brasilia, y anunció los primeros beneficiados con la Beca Atleta Podio. En octubre de 2015 contaban con patrocinio 242 atletas.

La Red Nacional del Deporte de Brasil, indica lo siguiente: "El Beca Atleta (Bolsa Atleta) es el mayor programa de patrocinio individual de deportistas del mundo. De 2005 a, e 2012 programa invirtió $\mathrm{R} \$ 331,64$ millones en el pago de beneficios. En el primer año, el programa benefició a 924 deportistas. En 2013, casi 5,7 mil reciben una Beca Atleta”.

El público a alcanzar del programa, son atletas de alto rendimiento o de base que obtienen buenos desempeños en competencias nacionales e internacionales. De acuerdo con los resultados, los deportistas son seleccionados para cada una de las cinco categorías: Atleta de Base, Estudiantil, Nacional, Internacional y Olímpico/Paralímpico. Los valores varían entre $R \$ 370$ y $R \$ 3.100$. Los atletas premiados tienen derecho a recibir el beneficio durante el período de un año. El dinero se deposita en una cuenta específica del atleta.

Uno de los pilares para el éxito del Beca Atleta es que el programa atiende a deportistas que hayan obtenido buenos resultados, independientemente de su condición económica y 
sin la necesidad de intermediarios. Para ser acreedor a tal beneficio, basta que el atleta cumpla con los requisitos técnicos, se mantenga entrenando, compitiendo y, finalmente, alcance buenos resultados en las competiciones indicadas por las respectivas confederaciones. (2016, s.p.).

\section{c. CHILE}

El Programa de Becas para Deportistas de Alto Rendimiento, conocido como Proddar, corresponde a la entrega mensual de un incentivo económico a aquellos deportistas beneficiarios y su cuerpo técnico asociado, acorde a lo indicado en el Decreto Supremo $\mathrm{N}^{\circ} 04$. (9).

\section{d. CUBA}

El secreto del potencial deportivo de Cuba es un gigantesco sistema de promoción del deporte que incluye en su cantera a todos los ciudadanos del país, y que los capta desde la temprana infancia para entrenarlos sin que le cueste un solo centavo al deportista o a su familia (Ravsberg - BBC MUNDO, 2008).

Cuba tiene políticas orientadas al desarrollo del deporte y principalmente a la alta competencia, estas políticas han sido sólidas y sostenibles en el tiempo, los resultados que trajo consigo lograron abrir una ventana al mundo posicionando a Cuba como una potencia mundial en el deporte, no solo a nivel competitivo, sino también a nivel de profesionalización en el deporte exportando a profesionales del deporte a muchas partes del mundo.

Uno de los principales factores que determinan el resultado deportivo de Cuba es su pirámide deportiva, la cual incluye las escuelas de formación deportiva, logrando establecer una secuencia lógica en el proceso de formación de los niños, que abarca desde la educación primaria, secundaria e incluso universidades. 
El sistema además se autoabastece a sí mismo. Los propios deportistas retirados se convierten en entrenadores, lo cual ha permitido crear una "escuela cubana" casi en cada modalidad, que conserva la experiencia acumulada durante los últimos 50 años. (Ravsberg - BBC MUNDO, 2008). 
Tabla 13.

Cuadro comparativo del sistema de alto rendimiento peruano con el país de Cuba.

\begin{tabular}{|c|c|}
\hline CUBA & PERÚ \\
\hline $\begin{array}{l}\text { El Instituto Nacional de Deportes Educación Física y Recreación (INDER) con sus } \\
\text { direcciones provinciales y municipales es el organismo encargado de dirigir, ejecutar y controlar la } \\
\text { política del Estado y el Gobierno de la República de Cuba en cuanto a los programas deportivos y está } \\
\text { considerado entre los cinco organismos docentes del país, junto con los Ministerios de Educación, } \\
\text { Educación Superior, Salud Pública y Cultura. }\end{array}$ & $\begin{array}{l}\text { El Instituto Peruano del Deporte IPD es el órgano rector del Sistema Deportivo } \\
\text { Nacional, tiene como función formular, planificar y dirigir la política deportiva, recreativa y } \\
\text { de educación física del país. }\end{array}$ \\
\hline $\begin{array}{l}\text { PRIMER NIVEL - LA EDUCACIÓN FÍSICA Y EL ÁREA DEPORTIVA ESPECIALIZADA } \\
\text { En todos los colegios se imparte la educación física con objeto de lograr el perfeccionamiento } \\
\text { corporal de los niños adolescentes y jóvenes del primer al cuarto grado de primaria. En tal sentido las } \\
\text { escuelas primarias se convierten en cantera fundamental donde se descubren y seleccionan niños con } \\
\text { aptitudes. }\end{array}$ & $\begin{array}{l}\text { En este nivel, se encuentra El Plan de Fortalecimiento de la Educación Física y el Deporte } \\
\text { Escolar al 2021, lográndose el incremento de la Educación Física de } 2 \text { a } 5 \text { horas en el de nivel } \\
\text { inicial a secundaria. Asimismo, la activación de los Juegos Deportivos Escolares con la } \\
\text { participación en competenciasdeportivas nacionales e internacionales a nivel interescolar. }\end{array}$ \\
\hline $\begin{array}{l}\text { SEGUNDO NIVEL - EIDE ESCUELA DE INICIACIÓN DEPORTIVA ESCOLAR } \\
\text { Son centros especializados dentro del sistema nacional de educación, donde se desarrollan } \\
\text { además de las enseñanzas académicas, se enfatiza el desarrollo de habilidades y destrezas deportivas. } \\
\text { Estas escuelas están presentes en todas las provincias y cuentan con alojamiento, alimentación, } \\
\text { implementos deportivos, servicio de medicina deportiva y con los mejores profesionales y técnicos de } \\
\text { cada una de las regiones, todo proporcionado de forma gratuita a los estudiantes atletas de los niveles } \\
\text { primaria, secundaria y preuniversitaria. }\end{array}$ & $\begin{array}{l}\text { En este nivel encontramos el Programa de Formación Deportiva que se imparte en } \\
\text { todas las regiones del país, Es un programa que tiene como propósito identificar, formar y } \\
\text { consolidar en los alumnos el proceso de enseñanza-aprendizaje de los fundamentos deportivos } \\
\text { y del gesto técnico de las } 19 \text { disciplinas priorizadas y articuladas con las federaciones } \\
\text { deportivas y la Dirección Nacional de Deporte Afiliado del IPD. Niños y adolescentes entre } \\
\text { los } 6 \text { y } 16 \text { años. }\end{array}$ \\
\hline
\end{tabular}




\section{TERCER NIVEL - ESCUELA SUPERIOR DE PERFECCIONAMIENTO ATLÉTICO (ESPA)}

Al terminar el ciclo escolar y pre-universitaria, si el deportista continúa con su rendimiento en ascenso son reclutados por esta escuela donde se perfecciona aún más en su disciplina.

Al terminar su tiempo en la ESPA se preparan como profesores de Educación Física y Deportes, fungen como técnicos, y/o entrenan en Academias y otros sitios para representar a esta provincia en justas nacionales de primera categoría. También muchos aprovechan su formación en la ESPA para luego estudiar otras carreras profesionales.

\section{CUARTO NIVEL - ESCUELA SUPERIOR DE FORMACIÓN DE ATLETAS DE ALTO}

\section{RENDIMIENTO (ESFAAR)}

En esta escuela son reclutados los mejores atletas, donde se encuentran los atletas que representan al país en competencias internacionales y también los juveniles.

Esta pirámide es complementada, con instituciones educativas como los Institutos Superiores de cultura física, donde egresan una cantera formidable de técnicos y la Escuela Internacional de cultura física y deportes

\section{INSTITUCIONES DE FORMACIÓN Y CAPACITACIÓN.}

Cuba cuenta con INSTITUTOS SUPERIORES DE CULTURA FÍSICA (ISFC), que se encarga de ampliar conocimientos en la esfera de la Cultura Física y el Deporte, estructurados en 6 esferas de trabajo: Deporte, Educación Física, Recreación, Promoción de Salud, Ciencias Aplicadas, Administración Deportiva.

ESCUELA INTERNACIONAL DE CULTURA FÍSICA Y DEPORTES

Esta escuela alberga a profesionales de todo el mundo donde se imparte licenciaturas a nivel pregrado y postgrado.

\section{ESTÍMULOS Y BENEFICIOS}

Los deportistas de alto rendimiento son contratados con un sueldo mensual que llega hasta 5 veces el sueldo mínimo, donde gozan de beneficios laborales.

Los medallistas olímpicos gozan de una pensión vitalicia.
En este nivel podemos encontrar los Centros de Alto Rendimiento deportivo

Los CAR son centros de formación para brindar una formación integral a los deportistas de alto rendimiento y con proyección, buscando su desarrollo personal, profesional y logros en el deporte competitivo, actualmente se encuentran en 7 regiones del Perú, Arequipa, Ancash, Loreto, Lambayeque, Ica, Cusco y Junín. Su objetivo es reclutar deportistas talentos con proyección al alto rendimiento en las disciplinas de Esta formación integral conlleva un equipo multidisciplinario de soporte (administrativos, técnicos, nutricionistas, psicólogos, fisioterapeutas, médicos, asistentes sociales, asistencia académica) así como los servicios integrales para su desarrollo, con el fin de resultados deportivos cada vez mejores.

A partir de los 11 años en adelante, con la aprobación y firma de compromisos de los padres o apoderados, recibir las fichas de ingreso y documentos firmados y llenados, podrán a formar parte de estos Centros. (Instituto Peruano del Deporte, 2018)

En este punto para la capacitación de agentes deportivos, técnicos, dirigentes, profesionales del deporte, se cuenta con una plataforma virtual de capacitación denominada TU OTRA MITAD, donde se imparte cursos básicos a toda la población. Su objetivo se encuentra más orientado a la masificación de la práctica deportiva.

\section{ESTÍMULOS Y BENEFICIOS}

Los deportistas de alto rendimiento reciben una compensación económica vigente mientras mantenga resultados deportivos. Solo se cubre aproximadamente al $30 \%$ del total de deportistas y los ingresos son de acuerdo a sus resultados. 
A forma de conclusión de la revisión de las condiciones que rodean a países de la región con mayor éxito deportivo, es más que evidente el apoyo y reconocimiento que se les da a sus deportistas de alto rendimiento, lo cual repercute en su gran performance y desempeño durante los eventos de alta competencia.

Por lo anteriormente descrito y analizado, a forma de conclusión identificamos que El problema central seria; "EL LIMITADO APOYO Y RECONOCIMIENTO A LOS DEPORTISTAS ORIENTADOS AL ALTO RENDIMIENTO DEPORTIVO”. La cual surge a raíz de una serie falencias en el sistema deportivo nacional, que parte desde las organizaciones deportivas incluso llegando a la ausencia de políticas públicas.

Por su parte, las Federaciones Deportivas Nacionales que son entes que dirigen sus respectivas disciplinas deportivas a nivel nacional y gestionan a los DECAN, tampoco se pronuncian al respecto, siendo ellos los principales actores en gestionar y velar por los intereses de los DECAN.

El estado no cuenta con un plan para los DECAN que pasan al retiro cuando finalizan su ciclo competitivo, no gozan de alguna pensión ni beneficios sociales, tampoco de inserción laboral, ya que la norma solo contemplan el beneficio de la bonificación cuando se encuentren vigentes como DECAN, el cual como se mencionó anteriormente no sobrepasa los 12 meses, asimismo debido a la dedicación que le dieron al deporte en muchos casos no pudieron realizar estudios de educación superior, de esta manera nuestros deportistas luego de culminar su ciclo competitivo quedan en el abandono y generalmente en situaciones poco favorables.

Los políticos de turno tienen una visión limitada del deporte, generando esto desinterés en el deporte y separándola de la agenda de gobierno, lo cual se refleja en la ausencia de políticas públicas orientadas al deporte con un adecuado diagnóstico y que responda a las necesidades de los DECAN y que generen valor público. 
El Instituto Peruano del Deporte es el ente rector del Sistema Deportivo Nacional, constituye un Organismo Público Descentralizado con rango ministerial adscrito al Ministerio de Educación, con autonomía técnica, funcional y administrativa para el cumplimiento de sus funciones. Constituye Pliego Presupuestal. El IPD en coordinación con los organismos del Sistema Deportivo Nacional, formula e imparte la política deportiva, recreativa y de educación física. Organiza, planifica, promueve, coordina, evalúa e investiga a nivel nacional el desarrollo del deporte, la recreación y la educación física en todas sus disciplinas, modalidades, niveles y categorías.

El deporte peruano, a lo largo de la historia a ha tenido muchos vaivenes con relación a los resultados deportivos y políticas públicas que fortalezcan la práctica deportiva y profesionalización del deporte. Tal es así que durante el gobierno del expresidente Alan García (1985-1990) se eliminó la educación física de los colegios y por ende el deporte y la educación física pasó a segundo plano, mermando de esta manera los resultados deportivos y ahuyentando a los posibles interesados en llevar una carrera con relación al deporte.

\subsubsection{Contexto interno y externo - Agenda gubernamental.}

Existen infinidad de problemas a lo largo y ancho del territorio nacional, cada uno con su complejidad respectiva y con un mayor o menor número de población afectada, sin embargo, todos pugnan por llegar hacia el gobierno para su atención y rápida solución.

Algunos problemas son respaldados por grupos sociales menores, en otros casos por organizaciones poderosas, pero en resumidas cuentas todos esperan una solución integral a su problema. En algunos casos existirá un consenso de opiniones en otros casos de dividirán.

Sin embargo, no todos los problemas llegan a ser de atención del gobierno, solo algunos problemas son considerados como prioridad. No todos los temas se vuelven públicos y no todas las cuestiones públicas son objeto de acciones de gobierno. 
En ese sentido se entiende por agenda gobierno, al conjunto de problemas, demandas, cuestiones, asuntos que los gobernantes han seleccionado y ordenado como objetos de su acción que tienen y deben actuar.

Al respecto, la política deportiva en el Perú, es llevada por el Instituto Peruano del Deporte, que es el ente rector del Sistema Deportivo Nacional y se constituye con un organismo público descentralizado con rango ministerial adscrita a la Presidencia del Consejo de Ministros.

En tal sentido, es el IPD el encargado de recabar los problemas, demandas o cuestiones de los grupos sociales, relacionados al deporte nacional, debiendo formular políticas que brinden una solución integral de los mismos.

\subsection{Diagnóstico de la situación.}

\subsubsection{Contexto Económico.}

El ambiente económico, se resume en la productividad de un país el cual se mide de acuerdo

al crecimiento del PBI, por lo que resulta necesario conocer este indicador económico para emprender cualquier tipo de proyecto social.

Parodi, en el blog del diario Gestión publicó el “Informe de Actualización de Proyecciones Macroeconómicas”.

Las cifras principales que van en aumento son las siguientes:

$\checkmark$ En primer lugar:

PBI - 3\% en el 2017--------- - 4.5\% en 2018.

$\checkmark$ En segundo lugar:

La inversión privada - 0.5\% 2017-------------- 5\% en 2018.

$\checkmark$ En tercer lugar:

La inversión pública - 15\%, tanto en 2017 como en 2018. 
$\checkmark$ En cuarto lugar:

La brecha fiscal $-3.0 \%$ en 2017 y de $3.5 \%$ en 2018.

$\checkmark$ En quinto lugar:

Entre 2017 y 2020, el documento plantea la introducción de US\$ 6400 millones de dólares a la reconstrucción con cambios.

$\checkmark$ En sexto lugar:

La deuda pública total aumentará de US\$ 156817 millones de dólares en 2016 a US\$ 183249 millones en 2017. (2017, s. p.).

Además de otras proyecciones, se puede decir que el MEF con las proyecciones ya planteadas tiene idea de lo que se puede esperar para el 2017 y el 2018. ¿Y el entorno económico externo? Pues el MEF sugiere un “impulso externo”, debido al mayor crecimiento de nuestros socios comerciales, los aumentos en los precios de las materias primas y el mayor ingreso de capitales externos. Estas tres condiciones tendrían un impacto sobre el crecimiento de las exportaciones (Parodi en el diario Gestión, 2017).

Según el diario Gestión, Parodi, indica: la propuesta del MEF es la siguiente: la mayor inversión pública, unida a una recuperación de la privada en 2018, generará el crecimiento económico de $4.5 \%$ en 2018, en un entorno económico externo favorable para el Perú. Una primera lectura sugiere los siguientes temas: a. Los aumentos de inversión pública serán financiados con mayor deuda. b. La recuperación de la confianza originará que la inversión privada crezca luego de tres años de caída. c. El déficit fiscal aumentará, hasta que la reforma tributaria genere los 
aumentos esperados en los ingresos fiscales. d. Hasta 2020 la inversión en reconstrucción será de US\$ 6400 millones de dólares. e. El entorno económico externo será favorable. (2017, s.p.).

Este escenario nos llama a revisar las cifras en base al gasto e inversión en los Deportistas de Alto Nivel, de acuerdo a la Memoria Anual para el año 2016, través de la entrega de dinero en efectivo y seguro médico. Cabe resaltar que estos atletas cuentan con marcas a nivel sudamericano, panamericano y mundial. El 2016 se benefició a 82 deportistas de alto nivel.

Según el diario Gestión, Perú en el 2013, invirtió USD 675 millones, aproximadamente S/ 1,889 millones en el deporte, de los cuales S/ 1,583 millones se destinó a infraestructura deportiva y S/ 307 millones para mejorar el desempeño de los deportistas. Mientras que, en el mismo año, Colombia invirtió alrededor de USD 167 millones, presupuesto que bastante inferior al de Perú, pero Colombia a pesar de ello, logro obtener mejores resultados que Perú.

Asimismo, en dicha publicación del diario gestión, indican que Perú necesita más deportistas de alto rendimiento y sobretodo mejorar la calidad del gasto público.

\subsubsection{Contexto Político.}

El tema actual con relación al deporte es la Organización de los Juegos Panamericanos Lima 2019, el gobierno centra su atención en la organización de estos juegos, y poco se habla de la preparación de los deportistas que participarán en esta competencia. Mucho menos se toca el tema de la formación profesional de los deportistas.

La congresista Noceda, a través de un medio de comunicación, mencionó el diario Ovación, lo siguiente; "Como deportista estoy a favor de la realización de los Juegos. Me preocupa que se esté tratando de comparar con los desastres naturales y eso no es así. No podemos ponerlo 
en una balanza los dos temas. El Estado cuenta con los recursos para cumplir con los dos. No sé por qué están en contra de los Juegos Panamericanos", afirmó la congresista (2017, s.p.).

Por su parte la congresista Luz Salgado, a través PERÚ 21, señala que no es de relevancia realizar los Juegos Panamericanos habiendo temas más importantes que atender en el Perú (2017, p.s.).

En el mismo orden de ideas, muchas Federaciones Deportivas Nacionales no reciben subvenciones por parte del IPD debido a problemas dirigenciales, Solo 25 de 56 Federaciones pueden recibir dinero del Estado para poner en marcha sus respectivos planes deportivos 2017. Algunos sectores culpan al Instituto Peruano del Deporte por la situación de algunas Federaciones Deportivas Nacionales (FDN). La realidad indica que el ente rector del deporte nacional está velando porque se cumpla la normativa vigente para poder reconocer a las nuevas juntas directivas.

Es importante resaltar la evolución histórica de la legislación peruana del deporte con relación a las políticas públicas que se han venido implementado en el tiempo, las mismas que han convertido al deporte nacional en aquel que hoy conocemos.

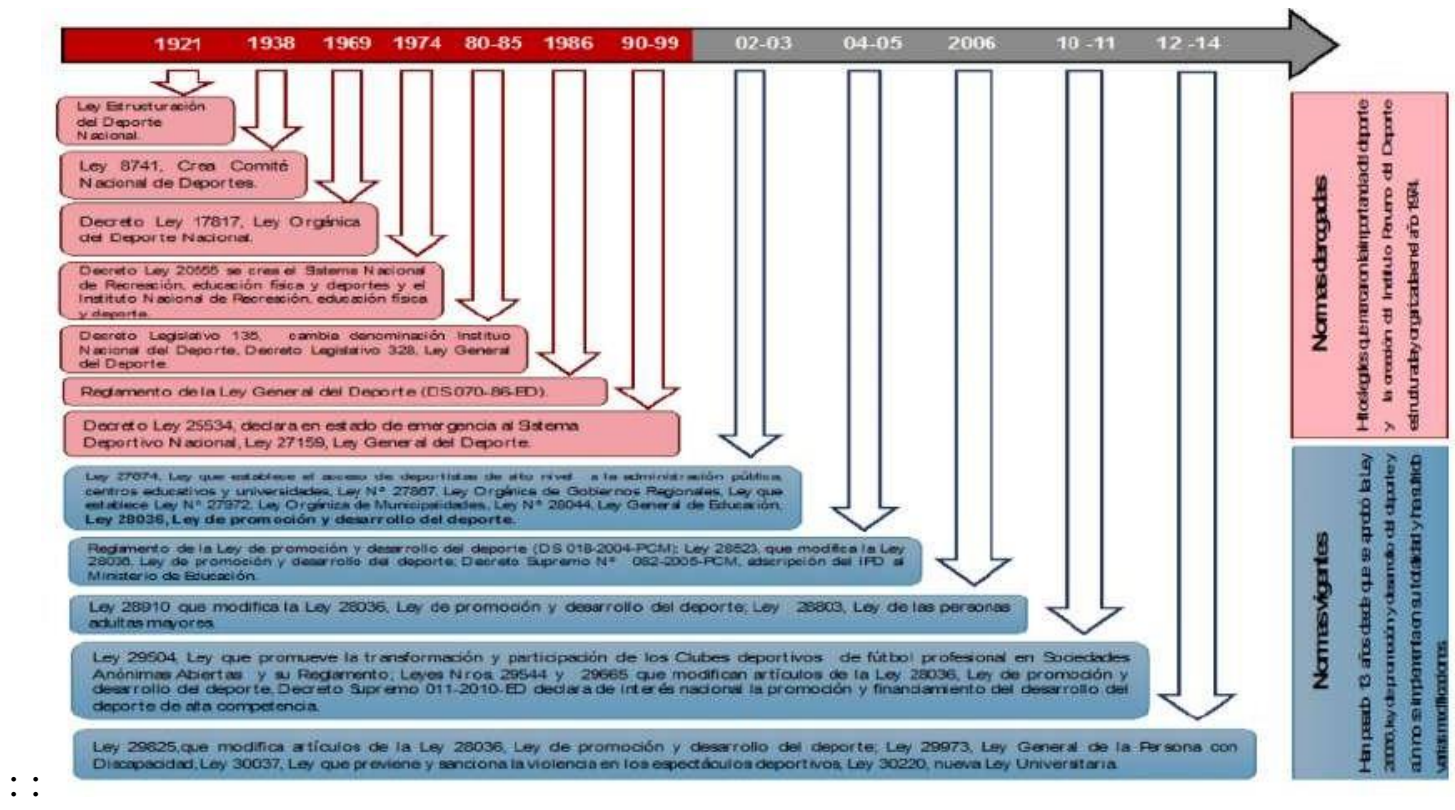

Figura 14. Evolución histórica de la legislación peruana deporte.

Fuente: Política Nacional del deporte - IPD. 
Finalmente, en el año 2016, se promulga la Ley Nº 30476 - Ley que Regula los Programas Deportivos de Alta Competencia en las Universidades (PRODAC), cuyo fin es regular los Programas Deportivos de Alta Competencia en las universidades tanto públicas como privadas. Esta norma dispone que las Universidades privadas otorguen un número de becas integrales, becas al 100\% y becas al 50\% y sostener un Programa Deportivo de Alta Competencia para al menos 3 disciplinas deportivas a su elección. Igualmente, se promulga la Ley N 30479 - Ley de Mecenazgo Deportivo. Esta norma consiste en regular las donaciones por parte del privado, para financiar actividades relacionadas al deporte, donde se incluye infraestructura deportiva, programas de gestión deportiva, contrataciones y pago de subvenciones a deportistas calificados y entrenadores, investigación en deporte y medicina deportiva, subvenciones en viajes entre otros. Estas donaciones tienen un beneficio tributario que consiste en deducir como gasto a las donaciones hasta un $10 \%$ de la renta neta.

Es importante precisar que todas estas políticas implementadas en el tiempo, sin duda han ido resolviendo los principales problemas en su debido momento, así como también han contribuido en sentar las bases del deporte nacional en sus diversas áreas, pero con relación al DECAN, creemos que las políticas implementadas han estado orientadas prioritariamente a su desarrollo deportivo, aspecto que no está mal, muy por el contrario, es bueno potenciar el desarrollo técnico para alcanzar resultados deportivos en torneos internacionales y del circuito Olímpico, sin embargo, no hay políticas públicas que estén orientadas en profesionalizar al DECAN a fin de brindarles una herramienta sólida que les sirva con respaldo una vez concluida su carrera deportiva.

Como lo planteamos en el capítulo anterior, los PRODAC, la cual es una ley que a primera vista pareciera que cubre esta brecha, pues no lo es, los motivos que sustentan esta afirmación son los siguientes:

- La Ley PRODAC, en resumen, obliga a las universidades a tener por lo menos 3 programas deportivos (tres disciplinas deportivas) que cuenten con los beneficios de becas solicitados por ley. En ese caso, las universidades son libres de elegir los tres deportes que respondan a sus propios intereses, dejando así una brecha con relación a 
la igualdad de oportunidades y de acceso a ese beneficio, puesto que las universidades priorizaran el otorgamiento de becas para tres deportes de su elección. es preciso señalar que en Perú existen más de 50 Federaciones Deportivas Nacionales, de las cuales las universidades priorizan en otorgamiento de becas a los deportes que participan en los campeonatos universitarios organizados por la Federación Deportiva Universitaria del Perú - FEDUP, dejando así a más del 70\% de disciplinas deportivas sin poder acceder a los beneficios de becas de estudio.

- Finalmente, no se tiene claro cuál es el perfil del beneficiario, esta ley a simple vista estaría más orientado a promover el movimiento deportivo y a la masificación del deporte en las universidades que a cubrir las brechas en el alto rendimiento deportivo.

\subsubsection{Contexto Social.}

Debido a los vaivenes políticos, políticas que no responden a las necesidades de nuestros deportistas, ausencia de planes que garanticen un digno retiro de los deportistas, entre otros aspectos, hacen que el deporte de alto rendimiento no sea una opción para muchos talentos en potencia.

Los padres de familia influyen de manera directa en los hijos, en la gran mayoría de los casos evitando que los niños inicien una formación deportiva con miras a llegar al alto rendimiento, generalmente hacen que los niños se inserten al deporte, pero con objetivo recreativo y de salud. Este desinterés por parte de los padres de familia en orientar a sus hijos al deporte de alto rendimiento, surge a raíz de que el estado peruano no tiene políticas públicas que salvaguardan y protegen al DECAN.

El IPD en una de las conclusiones para la elaboración de la Política Nacional de Deporte IPD, sostiene que existe un Incipiente desarrollo del deporte a nivel universitario. Ello radica en la ausencia de compromiso por parte de las universidades para impulsar el desarrollo deportivo de alta competencia, El deportista cuando ingresa a la universidad debe decidir si continuar con el 
deporte o dedicarse a los estudios porque la carga académica no es diferenciada entre un deportista y un alumno regular, entendiendo que al final la adquisición del conocimiento no debe ser diferenciado.

Otro aspecto influyente son los medios de comunicación, que sin duda juega un rol importante en la sociedad, en este sentido y con relación al deporte, su aporte es deficiente, más del 90\% de los programas o espacios dedicados al deporte, están orientado al futbol, no hay una variedad de programas que promuevan los deportes con la misma importancia que le dan al futbol, más aún habiendo otros deportes que obtienen importantes resultados deportivos internacionales.

\section{DEPORTE COMO HERRAMIENTA DE CAMBIO}

Gobierno del Estado de Chiapas El deporte no es solo una actividad que se orienta únicamente al gasto energético, va más allá, y en muchos lugares es utilizado como herramienta principal para combatir la anomia social, como por ejemplo, en México, el estado de Chiapas utiliza el deporte como herramienta fundamental para combatir el tabaquismo, al mismo tiempo combatir el sedentarismo que trae consigo múltiples enfermedades asociadas a ella, para ello, el alcalde de dicho estado, impulsa la construcción de espacios deportivos para el libre disfrute de los ciudadanos y orientando actividades deportivas en niños, niñas y adolescentes. (2017, s.p.).

En Brasil, diciembre del 2016, el Gobierno del Distrito Federal de Brasilia y la Oficina de las Naciones Unidas Contra la Droga y el Delito, firmaron un nuevo acuerdo conjunto que busca utilizar el deporte como herramienta para prevenir el delito y el uso de drogas entre los jóvenes. La iniciativa, que forma parte del Programa Mundial de Implementación de la Declaración de Doha ( Global Programme on the Implementation of the Doha Declaration), ofrece un programa de capacitación sobre aptitudes para la vida para mejorar la inclusión de los jóvenes en riesgo y reducir el comportamiento antisocial. Emplea la enseñanza de habilidades para fortalecer el comportamiento adaptativo y positivo, y abordar los factores de riesgo relacionados con la violencia, el crimen y el uso de drogas. (UNODC, 2016). 
Sin ir tan lejos, en Lima - Perú, en el distrito de la Victoria también se promueve el deporte como herramienta fundamental para combatir la delincuencia y fomentar estilos de vida saludable, así lo precisa el alcalde de dicho distrito Elías Cuba: Mente sana en cuerpo sano. Hay que motivar a la juventud a hacer deporte, hay que incentivarlos a venir a los complejos y dedicar parte de su tiempo a ejercitarse. Además, vamos a encontrar talentos para que nos representen en competencias locales e internacionales (El Comercio, 2017). 


\section{CAPÍTULO IV \\ FORMULACIÓN DE LA POLÍTICA PÚBLICA}




\section{Formulación de la Política Pública}

\subsection{Generación de Valor Público.}

El valor público que se quiere generar a través de esta propuesta es brindar a los Deportistas Calificados de Alto Nivel una herramienta educativa que los respalde una vez culminado su ciclo competitivo, que logre insertarlos al mercado laboral, finalmente, ser un atractivo para poder captar a más personas a la práctica deportiva y de esta manera elevar el nivel competitivo.

De la misma manera, se fomentará la descentralización deportiva a nivel nacional a través del otorgamiento de becas de estudio para los deportistas en edad escolar que clasifiquen a la etapa nacional de los juegos deportivos escolares nacionales en la categoría $\mathrm{C}$.

Esta propuesta será sostenible en el tiempo debido a que convergen las tres dimensiones planteadas por Mark Moore.

\subsubsection{Dimensión Sustantiva de la Política.}

Para lograr que esta propuesta de política, sea sostenible en el tiempo y genere el valor público deseado, tal como lo define Mark Moore, es necesario analizar a fondo nuestra problemática hasta llegar a lo sustantivo. Dentro de este análisis se ha delimitado previamente como problema central, Deportistas Calificados de Alto Nivel no cuentan con subvenciones del estado para costear estudios de educación superior.

Estos DECAN, como bien se ha definido anteriormente, son los deportistas que nos han representado en eventos internacionales y han obtenido resultados positivos. Al respecto es necesario identificar indicadores y definir una línea de base, el cual nos servirá como referencia para plantear objetivos, metas y estrategias de nuestra política pública.

Como se ha descrito en la formulación del problema, los resultados deportivos que ha obtenido Perú en las últimas competencias internacionales, son poco alentadores y esto se debe a múltiples factores, pero principalmente aterriza en la ausencia de profesionales multidisciplinarios 
del deporte que fomenten la investigación científica y promuevan la práctica deportiva desde una perspectiva estructurada, planificada desde todos los enfoques y que responda a las necesidades de los DECAN.

La descentralización deportiva hoy es una teoría que aún no aterriza a la práctica, las regiones no cuentan con escuelas deportivas que garanticen la preparación del deportista hacia el alto rendimiento deportivo.

La formación de profesionales en el deporte hoy en día es un reto, así como la deserción de deportistas calificados de alto nivel, debido a que no existen mecanismos y/o estímulos que atraigan a deportistas a dedicarse al deporte y posteriormente profesionalizarse en carreras ligadas al deporte y de esta manera impulsar su desarrollo.

- Políticas de apoyo, ley de educación física (déficit de profesores de educación física)

- Prodac (vinculación a estos programas)

- Política nacional del deporte

\section{DEPORTE ESCOLAR}

A nivel escolar, escolar aún existen brechas con relación a la formación de deportistas, de todo el universo de deportistas que participan en los Juegos Escolares en todas sus etapas, solo unos cuantos logran continuar en el deporte, existe un gran índice de deserción y esto principalmente se debe a que, en estas categorías, son los padres quienes deciden el futuro de los hijos, siendo el deporte una opción no contemplada dentro de todas sus variables de posibilidades.

\section{DEPORTE DE ALTO RENDIMIENTO DEPORTIVO}

El deporte de alto rendimiento es una actividad que se caracteriza por tener un trabajo riguroso y disciplinado cuyo fin es la competitividad, esta actividad muchas veces somete al cuerpo humano a situaciones que incluso atentan contra su salud, para ello requieren de equipos multidisciplinarios que respalden la preparación de los deportistas, así como también de adecuados 
escenarios deportivas para la correcta preparación.

$\mathrm{Al}$ respecto, es necesario que el deportista cuente con estímulos extrínsecos que le permita estar motivado para alcanzar su más alto nivel de competencia, el cual dentro del entorno internacional existen una variedad de estímulos que podrían surgir como propuestas para mejorar el deporte de alto rendimiento en el país.

La falta de planificación y de políticas públicas eficientes, ha originado que los deportistas que han entregado tanto sacrificio por obtener logros para el País, ahora se encuentran en un completo estado de abandono por parte del Gobiernos, no teniendo los medios, ni las fuerzas necesarias para generar ingresos económicos, ya que en su tiempo no tuvieron la oportunidad de adoptar capacidades que le permita en el futuro, desarrollarse en un campo alternativo al deporte que le permita generar ingresos económicos.

En ese sentido, esta Política pretende cambiar el curso de esta historia, generando un ambiente de cambio, dando las oportunidades a los Deportistas de Alto Nivel, para que puedan adoptar capacidades a través de su profesionalización técnica o profesional, el cual sumado a su experiencia en el deporte, permita contar con profesionales del deporte y a la vez incentivarlos a continuar dando su mayor esfuerzo en las competiciones en la que nos representan.

Por lo expuesto anteriormente, surge la siguiente interrogante; ¿Por qué otorgar becas de estudio como estímulo a los DECAN y Deportistas Calificados de colegio?.

Son múltiples los motivos por los cuales se considera necesario otorgar becas de estudio a los DECAN, toda vez que ellos dedican valiosos años de su vida al deporte, cumpliendo una función que se asemeja a una actividad laboral, pero esta no tiene remuneración salarial alguna, apenas reciben algún tipo de apoyo para cubrir sus gastos de preparación deportiva. Entonces existe una suerte de ingratitud por parte del estado hacia los deportistas, existiendo un evidente abandono al DECAN una vez que se retira del deporte. 
Las principales brechas que se cubrirán con el otorgamiento de estas becas serán las siguientes:

- Impulsar el desarrollo deportivo en las regiones, a través de las becas otorgadas a los deportistas de colegio que clasificaron a la etapa nacional, se garantizará la permanencia de los mismos en el deporte que además llevaran consigo una formación profesional paralela que posteriormente redundará en contribuir en el desarrollo deportivo de su región.

- Generar oportunidades laborales para Ex deportistas.- A través de estas becas de estudio, los DECAN podrán estudiar una carrera profesional de su agrado, y el estado generará acciones de articulación interinstitucional para garantizar la inserción laboral.

- Consolidar el compromiso y voluntad de los DECAN en su preparación deportiva.Con este beneficio el DECAN se liberará de preocupaciones que interfieren en su preparación; tendrán el respaldo de un estado preocupado por su desarrollo integral, no desviaran su atención en aspectos secundarios como por ejemplo; buscar un trabajo para costear estudios superiores o dejar el deporte y dedicarse a trabajar y estudiar.

- Formar profesionales que impulsen el desarrollo del deporte.- Actualmente se carece de profesionales deportivos en las distintas ramas; psicología deportiva, medicina deportiva, Administración deportiva, Entrenadores, entre otros, a través de las becas de estudio, se podrá cubrir el déficit de profesionales ligados al deporte, de esta manera se contribuirá en la consolidación del sistema deportivo nacional.

- Promover la investigación científica en el deporte.- La investigación no lleva a otra cosa que el desarrollo, pues en este sentido, con la formación de profesionales en el deporte se generará un estado de competitividad promoviendo la investigación en todas las ramas deportivas y por consiguiente el despegue de Perú como potencia en deporte.

- Incrementar la cantidad de DECAN.- actualmente, muchos padres de familia prefieren alejar a los hijos de la práctica deportiva orientada al alto rendimiento por los motivos planteados anteriormente, pero con la propuesta de Becas de estudio para los DECAN, los padres de familia considerarán una opción más en el desarrollo y formación de sus hijos.

- Incrementar los resultados deportivos.- Gracias a los nuevos profesionales egresados en carreras afines al deporte, se podrán concebir equipos multidisciplinarios que contribuirán en la preparación del deportista para alcanzar importantes resultados deportivos. 
Por lo expuesto, a continuación, se describe la intervención pública que se propone para paliar la problemática, la cual cumplirá con objetivos y actividades en específico:

\section{Descripción de la Intervención Pública.}

La propuesta que se plantea como alternativa de solución a esta problemática, es de financiar el acceso, permanencia y culminación de estudios de educación superior en Universidades e Institutos a los Deportistas Calificados de Alto Nivel (DECAN) peruanos, con

alto rendimiento deportivo, como parte de su formación integral a cargo del Instituto Peruano del Deporte IPD.

ENTIDAD RESPONSABLE: Dirección Nacional de Capacitación y Técnica Deportiva del Instituto Peruano del deporte y Gobiernos regionales.

\section{BENEFICIOS CUBIERTOS:}

- Gastos de matrícula

- Gastos de laptop por única vez

- Gastos de mensualidad universitaria

- Gastos de materiales de estudios que en ningún caso superará el 25\% de una UIT durante un ciclo académico

- Gastos de Titulación

\section{REQUISITOS:}

- Podrán acceder a este beneficio los DECAN a partir de los 18 años hasta los 30 años

- DECAN con participación mínima en dos competencias de un circuito olímpico.

- Deportistas de colegio que haya campeonato en los Juegos Deportivos Escolares Nacionales en edades comprendidas entre 15 y 17 años

- Todas las disciplinas deportivas.

- Para la permanencia de las becas, deberán estar debidamente registrados como DECAN

- DECAN que cuente con beca y esté imposibilitado de entrenar y/o competir por motivos de salud, continuarán con la Beca. 


\section{CONSIDERACIONES FINALES:}

- Esta política es de alcance nacional.

- Los Beneficiarios graduados en carreras relacionadas al deporte, pasarán a formar parte de los profesionales calificados del IPD o en entidades públicas que ofertan trabajos relacionados al deporte.

\subsubsection{Dimensión Operativa de la Política.}

A continuación, se describen los principales recursos que demandará la puesta en marcha de la política pública a implementar.

\subsubsection{Recursos Humanos}

Los recursos humanos que interactúan en esta política lo podemos dividir en 2:

- DECAN y Deportistas de colegio campeones de los juegos deportivos escolares nacionales: Considerados como beneficiarios directos de esta política.

- EQUIPO DE PROFESIONALES: hace referencia al grupo de profesionales de diferentes especialidades que se encargaran de la puesta en marcha de la política.

\subsubsection{Recursos Logísticos}

Con relación a los recursos logísticos, se deberá contar con un espacio físico para el trabajo administrativo y para la atención de los deportistas, así como también la dotación de suministros, mobiliario necesario y transporte para las coordinaciones con universidades.

\subsubsection{Recursos Financieros}

Los recursos financieros provendrán del estado y se canalizará a través de la Dirección de Capacitación y Técnica Deportiva del IPD, cubrirán todos los gastos previstos para la implementación de la política pública, con relación a los beneficiarios cubrirá: 
- Coste de matrículas

- Coste de ciclo académico

- Laptop

- Materiales de estudio

- Coste de titulación

Con relación al equipo ejecutor cubrirá:

- Honorarios profesionales

- Equipo tecnológico

- Materiales de oficina

- Transporte

El presupuesto anual estimado que se requiere para la implementación de la presente política pública a través del IPD y Gobiernos Regionales, es el siguiente: 
Tabla 14.

Presupuesto en soles: becas de estudio.

PRESUPUESTO EN SOLES: BECAS DE ESTUDIO - DECAN - IPD

\begin{tabular}{|c|c|c|c|c|c|c|c|c|c|c|c|c|c|}
\hline \multirow[b]{2}{*}{ RUBROS } & \multicolumn{3}{|l|}{ AÑO 1} & \multicolumn{2}{|l|}{ AÑ̃ 2} & \multicolumn{2}{|l|}{ AÑ̃ 3} & \multicolumn{2}{|l|}{ AÑ̃ 4} & \multicolumn{2}{|l|}{ AÑO 5} & \multicolumn{2}{|l|}{ AÑO 6} \\
\hline & 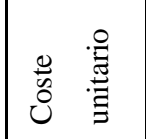 & Z & & 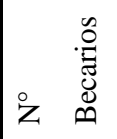 & 劳 & 范 & 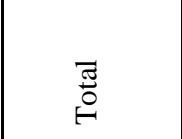 & 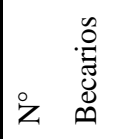 & 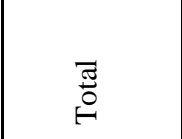 & 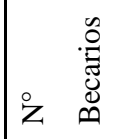 & 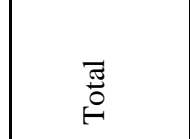 & 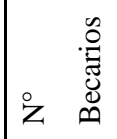 & 劳 \\
\hline $\begin{array}{lr}\text { Coste } & \text { de } \\
\text { matrículas } & \end{array}$ & 300.00 & 60 & $18,000.00$ & 120 & $36,000.00$ & 180 & $54,000.00$ & 240 & $72,000.00$ & 300 & $90,000.00$ & 300 & $90,000.00$ \\
\hline $\begin{array}{ll}\text { Coste } & \text { de } \\
\text { pensión anual }\end{array}$ & $\begin{array}{l}15,000.0 \\
0\end{array}$ & 60 & $900,000.00$ & 120 & $1,800,000.00$ & 180 & $2,700,000.00$ & 240 & $3,600,000.00$ & 300 & $4,500,000.00$ & 300 & $4,500,000.00$ \\
\hline Laptop & $1,500.00$ & 60 & $90,000.00$ & 60 & $90,000.00$ & 60 & $90,000.00$ & 60 & $90,000.00$ & 60 & $90,000.00$ & 60 & $90,000.00$ \\
\hline $\begin{array}{l}\text { Materiales de } \\
\text { estudio }\end{array}$ & 2,000.00 & 60 & $120,000.00$ & 120 & $240,000.00$ & 180 & $360,000.00$ & 240 & $480,000.00$ & 300 & $600,000.00$ & 300 & $600,000.00$ \\
\hline $\begin{array}{ll}\text { Coste } & \text { de } \\
\text { titulación } & \end{array}$ & $1,000.00$ & & 0.00 & & 0.00 & & 0.00 & & & & 0.00 & 60 & $60,000.00$ \\
\hline \begin{tabular}{|l|} 
SUB \\
TOTALES
\end{tabular} & & & $\begin{array}{l}1,128,000.0 \\
0\end{array}$ & & $2,166,000.00$ & & $3,204,000.00$ & & $4,242,000.00$ & & $5,280,000.00$ & & $5,340,000.00$ \\
\hline \multicolumn{14}{|c|}{ PRESUPUESTO EN SOLES: ADMINISTRATIVO - LOGÍSTICO } \\
\hline \multirow[b]{2}{*}{ RUBROS } & \multicolumn{3}{|l|}{ AÑ̃ 1} & \multicolumn{2}{|l|}{ AÑ̃ 2} & \multicolumn{2}{|l|}{ AÑ̃ 3} & \multicolumn{2}{|l|}{ AÑO 4} & \multicolumn{2}{|l|}{ AÑO 5} & \multicolumn{2}{|l|}{ AÑ̃ 6} \\
\hline & 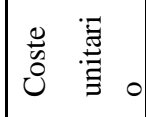 & z & 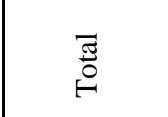 & z & 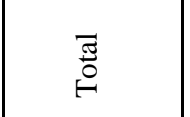 & ¿ & $\stackrel{\vec{J}}{\circ}$ & z & $\stackrel{5}{0}$ & 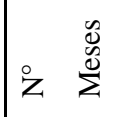 & $\stackrel{\bar{\pi}}{0}$ & 范 & $\stackrel{\pi}{0}$ \\
\hline $\begin{array}{l}\text { Coordinador } \\
\text { Gral. }\end{array}$ & $5,000.00$ & 12 & 60,000.00 & 12 & $60,000.00$ & 12 & $60,000.00$ & 12 & $60,000.00$ & 12 & $60,000.00$ & 12 & $60,000.00$ \\
\hline $\begin{array}{l}\text { asistente } \\
\text { técnico } 1\end{array}$ & $3,000.00$ & 12 & $36,000.00$ & 12 & $36,000.00$ & 12 & $36,000.00$ & 12 & $36,000.00$ & 12 & $36,000.00$ & 12 & $36,000.00$ \\
\hline $\begin{array}{l}\text { asistente } \\
\text { técnico } 2\end{array}$ & $3,000.00$ & 12 & $36,000.00$ & 12 & $36,000.00$ & 12 & $36,000.00$ & 12 & $36,000.00$ & 12 & $36,000.00$ & 12 & $36,000.00$ \\
\hline
\end{tabular}




\begin{tabular}{|c|c|c|c|c|c|c|c|c|c|c|c|c|c|}
\hline $\begin{array}{l}\text { Analista de } \\
\text { marketing }\end{array}$ & $4,000.00$ & 12 & $48,000.00$ & 12 & $48,000.00$ & 12 & $48,000.00$ & 12 & $48,000.00$ & 12 & $48,000.00$ & 12 & $48,000.00$ \\
\hline $\begin{array}{l}\text { Equipo } \\
\text { tecnológico } \\
\text { (computadoras } \\
\text {, impresoras, } \\
\text { entre otros. }\end{array}$ & $\begin{array}{l}10,000.0 \\
0\end{array}$ & 1 & $10,000.00$ & 0 & 0.00 & 0 & 0.00 & 0 & 0.00 & 0 & 0.00 & 1 & $10,000.00$ \\
\hline $\begin{array}{l}\text { Materiales de } \\
\text { oficina }\end{array}$ & 800.00 & 12 & $9,600.00$ & 12 & $9,600.00$ & 12 & $9,600.00$ & 12 & $9,600.00$ & 12 & $9,600.00$ & 12 & $9,600.00$ \\
\hline Mobiliario & $\begin{array}{l}15,000.0 \\
0\end{array}$ & 1 & $15,000.00$ & 0 & 0.00 & 0 & 0.00 & 0 & 0.00 & 0 & 0.00 & 1 & $15,000.00$ \\
\hline $\begin{array}{l}\text { Servicios } \\
\text { varios }\end{array}$ & $1,000.00$ & 12 & $12,000.00$ & 12 & $12,000.00$ & 12 & $12,000.00$ & 12 & $12,000.00$ & 12 & $12,000.00$ & 12 & $12,000.00$ \\
\hline $\begin{array}{l}\text { SUB } \\
\text { TOTALES }\end{array}$ & & & $226,600.00$ & & $201,600.00$ & & $201,600.00$ & & $201,600.00$ & & $201,600.00$ & & $226,600.00$ \\
\hline \multicolumn{14}{|c|}{ PRESUPUESTO TOTAL POR AÑO } \\
\hline \multirow{2}{*}{ TOTAL } & \multicolumn{3}{|l|}{ AÑ̃ 1} & \multicolumn{2}{|c|}{ AÑO 2} & \multicolumn{2}{|c|}{ AÑ̃ 3} & \multicolumn{2}{|c|}{ AÑO 4} & \multicolumn{2}{|c|}{ AÑO 5} & \multicolumn{2}{|c|}{ AÑO 6} \\
\hline & \multicolumn{3}{|c|}{\begin{tabular}{|l|}
$1,354,600.00$ \\
\end{tabular}} & \multicolumn{2}{|c|}{$2,367,600.00$} & \multicolumn{2}{|c|}{$3,405,600.00$} & \multicolumn{2}{|c|}{$4,443,600.00$} & \multicolumn{2}{|c|}{$5,481,600.00$} & \multicolumn{2}{|c|}{$5,566,600.00$} \\
\hline
\end{tabular}

Fuente: Elaboración propia. 
Tabla 15.

PRESUPUESTO EN SOLES: BECAS DE ESTUDIO - DEPORTISTA DE COLEGIO - GOBIERNOS REGIONALES.

PRESUPUESTO EN SOLES: BECAS DE ESTUDIO - DEPORTISTA DE COLEGIO - GOBIERNOS REGIONALES

\begin{tabular}{|c|c|c|c|c|c|c|c|c|c|c|c|c|c|}
\hline \multirow[b]{2}{*}{ RUBROS } & \multicolumn{3}{|l|}{ AÑ̃ 1 } & \multicolumn{2}{|l|}{ AÑO 2} & \multicolumn{2}{|l|}{$\overline{\mathrm{AÑO} 3}$} & \multicolumn{2}{|l|}{ AÑO 4} & \multicolumn{2}{|l|}{ AÑO 5} & \multicolumn{2}{|l|}{ AÑO 6} \\
\hline & \begin{tabular}{|l|} 
Coste \\
unitario
\end{tabular} & $\begin{array}{l}\mathrm{N}^{\circ} \\
\text { Becarios }\end{array}$ & Total & $\begin{array}{l}\mathrm{N}^{\circ} \\
\text { Becarios }\end{array}$ & Total & $\begin{array}{l}\mathrm{N}^{\circ} \\
\text { Becarios }\end{array}$ & Total & $\begin{array}{l}\mathrm{N}^{\circ} \\
\text { Becarios }\end{array}$ & Total & $\begin{array}{l}\mathrm{N}^{\circ} \\
\text { Becarios }\end{array}$ & Total & $\begin{array}{l}\mathrm{N}^{\circ} \\
\text { Becarios }\end{array}$ & Total \\
\hline $\begin{array}{|ll|}\text { Coste } & \text { de } \\
\text { matrículas } & \\
\end{array}$ & 300.00 & 120 & $36,000.00$ & 240 & $72,000.00$ & 360 & $108,000.00$ & 480 & $144,000.00$ & 600 & $180,000.00$ & 600 & $180,000.00$ \\
\hline \begin{tabular}{|l|} 
Coste de pensión \\
anual
\end{tabular} & $\begin{array}{l}11,000.0 \\
0\end{array}$ & 120 & $\begin{array}{l}1,320,000.0 \\
0\end{array}$ & 240 & $\begin{array}{l}2,640,000.0 \\
0\end{array}$ & 360 & $\begin{array}{l}3,960,000.0 \\
0\end{array}$ & 480 & $\begin{array}{l}5,280,000.0 \\
0\end{array}$ & 600 & $\begin{array}{l}6,600,000.0 \\
0\end{array}$ & 600 & $\begin{array}{l}6,600,000.0 \\
0\end{array}$ \\
\hline Laptop & $1,500.00$ & 120 & $180,000.00$ & 120 & $180,000.00$ & 120 & $180,000.00$ & 120 & \begin{tabular}{|l|}
$180,000.00$ \\
\end{tabular} & 120 & $180,000.00$ & 120 & $180,000.00$ \\
\hline $\begin{array}{|ll|}\begin{array}{l}\text { Materiales } \\
\text { estudio }\end{array} & \text { de } \\
\end{array}$ & $2,000.00$ & 120 & $240,000.00$ & 240 & $480,000.00$ & 360 & $720,000.00$ & 480 & $960,000.00$ & 600 & $\begin{array}{l}1,200,000.0 \\
0\end{array}$ & 600 & $\begin{array}{l}1,200,000.0 \\
0\end{array}$ \\
\hline \begin{tabular}{ll|} 
Coste & de \\
titulación & \\
\end{tabular} & $1,000.00$ & & 0.00 & & 0.00 & & 0.00 & & & & 0.00 & 120 & $120,000.00$ \\
\hline SUB TOTALES & & & $\begin{array}{l}1,776,000.0 \\
0\end{array}$ & & $\begin{array}{l}3,372,000.0 \\
0\end{array}$ & & $\begin{array}{l}4,968,000.0 \\
0\end{array}$ & & $\begin{array}{l}6,564,000.0 \\
0\end{array}$ & & $\begin{array}{l}8,160,000.0 \\
0\end{array}$ & & $\begin{array}{l}8,280,000.0 \\
0\end{array}$ \\
\hline
\end{tabular}

\section{PRESUPUESTO EN SOLES: ADMINISTRATIVO - LOGÍSTICO}

\begin{tabular}{|c|c|c|c|c|c|c|c|c|c|c|c|c|c|}
\hline \multirow[b]{2}{*}{ RUBROS } & \multicolumn{3}{|l|}{ AÑ̃ 1} & \multicolumn{2}{|l|}{ AÑ̃ 2} & \multicolumn{2}{|l|}{ AÑ̃ 3 } & \multicolumn{2}{|l|}{ AÑ̃O 4} & \multicolumn{2}{|l|}{ AÑNO 5} & \multicolumn{2}{|l|}{ AÑNO 6} \\
\hline & $\begin{array}{l}\text { Coste } \\
\text { unitario }\end{array}$ & $\begin{array}{l}\mathrm{N}^{\circ} \\
\text { Meses }\end{array}$ & Total & $\begin{array}{l}\mathrm{N}^{\circ} \\
\text { Meses }\end{array}$ & Total & $\begin{array}{l}\mathrm{N}^{\circ} \\
\text { Meses }\end{array}$ & Total & $\begin{array}{l}\mathrm{N}^{\circ} \\
\text { Meses }\end{array}$ & Total & $\begin{array}{l}\mathrm{N}^{\circ} \\
\text { Meses }\end{array}$ & Total & $\begin{array}{l}\mathrm{N}^{\circ} \\
\text { Meses }\end{array}$ & Total \\
\hline $\begin{array}{l}\text { Coordinador } \\
\text { Gral. }\end{array}$ & $5,000.00$ & 12 & $60,000.00$ & 12 & $60,000.00$ & 12 & $60,000.00$ & 12 & $60,000.00$ & 12 & $60,000.00$ & 12 & $60,000.00$ \\
\hline $\begin{array}{l}\text { asistente técnico } \\
1\end{array}$ & $3,000.00$ & 12 & $36,000.00$ & 12 & $36,000.00$ & 12 & $36,000.00$ & 12 & $36,000.00$ & 12 & $36,000.00$ & 12 & $36,000.00$ \\
\hline $\begin{array}{l}\text { asistente técnico } \\
2\end{array}$ & $3,000.00$ & 12 & $36,000.00$ & 12 & $36,000.00$ & 12 & $36,000.00$ & 12 & $36,000.00$ & 12 & $36,000.00$ & 12 & $36,000.00$ \\
\hline \begin{tabular}{ll|} 
Analista & de \\
marketing &
\end{tabular} & $4,000.00$ & 12 & $48,000.00$ & 12 & $48,000.00$ & 12 & $48,000.00$ & 12 & $48,000.00$ & 12 & $48,000.00$ & 12 & $48,000.00$ \\
\hline
\end{tabular}




\begin{tabular}{|c|c|c|c|c|c|c|c|c|c|c|c|c|c|}
\hline $\begin{array}{l}\text { Equipo } \\
\text { tecnológico } \\
\text { (computadoras, } \\
\text { impresoras, entre } \\
\text { otros. }\end{array}$ & $\begin{array}{l}10,000.0 \\
0\end{array}$ & 1 & $10,000.00$ & 0 & 0.00 & 0 & 0.00 & 0 & 0.00 & 0 & 0.00 & 1 & $10,000.00$ \\
\hline $\begin{array}{l}\text { Materiales } \mathrm{de} \\
\text { oficina }\end{array}$ & 800.00 & 12 & $9,600.00$ & 12 & $9,600.00$ & 12 & $9,600.00$ & 12 & $9,600.00$ & 12 & $9,600.00$ & 12 & $9,600.00$ \\
\hline Mobiliario & $\begin{array}{l}15,000.0 \\
0\end{array}$ & 1 & $15,000.00$ & 0 & 0.00 & 0 & 0.00 & 0 & 0.00 & 0 & 0.00 & 1 & $15,000.00$ \\
\hline Servicios varios & $1,000.00$ & 12 & $12,000.00$ & 12 & $12,000.00$ & 12 & $12,000.00$ & 12 & $12,000.00$ & 12 & $12,000.00$ & 12 & $12,000.00$ \\
\hline SUB TOTALES & & & $226,600.00$ & & $201,600.00$ & & $201,600.00$ & & $201,600.00$ & & $201,600.00$ & & $226,600.00$ \\
\hline \multicolumn{14}{|c|}{ PRESUPUESTO TOTAL POR AÑO - GOBIERNOS REGIONALES } \\
\hline \multirow{2}{*}{ TOTAL } & \multicolumn{3}{|l|}{ AÑNO 1 } & \multicolumn{2}{|c|}{ AÑNO 2} & \multicolumn{2}{|c|}{ AÑO 3 } & \multicolumn{2}{|c|}{ AÑO 4} & \multicolumn{2}{|c|}{ AÑO 5 } & \multicolumn{2}{|c|}{ AÑO 6} \\
\hline & \multicolumn{3}{|c|}{$2,002,600.00$} & \multicolumn{2}{|c|}{$3,573,600.00$} & \multicolumn{2}{|c|}{$5,169,600.00$} & \multicolumn{2}{|c|}{$6,765,600.00$} & \multicolumn{2}{|c|}{$8,361,600.00$} & \multicolumn{2}{|c|}{$8,506,600.00$} \\
\hline
\end{tabular}

Fuente: Elaboración propia. 
Tabla 16

Presupuesto del Instituto Peruano del Deporte. Año de ejecución 2017.

\begin{tabular}{|c|c|c|c|c|c|c|}
\hline Actividad / Acción de Inversión / Obra & PIA & PIM & Certificación & Compromiso Anual & Devengado & Avance $\%$ \\
\hline TOTAL & $142,471,518,545$ & $176,300,549,759$ & $161,079,975,365$ & $153,594,456,817$ & $150,169,173,110$ & 85.2 \\
\hline Nivel de Gobierno E: GOBIERNO NACIONAL & $105,113,439,451$ & $107,508,500,596$ & $99,439,569,928$ & $97,281,323,378$ & $96,653,855,673$ & 89.9 \\
\hline Sector 10: EDUCACION & $16,379,171,034$ & $12,496,753,032$ & $11,778,094,976$ & $11,222,810,140$ & $11,165,122,144$ & 89.3 \\
\hline Pliego 342: INSTITUTO PERUANO DEL DEPORTE & $187,057,963$ & $237,742,301$ & $223,047,034$ & $213,764,941$ & $213,692,549$ & 89.9 \\
\hline $\begin{array}{l}\text { Unidad Ejecutora 001-994: INSTITUTO PERUANO DEL } \\
\text { DEPORTE - IPD }\end{array}$ & $187,057,963$ & $237,742,301$ & $223,047,034$ & $213,764,941$ & $213,692,549$ & 89.9 \\
\hline $\begin{array}{l}\text { Producto/Proyecto 3000423: DEPORTISTAS ACCEDEN A } \\
\text { DESARROLLO DEPORTIVO DE ALTA COMPETENCIA }\end{array}$ & $56,874,765$ & $93,189,640$ & $90,076,641$ & $88,856,434$ & $88,811,608$ & 95.3 \\
\hline $\begin{array}{l}\text { Categoría Presupuestal 0101: INCREMENTO DE LA } \\
\text { PRACTICA DEACTIVIDADESFISICAS, DEPORTIVASY } \\
\text { RECREATIVAS ENLAPOBLACION PERUANA }\end{array}$ & $56,874,765$ & $93,189,640$ & $90,076,641$ & $88,856,434$ & $88,811,608$ & 95.3 \\
\hline $\begin{array}{l}\text { 5001515: DOTACION DE SERVICIOS BIOMEDICOS } \\
\text { A LOS DEPORTISTAS }\end{array}$ & $1,086,080$ & $11,822,751$ & $11,409,423$ & $10,460,355$ & $10,458,149$ & 88.5 \\
\hline $\begin{array}{l}\text { 5003176: DESARROLLO DE ESTIMULOS A LOS } \\
\text { DEPORTISTAS DE ALTA COMPETENCIA }\end{array}$ & $11,210,410$ & $14,531,241$ & $14,239,132$ & $14,170,636$ & $14,136,969$ & 97.3 \\
\hline $\begin{array}{l}\text { 5003258: SUBVENCION A LAS FEDERACIONES } \\
\text { DEPORTIVAS }\end{array}$ & $40,165,741$ & $63,595,231$ & $61,461,528$ & $61,341,891$ & $61,341,891$ & 96.5 \\
\hline $\begin{array}{l}\text { 5005871: CAPACITACION DE AGENTES } \\
\text { DEPORTIVOS DE ALTA COMPETENCIA }\end{array}$ & 353,236 & 67,310 & 66,335 & 66,335 & 66,335 & 98.6 \\
\hline $\begin{array}{l}\text { 5005872: PERFECCIONAMIENTO DEPORTIVO EN } \\
\text { CENTROS DE ENTRENAMIENTO DE ALTO } \\
\text { RENDIMIENTO }\end{array}$ & $4,059,298$ & $3,173,107$ & $2,900,222$ & $2,817,217$ & $2,808,263$ & 88.5 \\
\hline
\end{tabular}

Fuente: Ministerio de Economía y Finanzas - MEF, 2018. 


\subsubsection{Dimensión Política de la Política}

En este contexto se identifica a los principales actores políticos que intervienen para la formulación de la política pública, así como también el balance político que muestra la tendencia y el peso que representa cada actor.

\section{Sector público:}

- Instituto Peruano del Deporte

- Ministerio de Economía y Finanzas

- Presidencia de Consejo de Ministros

-Ministerio de Educación

- Ministerio del Trabajo y promoción del empleo

- Ministerio de Salud

- Gobiernos Regionales

Sector Privado:

- Federaciones Deportivas Nacionales

- Federación deportiva Universitaria del Perú

- Comité Olímpico Peruano

- Clubes deportivos

- Medios de comunicación

- Universidades privadas e Institutos privados

- Empresa

\section{Sociedad Civil:}

- Deportistas

- Entrenadores

- Padres de familia de deportistas

- Ciudadanos en general

- Iglesia 


\subsubsection{Identificación de los grupos de interés}

Instituto Peruano del Deporte - IPD, ente rector del Sistema Deportivo Nacional SISDEN, según artículo 8 la Ley Nº 28036, Ley de Promoción y Desarrollo del Deporte y normas modificatorias, en este marco sus principales responsabilidades son: a) Liderar y gestionar estratégicamente el SISDEN buscando la articulación de los actores. b) Promover la cultura deportiva a nivel nacional en articulación con instituciones públicas y privadas. c)Asesorar, asistir técnicamente y apoyar al fortalecimiento de las organizaciones que forman parte del SISDEN. d) Gestionar la información estadística del SISDEN y monitorear, evaluar y difundir los principales indicadores de desempeño. (2018, s.p.).

Ministerio de Economía y Finanzas, es un organismo del Poder Ejecutivo, cuya organización, competencia y funcionamiento está regido por el Decreto Legislativo $\mathrm{N}^{\circ} 183$ y sus modificatorias. Está encargado de planear, dirigir y controlar los asuntos relativos a presupuesto, tesorería, endeudamiento, contabilidad, política fiscal, inversión pública y política económica y social. Asimismo, diseña, establece, ejecuta y supervisa la política nacional y sectorial de su competencia asumiendo la rectoría de ella.

Ministerio de Educación - MINEDU, Organismo que cumple el rol como iniciador o base, ya que dentro de sus funciones es el integrar y articular los aprendizajes obtenidos en la escuela, entre ellos lo relacionado a la educación física y el deporte. según el artículo 21 de la Ley No 28044, Ley General de Educación.

Presidencia de Consejo de Ministros, Coordinar las políticas públicas en las entidades de los tres niveles de gobierno y las relaciones con los demás poderes del Estado y los organismos constitucionales, con eficiencia y eficacia.

Ministerio de Trabajo y promoción del empleo, El Ministerio de Trabajo y Promoción del Empleo es el organismo rector de los sectores Trabajo y Promoción del Empleo. Forma parte

del Poder Ejecutivo y constituye un pliego presupuestal con autonomía administrativa y económica, de acuerdo a Ley. 
Según el Ministerio de Salud:

Ministerio de Salud.- Es un organismo del Poder Ejecutivo que ejerce la rectoría del Sector Salud a nivel nacional, diseña, establece, ejecuta y supervisa políticas nacionales y sectoriales de salud y ejerce la rectoría respecto de ellas. Constituye el ente rector del Sistema Nacional Coordinado y Descentralizado de Salud (2017, p.3.).

Sus principales funciones:

- Ejercer la rectoría del Sector Salud.

Formular, planear, dirigir, coordinar, ejecutar la política nacional y sectorial de Promoción de la salud, Prevención de enfermedades, Recuperación y Rehabilitación en Salud, bajo su competencia, aplicable a todos los niveles de gobierno.

- Dictar normas y lineamientos técnicos para la adecuada ejecución y supervisión de las políticas nacionales y sectoriales de salud, la gestión de los recursos del sector; así como para el otorgamiento y reconocimiento de derechos, fiscalización, sanción y ejecución coactiva en las materias de su competencia.

- Conducir el Sistema Nacional Coordinado y Descentralizado de Salud. (2017, p.3).

Según el Ministerio de Salud: "Realizar el seguimiento y evaluación respecto del desempeño y obtención de resultados alcanzados de las políticas, planes y programas en materia de su competencia, en el niveles nacional, regional y local, así como a otros actores del Sistema Nacional Coordinado y Descentralizado de Salud en todo el territorio nacional y adoptar las acciones que se requieran de acuerdo a Ley" (2017, p.3. ).

- Otorgar, reconocer derechos a través de autorizaciones y permisos, de acuerdo con las normas de la materia, en el ámbito de su competencia.

- Las demás funciones que se establezca por ley. 
Gobiernos Regionales.- tienen como finalidad principal fomentar el desarrollo regional integral sostenible, promoviendo la inversión pública, privada y el empleo, garantizando el ejercicio pleno de los derechos y la igualdad de oportunidades de sus habitantes. Ley Orgánica de Gobiernos Regionales, Art. 4.

Según el IPD las Federaciones Deportivas Nacionales - FDN, según el artículo 44 de la Ley No 28036, Ley de Promoción y Desarrollo del Deporte y normas modificatorias, en este marco sus principales responsabilidades son:

- Liderar y gestionar estratégicamente el deporte a su cargo a nivel nacional

- Diseñar las estrategias para el desarrollo del deporte a su cargo, priorizando actividades y generando alianzas con distintas instituciones públicas y privadas.

- Representar al deporte peruano a nivel internacional.

- Facilitar, formar y desarrollar deportistas en el deporte a su cargo, articulando esfuerzos con otros actores y contando con la asistencia técnica del IPD.

- Articular esfuerzos con colegios, universidades, clubes deportivos, clubes de barrio, academias deportivas, gobiernos regionales y locales para el fomento y desarrollo de su deporte a nivel nacional. (s.a, s.p.).

Federación Deportiva Universitaria del Perú.- contribuye en la formación integral de los universitarios y alumnos de la Educación Superior del Perú. Promoviendo el desarrollo humano en nuestros futuros profesionales. Fortaleciendo la importancia de la actividad física como parte de la formación integral de los estudiantes universitarios del país.

Comité Olímpico Peruano - COP, según el artículo 28 de la Ley No 28036, Ley de Promoción y Desarrollo del Deporte y normas modificatorias, en este marco sus principales responsabilidades son: a) Fomentar el desarrollo del deporte de alta competencia a nivel nacional. b) Contribuir a la organización de programas deportivos de alta competencia en coordinación con las Federaciones Deportivas Nacionales. c) Apoyar e incentivar para el desarrollo deportivo de los atletas de alta competencia en búsqueda de la excelencia deportiva. (IPD, s.p.). 
Clubes deportivos, son asociaciones deportivas privadas, orientadas a la promoción y masificación del deporte o varias modalidades deportivas, las mismas que tienen capacidad de participar en competencias deportivas.

Universidades e Institutos privados, son entidades privadas orientadas a la enseñanza superior, a la investigación y la formación de profesionales en distintos rubros, son auto sostenibles.

Medios de comunicación, su principal rol es informar a la población acerca de los últimos acontecimientos de orden político, social, deportivo, cultural, entre otros.

Empresa privada, pueden ser pequeñas, medianas y grandes empresas, su principal actividad está orientada a generar rentabilidad y posicionarse como líderes en el mercado nacional e internacional.

Deportistas, Personas que practican una o varias disciplinas deportivas, que buscan mejorar sus capacidades físicas y destrezas deportivas para obtener importantes resultados en competencias.

Entrenadores, Personas que se dedican a la enseñanza del deporte con una o varias especialidades, buscan lograr en el deportista el desarrollo de sus potencialidades y llevarlos al alto rendimiento deportivo.

Padres de familia de deportistas, Velan por los intereses de sus hijos, proporcionan respaldo y estabilidad para la práctica deportiva.

Ciudadanos en general, personas que buscan oportunidades de desarrollo profesional, económico y social, velan por el cumplimiento de sus derechos y deberes.

Iglesia, vela por el cumplimiento de las normas espirituales, fomenta la paz, armonía, el respeto, defiende los derechos humanos. 


\subsubsection{Elaboración del Mapa Político (posicionamiento de actores)}

Tabla 17.

\section{Elaboración del Mapa Político (posicionamiento de actores).}

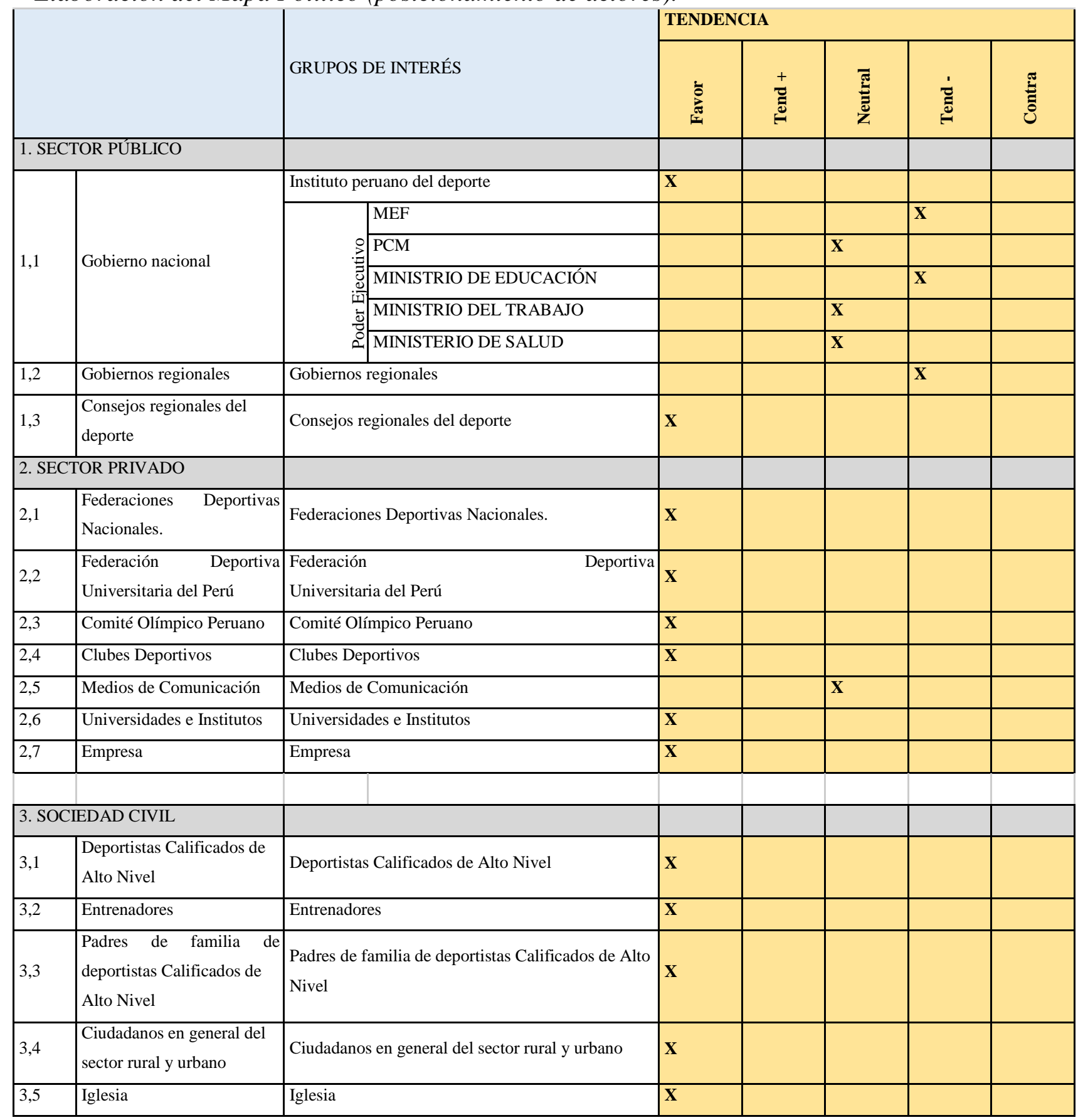

Fuente: Elaboración propia. 


\subsubsection{Elaboración de la Tipología de Intereses de los Grupos de Interés}

Tabla 18.

Elaboración de la Tipología de Intereses de los Grupos de Interés.

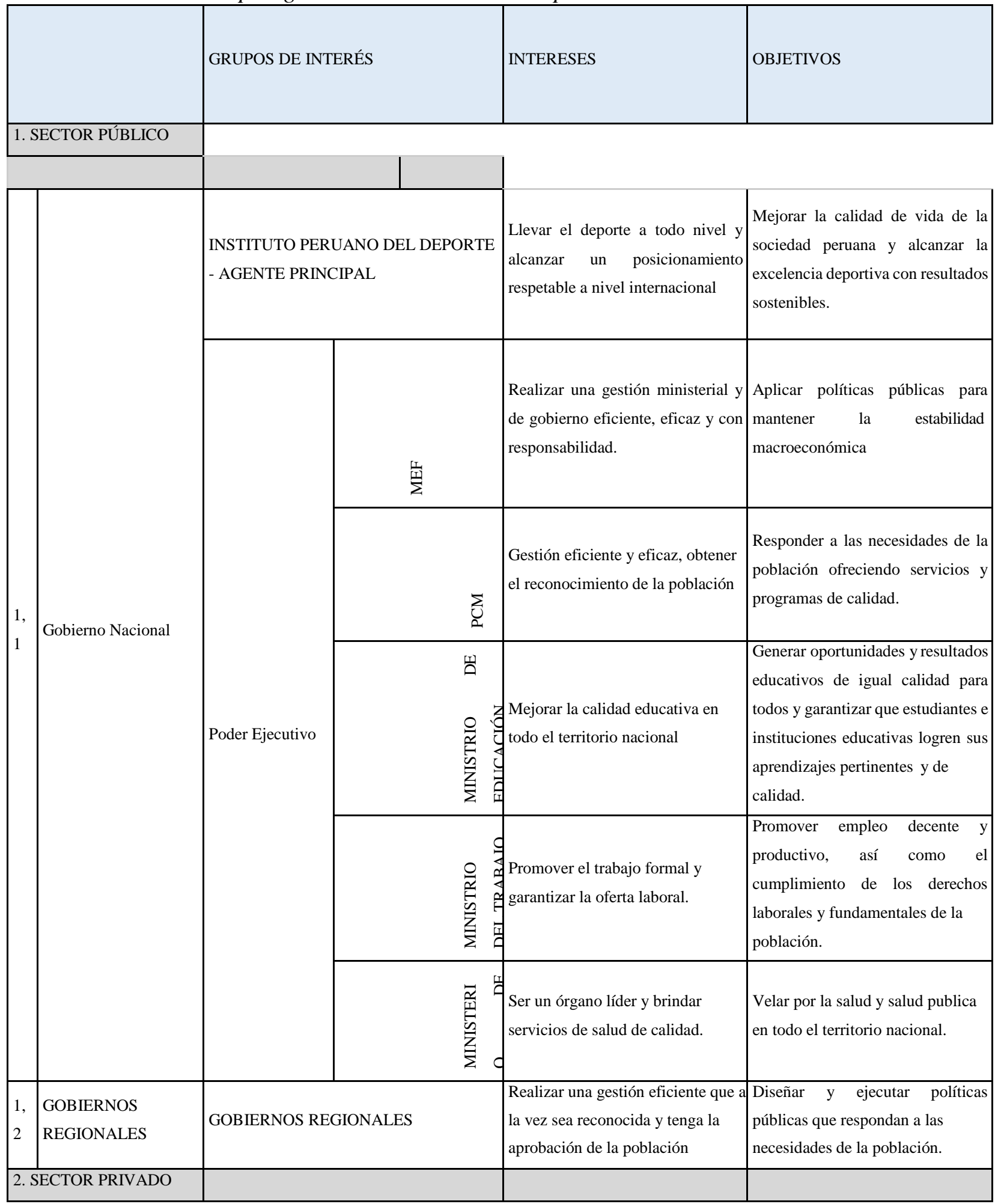




\begin{tabular}{|c|c|c|c|c|}
\hline $\begin{array}{l}2, \\
1\end{array}$ & $\begin{array}{l}\text { Federaciones } \\
\text { Deportivas Nacionales. }\end{array}$ & Federaciones Deportivas Nacionales. & $\begin{array}{l}\text { Aumentar la cantidad de } \\
\text { Deportistas Calificados de Alto } \\
\text { Nivel, Masificar el deporte a nivel } \\
\text { nacional, Obtener beneficios para } \\
\text { sus deportistas }\end{array}$ & $\begin{array}{l}\text { Lograr importantes resultados en } \\
\text { competencias oficiales del circuito } \\
\text { Olímpico }\end{array}$ \\
\hline $\begin{array}{l}2, \\
2\end{array}$ & $\begin{array}{l}\text { Federación Deportiva } \\
\text { Universitaria del Perú }\end{array}$ & $\begin{array}{ll}\text { Federación } & \text { Deportiva } \\
\text { Universitaria del Perú } & \end{array}$ & $\begin{array}{l}\text { Incrementar la práctica deportiva } \\
\text { en todas las universidades a nivel } \\
\text { nacional }\end{array}$ & $\begin{array}{l}\text { promover el deporte universitario } \\
\text { en todos sus niveles }\end{array}$ \\
\hline $\begin{array}{l}2, \\
3\end{array}$ & $\begin{array}{l}\text { Comité } \quad \text { Olímpico } \\
\text { Peruano }\end{array}$ & Comité Olímpico Peruano & $\begin{array}{l}\text { Ostentar poder y reconocimiento a } \\
\text { nivel nacional e internacional }\end{array}$ & $\begin{array}{l}\text { Fomentar el movimiento Olímpico } \\
\text { y garantizar la participación de los } \\
\text { deportistas en competencias } \\
\text { Oficiales. }\end{array}$ \\
\hline $\begin{array}{l}2, \\
4\end{array}$ & Clubes Deportivos & Clubes Deportivos & Ostentar poder y reconocimiento. & $\begin{array}{l}\text { Promover la práctica deportiva y } \\
\text { generar rentabilidad. }\end{array}$ \\
\hline $\begin{array}{l}2, \\
5\end{array}$ & \begin{tabular}{ll|} 
Medios & $\mathrm{de}$ \\
Comunicación &
\end{tabular} & Medios de Comunicación & $\begin{array}{l}\text { Obtener reconocimiento y ser líder } \\
\text { a nivel nacional. }\end{array}$ & Generar mayores utilidades \\
\hline $\begin{array}{l}2, \\
6\end{array}$ & $\begin{array}{l}\text { Universidades } \\
\text { Institutos }\end{array}$ & Universidades e Institutos & $\begin{array}{l}\text { Ostentar poder y posicionarse } \\
\text { como líder a nivel nacional }\end{array}$ & Apoyo a la educación con valores \\
\hline $\begin{array}{l}2, \\
7\end{array}$ & Empresa & Empresa & $\begin{array}{l}\text { Mejorar la calidad de los servicios } \\
\text { ofertados. }\end{array}$ & $\begin{array}{l}\text { Lograr competitividad y generar } \\
\text { mayores utilidades }\end{array}$ \\
\hline \multicolumn{5}{|c|}{ 3. SOCIEDAD CIVIL } \\
\hline $\begin{array}{l}3, \\
1\end{array}$ & $\begin{array}{l}\text { Deportistas Calificados } \\
\text { de Alto Nivel }\end{array}$ & Deportistas Calificados de Alto Nivel & 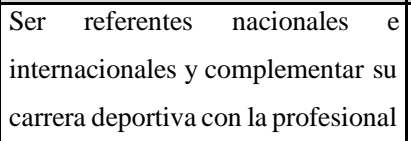 & $\begin{array}{l}\text { Obtener importantes resultados } \\
\text { deportivos en competencias } \\
\text { internacionales. }\end{array}$ \\
\hline $\begin{array}{l}3, \\
2\end{array}$ & Entrenadores & Entrenadores & $\begin{array}{l}\text { Obtener reconocimiento en base a } \\
\text { resultados deportivos. }\end{array}$ & $\begin{array}{l}\text { Formar deportistas de alto nivel } \\
\text { que logren obtener importantes } \\
\text { resultados deportivos. }\end{array}$ \\
\hline $\begin{array}{l}3, \\
3\end{array}$ & \begin{tabular}{|l|} 
Padres de familia de \\
deportistas Calificados \\
de Alto Nivel
\end{tabular} & $\begin{array}{l}\text { Padres de familia de deportistas Calificados } \\
\text { de Alto Nivel }\end{array}$ & $\begin{array}{l}\text { Mejora de los beneficios para los } \\
\text { Deportistas Calificados de Alto } \\
\text { Nivel }\end{array}$ & $\begin{array}{l}\text { Que los hijos tengan acceso a una } \\
\text { educación de calidad }\end{array}$ \\
\hline $\begin{array}{l}3, \\
4\end{array}$ & 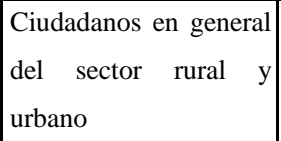 & $\begin{array}{l}\text { Ciudadanos en general del sector rural y } \\
\text { urbano }\end{array}$ & $\begin{array}{l}\text { Estudiar una carrera profesional } \\
\text { para que puedan sustentarse en la } \\
\text { adultez. }\end{array}$ & $\begin{array}{l}\text { Ser profesionales y acceder a } \\
\text { trabajos sostenibles. }\end{array}$ \\
\hline $\begin{array}{l}3, \\
5\end{array}$ & Iglesia & Iglesia & $\begin{array}{l}\text { Propiciar un entorno saludable para } \\
\text { todos }\end{array}$ & $\begin{array}{l}\text { Buscar el bienestar y equilibrio en } \\
\text { la sociedad. }\end{array}$ \\
\hline
\end{tabular}

Fuente: Elaboración propia. 


\subsubsection{Análisis del Poder de los Grupos de Interés}

Tabla 19.

Análisis del Poder de los Grupos de Interés.

\begin{tabular}{|c|c|c|c|c|c|c|c|c|}
\hline & \multirow{2}{*}{\multicolumn{2}{|c|}{ GRUPOS DE INTERÉS }} & \multicolumn{5}{|c|}{ | PESO POLÍTICO } \\
\hline & & & & 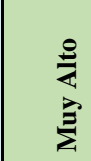 & $\stackrel{\ominus}{\gtrless}$ & 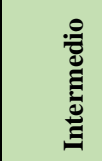 & $\stackrel{\circ}{\stackrel{9}{\pi}}$ & 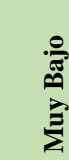 \\
\hline \multicolumn{9}{|c|}{ 1. SECTOR PÚBLICO } \\
\hline \multirow{6}{*}{1,1} & \multirow{6}{*}{ Gobierno nacional } & \multicolumn{2}{|c|}{ Instituto peruano del deporte } & $\mathbf{X}$ & & & & \\
\hline & & \multirow{5}{*}{ Poder Ejecutivo } & MEF & $\mathbf{X}$ & & & & \\
\hline & & & PCM & & & $\mathbf{X}$ & & \\
\hline & & & \begin{tabular}{|l} 
MINISTRIO DE EDUCACIÓN \\
\end{tabular} & $\mathbf{X}$ & & & & \\
\hline & & & \begin{tabular}{|l} 
MINISTRIO DEL TRABAJO \\
\end{tabular} & & & $\mathbf{X}$ & & \\
\hline & & & \begin{tabular}{|l} 
MINISTERIO DE SALUD \\
\end{tabular} & & & $\mathbf{X}$ & & \\
\hline 1,2 & Gobiernos regionales & \multicolumn{2}{|c|}{ Gobiernos regionales } & $\mathbf{X}$ & & & & \\
\hline 1,3 & $\begin{array}{|lll|}\begin{array}{l}\text { Consejos } \\
\text { deporte }\end{array} & \text { regionales } & \text { del } \\
\end{array}$ & \multicolumn{2}{|c|}{ Consejos regionales del deporte } & & & $\mathbf{X}$ & & \\
\hline \multicolumn{9}{|c|}{ 2. SECTOR PRIVADO } \\
\hline 2,1 & $\begin{array}{ll}\text { Federaciones } & \text { Deportivas } \\
\text { Nacionales. } & \end{array}$ & \multicolumn{2}{|c|}{ Federaciones Deportivas Nacionales. } & & $\mathbf{X}$ & & & \\
\hline 2,2 & \begin{tabular}{|l|} 
Federación $\quad$ Deportiva \\
Universitaria del Perú
\end{tabular} & \multicolumn{2}{|c|}{ Federación Deportiva } & & $\mathbf{X}$ & & & \\
\hline 2,3 & Comité Olímpico Peruano & \multicolumn{2}{|c|}{ Comité Olímpico Peruano } & & $\mathbf{X}$ & & & \\
\hline 2,4 & Clubes Deportivos & \multicolumn{2}{|c|}{ Clubes Deportivos } & & & & $\bar{X}$ & \\
\hline 2,5 & Medios de Comunicación & \multicolumn{2}{|c|}{ Medios de Comunicación } & & $\mathbf{X}$ & & & \\
\hline 2,6 & Universidades e Institutos & \multicolumn{2}{|c|}{ Universidades e Institutos } & & & & $\mathbf{X}$ & \\
\hline 2,7 & Empresa & \multicolumn{2}{|l|}{ Empresa } & & & & $\mathbf{X}$ & \\
\hline \multicolumn{9}{|c|}{ 3. SOCIEDAD CIVIL } \\
\hline 3,1 & \multicolumn{3}{|c|}{ Deportistas Calificados de Alto Nivel } & & $\mathbf{X}$ & & & \\
\hline 3,2 & \multicolumn{3}{|l|}{ Entrenadores } & & & & & $\mathbf{X}$ \\
\hline 3,3 & \multicolumn{3}{|c|}{ Padres de familia de deportistas Calificados de Alto Nivel } & & & & $\mathbf{X}$ & \\
\hline 3,4 & \multicolumn{3}{|c|}{ Ciudadanos en general del sector rural y urbano } & & & & $\mathbf{X}$ & \\
\hline 3,5 & \multicolumn{3}{|l|}{ Iglesia } & & & $\mathbf{X}$ & & \\
\hline
\end{tabular}

Fuente: Elaboración propia. 


\subsubsection{Elaboración de Estrategias para reposicionamiento de actores.}

Tabla 20.

Elaboración de Estrategias para reposicionamiento de actores.

\begin{tabular}{|c|c|c|c|c|c|}
\hline \multicolumn{2}{|c|}{ ACTORES POLÍTICOS } & \multicolumn{2}{|c|}{ GRUPOS DE INTERÉS } & $\begin{array}{|lc|}\text { PLANTEAMIENTO } & \text { DE } \\
\text { ESTRATEGIA } & \end{array}$ & NUEVOS OBJETIVOS \\
\hline \multicolumn{6}{|l|}{1} \\
\hline \multicolumn{6}{|c|}{ SECTOR } \\
\hline & \multirow{4}{*}{$\begin{array}{l}\text { GOBIERNO } \\
\text { NACIONAL }\end{array}$} & \multirow{4}{*}{ Poder Ejecutivo } & MEF & 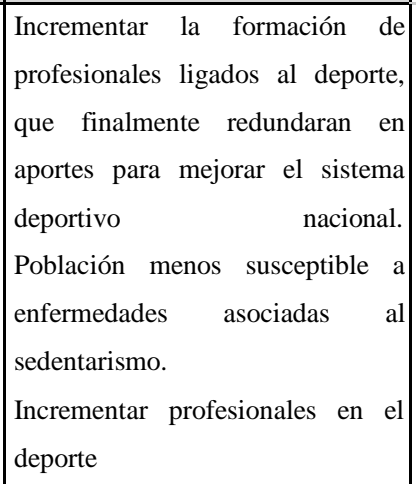 & $\begin{array}{l}\text { Aplicar políticas públicas para } \\
\text { mantener la estabilidad } \\
\text { macroeconómica y social }\end{array}$ \\
\hline & & & & $\begin{array}{l}\text { A través de esta política se cubrirá } \\
\text { el déficit de profesores de } \\
\text { educación física }\end{array}$ & \\
\hline & & & & $\begin{array}{l}\text { Fomentar el trabajo formal y } \\
\text { conforme al marco legal }\end{array}$ & \\
\hline & & & & $\begin{array}{llll}\text { Reducción } & \text { del } & \text { índice } & \text { del } \\
\text { sedentarismo } & \text { en } & \text { la } & \text { sociedad } \\
\text { Peruana } & & & \end{array}$ & \\
\hline & \multicolumn{3}{|c|}{ GOBIERNOS REGIONALES } & $\begin{array}{l}\text { Fortalecer el sector deportivo a } \\
\text { través de la profesionalización de } \\
\text { sus deportistas para mejorar la } \\
\text { estructura deportiva y fomentar la } \\
\text { investigación en el deporte }\end{array}$ & $\begin{array}{l}\text { Generar valor público en todas las } \\
\text { intervenciones del estado } \\
\text { respondiendo a las necesidades de } \\
\text { la población. }\end{array}$ \\
\hline 2 & \multicolumn{3}{|c|}{ SECTOR PRIVADO } & & \\
\hline 2,1 & \multicolumn{3}{|c|}{ Medios de Comunicación } & Generar espacios orientados al & Generar utilidades y fomentar \\
\hline 2,2 & \multicolumn{3}{|l|}{ Empresa } & & Lograr competitividad y generar \\
\hline
\end{tabular}

Fuente: Elaboración propia. 


\subsubsection{Elaboración del Balance Político.}

Tabla 21.

Elaboración del Balance Político.

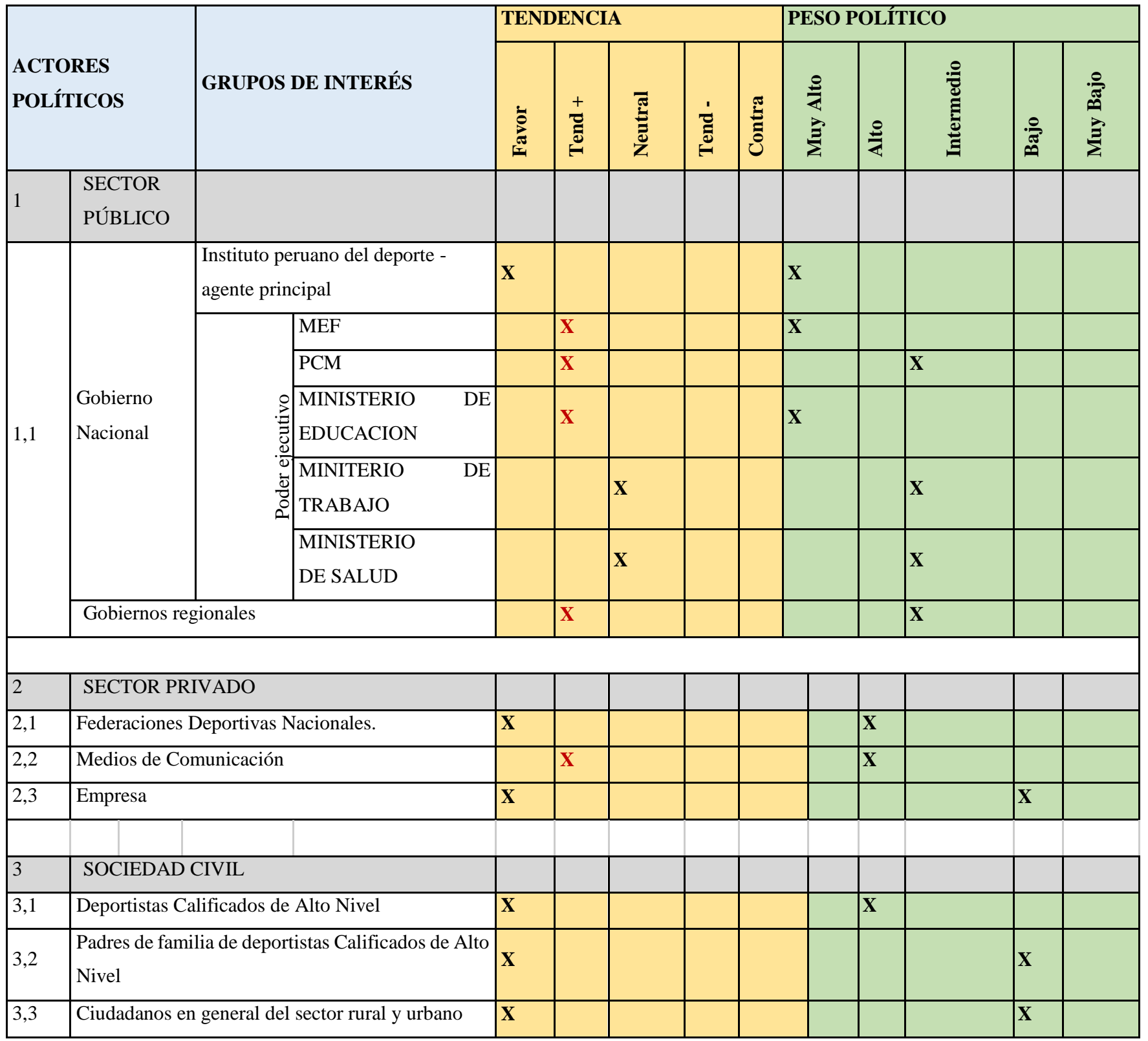

Fuente: Elaboración propia. 


\title{
4.2 Enfoque Integrado de Políticas Públicas.
}

\subsubsection{Identificación de Políticas de Apoyo.}

\author{
4.2.1.1 Políticas Nivel Meta
}

\section{Plan Bicentenario: El Perú hacia el 2021}

Según CEPLAN Aprobado por Decreto Supremo Nº54-2011-PCM. Si bien es cierto, no existe un enunciado directo relacionado al deporte, Podemos considerar que este se encuentra indirectamente relacionado con el Eje Estratégico 2: Oportunidades y acceso a los servicios. Objetivo Nacional: Igualdad de oportunidades y acceso universal a los servicios básicos. Objetivo Específico 1: Acceso equitativo a una educación integral que permita el desarrollo pleno de las capacidades humanas en sociedad. (2011, p. 55).

\section{Ley 28036, Ley de promoción y desarrollo del deporte.}

Esta ley promueve el otorgamiento de becas a través del Artículo 22.- Otorgamiento de becas Las universidades, institutos superiores y escuelas de las Fuerzas Armadas y de la Policía Nacional del Perú, como parte de su función social, están obligados a otorgar becas integrales y medias becas a los deportistas calificados y calificados de alto nivel, en no menos del uno por ciento (1\%) en cada caso, calculado sobre el número total de vacantes que ofrezcan en cada proceso de admisión, debiendo implementar mecanismos para garantizar que las becas o medias becas no se circunscriban en el tiempo a las mismas carreras de estudio. Estas becas están supeditadas a sus calificaciones académicas" (Congreso, 2004).

\subsubsection{Políticas Nivel Macro}

\section{Ley $N^{o} 27674$}

Ley que establece el acceso de deportistas de alto nivel a la administración pública, centros 
educativos y universidades. La calificación es otorgada por el Instituto Peruano del Deporte. Dicha norma se dictó con la finalidad de facilitar a los deportistas calificados, según su preparación técnico-deportiva y/o profesional, el acceso laboral a la Administración Pública. Dicha Ley fue reglamentada en el 2003 mediante Decreto Supremo No 089-2003-PCM (PCM, 2003).

\section{Ley $N^{o} 30220$, Ley Universitaria}

Plantea que las universidades públicas y privadas deben promover la práctica del deporte y la recreación como factores educativos coadyuvantes a la formación y desarrollo de la persona. De igual manera, la norma dispone que la universidad establezca Programas Deportivos de Alta Competencia - PRODAC. El funcionamiento de estos Programas se regula en el Estatuto de cada universidad." (MINEDU, s.a.) (9)

\subsubsection{Políticas Nivel Meso}

\section{Política Nacional del Deporte}

Aprobado por decreto supremo $\mathrm{N}^{\circ}$ 003-2017-MINEDUrysrt

En la descripción de la situación general del deporte peruano, se plantea que existe "Limitada oferta y capacitación especializada de agentes deportivos: (entrenadores, técnicos deportivos, profesores de educación física, jueces, árbitros)” (E1 Peruano, 2017). 


\subsubsection{Políticas Nivel Micro}

No se cuenta con políticas de nivel micro. 


\section{CAPÍTULO V \\ APLICACIÓN DE LA POLÍTICA EN UNA ENTIDAD PÚBLICA}




\section{Aplicación de la Política en una Entidad Pública}

\subsection{Planificación Estratégica de la Política con enfoque de Valor Público.}

La planificación Estratégica con enfoque de valor público, es la descripción de los objetivos y estrategias, mediante el cual se busca generar el ansiado Valor Público, los cuales recogen las inquietudes de los actores políticos. En tal sentido los actores identificados en la Dimensión Política, nos revela los lineamientos estratégicos que se deben seguir.

La Entidad identificada como responsable de implementar esta política pública es el Instituto Peruano del Deporte, ente Rector del Sistema Deportivo Nacional. Esta Entidad ha elaborado su Plan Estratégico Institucional PEI 2016 - 2021, conforme lo establece el artículo $13^{\circ}$ de la Ley N²8036 “Ley de Promoción y Desarrollo del Deporte y sus Modificatorias.

Este Plan Estratégico, fue aprobado por Resolución de la Presidencia de Consejo Directivo $\mathrm{N}^{\circ}$ 062-2016-IPD-P/CD con fecha 09 de mayo del 2016, en este documento se recoge los principales objetivos y estrategias que se persiguen a mediano plazo, los cuales fueron elaborados en base a un diagnóstico situacional de la fuerzas internas y externas enfocadas al deportista y a la promoción del deporte.

Analizando previamente este documento de gestión, se puede observar que fue elaborado en base a 5 fases estratégicas denominadas Iniciación/Base; Formación y Competencia; Alta Competencia; Masificación y Gobernanza. 
Tabla 22.

Mapa estratégico del IPD 2016 - 2021.

\section{OBJETIVO ESTRATÉGICO GENERAL}

1. OEG: "Incrementar el desempeño del deporte peruano en eventos competitivos y promover la sostenibilidad de las actividades física, deportiva, recreativa en la sociedad peruana”

\begin{tabular}{|c|c|}
\hline OBJETIVOS ESTRATEGICOS ESPECIFICOS & ACCIONES ESTRATÉGICAS \\
\hline $\begin{array}{l}\text { 1.1 (OEE) Promover la masificación de la actividad física, } \\
\text { deportiva y recreativa. }\end{array}$ & $\begin{array}{l}\text { a.e.1.1. Fomentar las alianzas estratégicas con Instituciones públicas y privadas. } \\
\text { a.e.1.2. Establecer propuestas que diversifiquen la oferta de oportunidades, para la práctica permanente y sustentable del } \\
\text { deporte. }\end{array}$ \\
\hline $\begin{array}{l}1.2(\mathrm{OEE}) \text { Incrementar y Mejorar el nivel del deporte } \\
\text { peruano en los eventos competitivos. }\end{array}$ & $\begin{array}{l}\text { a.e.2.1. Diseñar e implementar un sistema de detección, selección y desarrollo de talentos deportivos. } \\
\text { a.e.2.2 Implementar infraestructura y equipamiento especializado para el deporte de alta competencia. } \\
\text { a.e.2.3. Fortalecer la preparación/entrenamiento de deportistas de alta competencia } \\
\text { a.e.2.4. Diseñar y ejecutar un sistema de estímulos, reconocimientos para los deportistas de alta competencia. } \\
\text { a.e.2.5. Incentivar la formación de agentes deportivos de manera descentralizada para la alta competencia. } \\
\text { a.e.2.6. Mejorar el rendimiento del deportista de alta competencia a través de las ciencias aplicadas en la medicina del deporte. } \\
\text { a.e.2.7. Promover la investigación del deporte de alta competencia. }\end{array}$ \\
\hline 1.3 (OEE) Fortalecer el IPD como ente rector del SISDEN & $\begin{array}{l}\text { a.e.3.1. Liderar y gestionar estratégicamente el SISDEN buscando la articulación de los actores. } \\
\text { a.e.3.2. Asesorar y asistir técnicamente al fortalecimiento de las organizaciones que forman parte del SISDEN. } \\
\text { a.e.3.3. Actualizar el marco regulatorio del deporte. } \\
\text { a.e.3.4. Establecer mecanismos de supervisión y control en el SISDEN } \\
\text { a.e.3.5. Posicionar al IPD en los diferentes canales de comunicación como el ente rector del SISDEN. } \\
\text { a.e.3.6. Implementar un sistema de seguridad deportiva para prevenir la violencia en el deporte nacional. }\end{array}$ \\
\hline $\begin{array}{l}1.4 \text { (OEE) Implementar una gestión por resultados en los } \\
\text { diferentes servicios hacia adentro y hacia afuera que brinda el IPD }\end{array}$ & $\begin{array}{l}\text { a.e.4.1. Fortalecer el compromiso de los colaboradores para mejorar calidad de nuestros servicios. } \\
\text { a.e.4.2. Optimizar procesos internos para lograr una eficiente implementación de la gestión por resultados. } \\
\text { a.e.4.3. Fortalecer los consejos regionales. }\end{array}$ \\
\hline
\end{tabular}

Fuente: Instituto Peruano del Deporte. 
Como Objetivo Estratégico General se señala: “INCREMENTAR EL DESEMPEÑO DEL DEPORTE PERUANO EN EVENTOS COMPETITIVOS Y PROMOVER LA SOSTENIBILIDAD DE LAS ACTIVIDADES FÍSICA, DEPORTIVA, RECREATIVA EN LA SOCIEDAD PERUANA"

Dentro de sus objetivos ya establecidos se encuentra el Objetivo Estratégico Específico $\mathrm{N}^{\circ}$ 2: "Incrementar y Mejorar el Nivel del Deporte Peruano en los eventos competitivos" y como segunda acción estratégica se encuentra, DISEÑAR Y EJECUTAR UN SISTEMA DE ESTÍMULOS Y RECONOCIMIENTOS PARA LOS DEPORTISTAS DE ALTA COMPETENCIA.

Esta acción estratégica se describe de la siguiente manera: "Mejorar el mecanismo que permita a los deportistas calificados (DC) y calificados de alto nivel acceder a beneficios, estímulos, reconocimiento y apoyo por parte del Gobierno y del Sector Privado en el marco de las normas legales vigentes que regulan la materia en mérito al logro deportivo destacado"

Lo subrayado en el párrafo anterior nos muestra que esta planificación estratégica fue diseñada, bajo el enfoque de lo que la organización se limita a cumplir con lo que tiene mandato por Ley, no trabaja buscando propuestas que respondan a las necesidades reales de la población.

En tal sentido, resulta necesario proponer los objetivos y acciones estratégicas que previamente han sido consultadas por los diferentes actores políticos y grupos de poder, por lo que a continuación se describe la Planificación Estratégica con Valor Público integrada a los objetivos que persigue actualmente la Institución. 


\subsubsection{Elaboración de la Gestión Estratégica de la Política.}

Tabla 23.

Elaboración de la Gestión Estratégica de la Política.

OBJETIVO GENERAL

"INCREMENTAR EL APOYO Y RECONOCIMIENTO A LOS DEPORTISTAS ORIENTADOS AL ALTO RENDIMIENTO DEPORTIVO"

\section{OBJETIVOS ESPECÍFICOS}

1. Consolidar el compromiso y voluntad de los DECAN y

Deportistas de Colegio en su preparación deportiva.

2. Contar con profesionales altamente calificados en

ciencias ligadas al deporte.

3. Disminuir la cantidad de deserciones en el deporte de alto rendimiento.

4. Incrementar el número de DECAN

5. Realizar un cambio cultural en la sociedad con

respecto al deporte de alto rendimiento.

\section{ACCIONES ESTRATÉGICAS}

1.1. Otorgar y mantener BECADOS a los DECAN y Deportistas de

Colegio que mantienen su alto rendimiento en las competiciones.

2.1 Incentivar a los DECAN y Deportistas de Colegio a la aplicación de becas relacionadas a las Ciencias del Deporte, ofreciendo la inclusión laboral en los estamentos del sector público a través de contratos de trabajos

3.1 Realizar gestiones con las Universidades para que ajusten su reglamento interno sobre las consideraciones y otorguen facilidades a los DECAN que cursan estudios superiores, con la beca otorgada.

3.2 Rodear al DECAN con los medios y recursos necesarios para que pueda desarrollarse integralmente, tanto en la parte profesional como en el alto rendimiento.

4.1 Realizar difusión a través de los medios de comunicación, redes sociales etc., dirigido a los menores de 18 años, para que participen de pruebas físicas en las diferentes disciplinas, la cual estará a cargo de las federaciones.

\subsection{Realizar difusión de los beneficios que otorga el practicar} deporte orientado a la alta competencia

Fuente: Elaboración propia. 


\subsubsection{Definición de Objetivo General}

Profesionalizar a los Deportistas Calificados de Alto nivel (DECAN) en Universidades Públicas y Privadas e Institutos Técnicos nacionales, como retribución por su dedicación al deporte y por los logros obtenidos para el País.

\subsubsection{Definición de Objetivos específicos}

- Incentivar a los DECAN a la aplicación de becas relacionadas a las Ciencias del Deporte, ofreciendo contratos de trabajo en la Gestión Deportiva en el sector público.

- Incrementar la participación de la población en actividades deportivas, para lograr su desarrollo integral.

- Incentivar la profesionalización deportiva de alto nivel, entre las personas con discapacidad.

\subsubsection{Elaboración de la Matriz Estratégica de Gestión}

(Objetivos, Estrategias, Resultados, indicadores de medición y responsables)

(Objetivos, Estrategias, Resultados, indicadores de medición y responsable). 
Tabla 24.

Elaboración de la Matriz Estratégica de Gestión.

\begin{tabular}{|c|c|c|c|c|c|}
\hline \multicolumn{6}{|c|}{ PLANIFICACIÓN ESTRATÉGICA CON ENFOQUE DE VALOR PUBLICO } \\
\hline $\begin{array}{l}\text { OBJETIVOS } \\
\text { GENERALES }\end{array}$ & $\begin{array}{l}\text { OBJETIVOS } \\
\text { ESPECIFICOS }\end{array}$ & ESTRATEGIAS & RESULTADOS & INDICADORES & RESPONSABLES \\
\hline \multirow[b]{3}{*}{$\begin{array}{l}\text { Incrementar el apoyo y } \\
\text { reconocimiento a los } \\
\text { deportistas orientados al } \\
\text { alto rendimientodeportivo }\end{array}$} & $\begin{array}{l}\text { 1.1 Consolidar el compromiso } \\
\text { y voluntad de los DECAN y } \\
\text { Deportistas de Colegio en su } \\
\text { preparación deportiva. }\end{array}$ & $\begin{array}{l}\text { 1.1.1 Otorgar y mantener } \\
\text { BECADOS a los DECAN y } \\
\text { Deportistas de Colegio que } \\
\text { mantienen su alto rendimiento en las } \\
\text { competiciones. }\end{array}$ & $\begin{array}{l}\text { Compromiso r y } \\
\text { voluntad de } r \text { los } \\
\text { DECAN y Deportistas } \\
\text { de Colegio. }\end{array}$ & $\begin{array}{l}\text { Incremento de resultados } \\
\text { deportivos en un } 20 \% \text { por cada } \\
\text { ciclo olímpico }\end{array}$ & $\begin{array}{llr}\text { Direccion } & \text { Nacional } & \text { de } \\
\text { Capacitación } & \text { y } & \text { Técnica } \\
\text { Deportiva } & - & \text { IPD } \\
& & \\
\text { Sub } & \text { Gerencia de deporte }- \\
\text { Gobierno Regional }\end{array}$ \\
\hline & $\begin{array}{l}\text { 1.2 Contar con profesionales } \\
\text { altamente calificados en } \\
\text { ciencias ligadas al deporte. }\end{array}$ & $\begin{array}{l}\text { 1.2.1 Incentivar a los DECAN y } \\
\text { Deportistas de Colegio a la } \\
\text { aplicación de becas relacionadas a } \\
\text { las Ciencias del Deporte, ofreciendo } \\
\text { la inclusión laboral en los } \\
\text { estamentos del sector público a } \\
\text { través de contratos de trabajos. }\end{array}$ & $\begin{array}{l}\text { Profesionales } \\
\text { altamente calificados } \\
\text { en ciencias ligadas al } \\
\text { deporte. }\end{array}$ & $\begin{array}{l}60 \% \text { de los becarios graduados } \\
\text { en carreras profesionales } \\
\text { ligadas al deporte }\end{array}$ & $\begin{array}{lcr}\text { Direccion } & \text { Nacional } & \text { de } \\
\text { Capacitación } & \text { y } & \text { Técnica } \\
\text { Deportiva } & - & \text { IPD } \\
\text { Sub } & \text { Gerencia } & \text { de } \\
\text { Gobierno Regional } & -\end{array}$ \\
\hline & $\begin{array}{l}\text { 2.1 Disminuir la cantidad de } \\
\text { deserciones en el deporte de } \\
\text { alto rendimiento. }\end{array}$ & 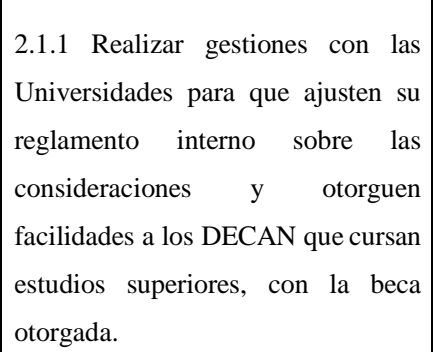 & $\begin{array}{l}\text { DECAN y Deportistas } \\
\text { de } \\
\text { su }\end{array}$ & $\begin{array}{l}95 \% \text { de los DECAN y } \\
\text { Deportistas de Colegio, } \\
\text { continúan su preparación con } \\
\text { miras en la Alta Competencia. }\end{array}$ & $\begin{array}{lcrr}\text { Direccion } & \text { Nacional } & \text { de } \\
\text { Capacitación } & \text { y } & \text { Técnica } \\
\text { Deportiva } & - & \text { IPD } \\
& & \\
\text { Sub } & \text { Gerencia de } & \text { deporte }- \\
\text { Gobierno Regional }\end{array}$ \\
\hline
\end{tabular}




\begin{tabular}{|c|c|c|c|c|}
\hline & $\begin{array}{l}\text { 2.1.2 Rodear al DECAN con los } \\
\text { medios y recursos necesarios para } \\
\text { que pueda desarrollarse } \\
\text { integralmente, tanto en la parte } \\
\text { profesional como en el alto } \\
\text { rendimiento. }\end{array}$ & & & \\
\hline $\begin{array}{l}\text { 2.2 Incrementar el número de } \\
\text { DECAN }\end{array}$ & $\begin{array}{l}\text { 2.2.1 Realizar difusión a través de } \\
\text { los medios de comunicación, redes } \\
\text { sociales etc., dirigido a los menores } \\
\text { de } 18 \text { años, para que participen de } \\
\text { pruebas físicas en las diferentes } \\
\text { disciplinas, la cual estará a cargo de } \\
\text { las federaciones. }\end{array}$ & $\begin{array}{l}\text { Federaciones } \\
\text { Deportivas Nacionales } \\
\text { Cuentan con DECAN } \\
\text { en todas las Categorías } \\
\text { Competitivas }\end{array}$ & $\begin{array}{l}\text { Anualmente incrementar en un } \\
10 \% \text { los DECAN }\end{array}$ & $\begin{array}{l}\text { Federaciones Deportivas } \\
\text { Nacionales }\end{array}$ \\
\hline $\begin{array}{l}\text { 3.1 Realizar un cambio } \\
\text { cultural en la sociedad con } \\
\text { respecto al deporte de alto } \\
\text { rendimiento. }\end{array}$ & $\begin{array}{l}\text { 3.1.1. Realizar difusión de los } \\
\text { beneficios que otorga el practicar } \\
\text { deporte orientado a la alta } \\
\text { competencia }\end{array}$ & $\begin{array}{l}\text { Padres de familia } \\
\text { promueven la práctica } \\
\text { deportiva en sus hijos. }\end{array}$ & $\begin{array}{l}\text { Incremento de niños, niñas y } \\
\text { adolescentes en los programas } \\
\text { de formación deportiva y } \\
\text { centros de alto rendimiento }\end{array}$ & \begin{tabular}{lcr} 
Direccion & \multicolumn{2}{c}{ Nacional } \\
Capacitación & y & Técnica \\
Deportiva & - & IPD \\
Sub Gerencia de deporte & \\
Gobierno Regional
\end{tabular} \\
\hline
\end{tabular}

Fuente: Elaboración propia. 


\section{CAPÍTULO VI EVALUACIÓN DE LA POLÍTICA}




\section{Evaluación de la Política}

\subsection{Análisis de la sostenibilidad de la Política.}

Es preciso señalar, para que una política pública sea sostenible en el tiempo se deben generar los medios necesarios de participación con los sectores y actores involucrados, sobre todo los que representan un mayor peso político y que podrían atentar negativamente con la viabilidad y sostenibilidad de esta política.

Dado que resulta necesario evolucionar en la forma de cómo se conciben las políticas públicas, el enfoque de Gobernanza, un paradigma emergente, donde las Instituciones estatales y no estatales, los actores públicos y privados, participan y a menudo cooperan con la formulación y aplicación de políticas públicas (Mayntz, 1993:3), nos señala un camino para poder formular políticas eficientes y que ofrezca el impacto esperado para que las que fueran diseñadas.

En tal sentido, esta política tendría el respaldo de la sociedad civil, al generar incentivos para impulsar el desarrollo del deporte de alto rendimiento y en general la visión de mejorar la calidad de vida de la población, con inclusión social, equidad, igualdad de oportunidades y su gran contribución a la reducción de muchos problemas sociales.

Asimismo, tenemos la certeza que el sector privado respaldaría a través de los años esta política, sobre todo en la industria deportiva y el sector educativo, ya que al generarse una demanda de las carreras ligadas al deporte de alto rendimiento y una oferta de profesionales especializados en el rubro, esto generaría un impulso considerable al sector y por lo tanto generaría valor a las inversiones privadas.

Por otro lado, Mark Moore, en su publicación Gestión Estratégica y creación de Valor en el sector público 1995, donde se introdujo el concepto de valor público y el desarrollo de una estructura de razonamiento práctico como guía para el gestor público, que se podría resumir en concebir políticas con un enfoque estratégico que satisfaga tres pruebas; primero lo sustantivo, segundo legítimo y políticamente sostenible y tercero debe ser operativa y administrativamente viable, dichas pruebas nos revelaría la acertada 
generación de valor público (1995, s.p.).

$\mathrm{Al}$ haberse formulado y evaluado estas tres pruebas en el Capítulo IV, a manera de conclusión se afirmaría que nuestra propuesta generaría valor público, al haberse identificado que esta propuesta responde a una necesidad y a la misión del Sistema Deportivo Nacional, además se identificó y valoró a los actores políticos, elaborando estrategias que nos permita obtener un mayor apoyo político y por último se describió e identificó los recursos necesarios con que cuenta la organización para su viable implementación.

A fin de conocer a más profundidad la percepción de los principales actores ligados al deporte, se aplicó entrevistas dejando como resultado lo siguiente:

Tabla 25.

Lista de entrevistados:

\begin{tabular}{|c|c|c|c|}
\hline $\mathbf{N}^{\circ}$ & Nombre Apellidos & Profesión & Centro de labores \\
\hline 1 & Coraima Gómez Urrutia & Deportista de Voleibol & $\begin{array}{l}\text { Federación Deportiva } \\
\text { Peruana de Voleibol }\end{array}$ \\
\hline 2 & Maitte Torres Córdova & Deportista de Atletismo & $\begin{array}{l}\text { Federación Deportiva } \\
\text { Peruana de Atletismo }\end{array}$ \\
\hline 3 & Andrea Almarza Cerpa & Deportista de Karate & $\begin{array}{l}\text { Federación Deportiva } \\
\text { Peruana de Karate }\end{array}$ \\
\hline 4 & Sol Romaní Cáceres & Deportista de Karate & $\begin{array}{l}\text { Federación Deportiva } \\
\text { Peruana de Karate }\end{array}$ \\
\hline 5 & $\begin{array}{l}\text { Marisel Vivanco } \\
\text { Cárdenas }\end{array}$ & Deportista de Judo & $\begin{array}{l}\text { Federación Deportiva } \\
\text { Peruana de Judo }\end{array}$ \\
\hline 6 & Chiara Reyes Roca & $\begin{array}{l}\text { Deportista de } \\
\text { Taekwondo }\end{array}$ & $\begin{array}{l}\text { Federación Deportiva } \\
\text { Peruana de Taekwondo }\end{array}$ \\
\hline 7 & $\begin{array}{l}\text { Eduardo Renteros } \\
\text { Tumay }\end{array}$ & Prof. Educación Física & $\begin{array}{l}\text { Jefe de la Unidad Técnica de } \\
\text { la Federación Deportiva } \\
\text { Peruana de Boxeo }\end{array}$ \\
\hline 8 & $\begin{array}{l}\text { Marcos Gonzales } \\
\text { Infante }\end{array}$ & $\begin{array}{l}\text { Lic. Educación Física y } \\
\text { Deportes }\end{array}$ & $\begin{array}{l}\text { Jefe de la Unidad Técnica de } \\
\text { la Federación Deportiva } \\
\text { Peruana de Esquí Acuático } \\
\text { Coordinador de Deportes de } \\
\text { la Universidad de Lima }\end{array}$ \\
\hline 9 & Joel Blanco Pérez & Prof. Educación Física & $\begin{array}{l}\text { Coord. Nacional. Dirección } \\
\text { de Educación Física y } \\
\text { Deporte, DEFID - MINEDU }\end{array}$ \\
\hline 10 & Ana Pinedo Trauco & Prof. Educación Física & $\begin{array}{l}\text { Coord. Nacional de los } \\
\text { Centros de Alto Rendimiento } \\
\text { - IPD }\end{array}$ \\
\hline
\end{tabular}




\begin{tabular}{|l|l|l|l|}
11 & $\begin{array}{l}\text { Milagros Aguilar } \\
\text { Quispe }\end{array}$ & Administradora & $\begin{array}{l}\text { Coordinadora de } \\
\text { competencias de Futbol } \\
\text { Femenino - FPF }\end{array}$ \\
\hline 12 & $\begin{array}{l}\text { Vladimir Armenteros } \\
\text { Rodríguez }\end{array}$ & $\begin{array}{l}\text { Lic. Educación Física y y } \\
\text { Deportes }\end{array}$ & $\begin{array}{l}\text { Jefe del Comité de Métodos } \\
\text { Técnicos de la Dirección } \\
\text { Nacional de Deporte Afiliado } \\
\text { - IPD }\end{array}$ \\
\hline 14 & Álvaro Díaz De la Vega & $\begin{array}{l}\text { Lic. en Gestión } \\
\text { Tecnológica del } \\
\text { Deporte }\end{array}$ & $\begin{array}{l}\text { Ex director Nacional de } \\
\text { Deporte Afiliado - IPD } \\
\text { Director de Cultura Deporte } \\
\text { de la USIL }\end{array}$ \\
\hline 15 & $\begin{array}{l}\text { Coordinador Técnico de la } \\
\text { Federación Deportiva } \\
\text { Universitaria del Perú - } \\
\text { FEDUP }\end{array}$ \\
\hline $\begin{array}{l}\text { Mejía } \\
\text { Ficón De la Borda }\end{array}$ & $\begin{array}{l}\text { Lic. Actividad física } \\
\text { salud. }\end{array}$ & $\begin{array}{l}\text { Entrenador y preparador } \\
\text { físico de la sub gerencia de } \\
\text { deportes de la Municipalidad } \\
\text { de San Isidro }\end{array}$ \\
\hline Lévano & Prof. Educación Física & $\begin{array}{l}\text { Ex boxeador profesional, } \\
\text { Disputó título Mundial }\end{array}$ \\
\hline
\end{tabular}

Fuente: Elaboración propia.

El 90\% de los entrevistados coinciden que en el Perú no hay suficientes Deportistas Calificados de Alto Nivel, que los principales motivos es la ausencia de un sólido sistema deportivo nacional, falta de apoyo y cultura deportiva en la sociedad.

- $\quad$ Todos coinciden que los deportes en Perú no tienen el mismo nivel de apoyo ni de igualdad de oportunidades, indican que unos son más mediáticos que otros por ello la diferencia, otros tienen más apoyo del gobierno de la empresa privada.

Con relación a las principales causas de las deserciones de los deportistas, opinaron que esto se debe principalmente a las desigualdades que existen entre las federaciones, ausencia de condiciones mínimas (Educación, salud y bienestar económico) para dedicarse al deporte y falta de adecuadas oportunidades académicas.

El 70\% de los entrevistados indican que no conocen políticas públicas a favor del deporte, el 30\% indican que conocen la Ley de Mecenazgo Deportivo y Programa de Apoyo al Deportista - IPD. 
- Todos los entrevistados coincides que Perú adolece de profesionales en el deporte y en todos los ámbitos de acción.

- Referente a los estímulos que podrían recibir los deportistas para potenciar su desarrollo deportivo, la mayoría coincide en que deberían recibir becas académicas, apoyo económico y adecuada nutrición.

- $\quad$ Todos los entrevistados consideran que es sumamente importante y motivante que los deportistas accedan a becas de estudio, de esta manera tendrían la tranquilidad de formarse profesionalmente mientras se encuentran compitiendo y además, estarían directamente involucrados en el desarrollo deportivo como profesionales una vez que se retiren de las competencias.

- $\quad$ En vista que no existen muchas profesionales relacionadas al deporte, los expertos consideran que se deberían potenciar la formación de profesionales en las siguientes carreras; Educación física deportes, Psicología deportiva, Nutrición deportiva, ciencias del deporte, gestión administración del deporte.

Con relación a la administración del deporte nacional, la mayoría coincide que fala mejorar, muchos de los que dirigen el deporte no son profesionales ligados a esta rama, en algunos casos son ex deportistas quienes dirigen, pero sin experiencia profesional ni mucho menos formación profesional ligada al deporte.

Finalmente, todos coinciden que el nivel del deporte peruano es muy bajo en comparación con los países del área sudamericana, que hacen falta más deportistas altamente competitivos y más profesionales que impulsen adecuadamente el desarrollo del deporte nacional.

\subsection{Evaluación del impacto de la política.}

\section{Impacto a nivel social:}

A nivel social se espera una mejora en la calidad de vida de los deportistas con proyección al alto rendimiento y de la población en general a través de la masificación deportiva, además de una reducción significativa en problemas sociales de diferentes índoles, entre ellos la drogadicción, delincuencia, desempleo y problemas de salud como 
la obesidad, estrés entre otras.

\section{Impacto a nivel cultural:}

A nivel sociocultural, a través de la masificación deportiva y la propuesta de incentivos para llevar la práctica deportiva a una inclinación por lo profesional, se espera a largo plazo que esta política influya positivamente en todos los estratos sociales, teniendo como premisa el cambio cultural que el deporte de alto rendimiento no es solo para algunos privilegiados que nacieron con talento. El cambio cultural que se desea, es que la sociedad en general tenga interiorizado el concepto que "El talento se nace, pero también se hace, con mucho esfuerzo y dedicación desde temprana edad”.

\section{Impacto a nivel económico:}

A nivel económico, se espera un desarrollo la industria deportiva y de la educación, con la oferta de más profesionales en el ámbito del deporte y con una demanda en aumento de la educación técnica y profesional para el desarrollo del deporte en el alto rendimiento. Asimismo, esto generaría más puesto de trabajo y una demanda de otros países por profesional especializados. Se empezaría a exportar profesionales y material deportivo.

\section{Impacto a nivel político:}

A nivel político, se espera una consolidación del Sistema Deportivo Nacional con la colaboración de todos sus integrantes, el cual será promovido por el ente rector, el Instituto Peruano del Deporte. Asimismo, deberán integrarse para ampliar la visión del deporte y no solo lograr la masificación, también lograr el desarrollo y consolidación del deporte alto rendimiento.

\section{Deportivo:}

En lo deportivo, en general se espera un mayor desempeño del deporte peruano en las competencias, logros que permitirán fortalecer los demás impactos, además de contribuir al patriotismo e identificación por el orgullo nacional. Asimismo, a mediano 
plazo contar con profesionales alta especializados en materia deportiva, lo que permitirá un desarrollo permanente del sector.

\section{Impacto en la salud:}

En la salud se espera una reducción de los índices de mortalidad por enfermedades relacionadas al sobrepeso, otras como el estrés, ansiedad y avances con la prevención de la salud. Por el lado de la nutrición se espera una mayor aceptación por la población por la comida saludable y una cultura en general de buena nutrición. 


\section{Impacto en el tiempo:}

Tabla 26.

Impacto en el tiempo.

\begin{tabular}{|c|c|c|}
\hline Al 2021 & Al 2025 & Al 2030 \\
\hline $\begin{array}{l}\text { Contar con más de } 500 \text { deportistas } \\
\text { insertados en la universidades de los } \\
\text { cuales un } 60 \% \text { estudiarán carreras } \\
\text { ligadas al deporte }\end{array}$ & $\begin{array}{l}\text { Contar con más de } 1200 \\
\text { deportistas insertados en la } \\
\text { universidades de los cuales un } 60 \% \\
\text { estudiarán carreras ligadas al deporte }\end{array}$ & $\begin{array}{l}\text { Contar con más de } 1800 \text { deportistas insertados en la } \\
\text { universidades de los cuales un } 80 \% \text { estudiarán carreras ligadas } \\
\text { al deporte }\end{array}$ \\
\hline $\begin{array}{l}\text { Incrementar en un } 50 \% \text { la cantidad } \\
\text { de DECAN }\end{array}$ & $\begin{array}{l}\text { Contar con más } 300 \\
\text { profesionales graduados, de los } \\
\text { cuales } 180 \text { serán ligados al deporte. }\end{array}$ & $\begin{array}{l}\text { Contar con más de } 500 \text { profesionales graduados, de los } \\
\text { cuales } 240 \text { serán ligados al deporte. }\end{array}$ \\
\hline $\begin{array}{l}\text { Se incrementará en un } 30 \% \text { la } \\
\text { participación de DECAN en } \\
\text { competencias del ciclo olímpico }\end{array}$ & $\begin{array}{l}\text { Se incrementará en un } 60 \% \text { la } \\
\text { participación de DECAN en } \\
\text { competencias del ciclo olímpico }\end{array}$ & $\begin{array}{l}\text { Se incrementará en un } 100 \% \text { la participación de } \\
\text { DECAN en competencias del ciclo olímpico }\end{array}$ \\
\hline
\end{tabular}

Fuente: Elaboración propia. 


\subsection{Evaluación de las Autoridades de la Institución Pública de la Política Pública propuesta.}

Tabla 27.

Evaluación de las Autoridades de la Institución Pública de la Política Pública propuesta.

\begin{tabular}{|l|r|}
\hline Instituto Peruano del Deporte (IPD) & $\begin{array}{r}\text { Considera que es un excelente aporte para potenciar el desarrollo del deporte nacional, más aún que en la política nacional del deporte no se } \\
\text { considera la profesionalización de agentes deportivos y es una realidad que Perú carece de profesionales en las diferentes ramas profesionales ligadas } \\
\text { al deporte. }\end{array}$ \\
\hline Comité Olímpico Peruano (COP) & $\begin{array}{l}\text { También es un actor con bastante predisposición para puesta en marcha de la presente política pública, su mayor interés es promover el } \\
\text { movimiento olímpico, y para ello necesita de más agentes deportivos en sus diferentes dimensiones, por ello el COP, considere importante la } \\
\text { aplicación de esta política }\end{array}$ \\
\hline $\begin{array}{l}\text { Los gobiernos regionales a través de los } \\
\text { consejos regionales del deporte }\end{array}$ & $\begin{array}{r}\text { Inicialmente plantearon un ligero rechazo a la implementación de la política, porque pensaron que esto generaría mayores gastos, pero al } \\
\text { plantear los objetivos y el impacto que trae consigo esta política, el cómo se vería reflejada el gobierno regional con mayor cantidad de profesionales } \\
\text { en el deporte, una región más activa, saludable y competitiva, cambiaron su perspectiva y manifestaron una tendencia a favor. }\end{array}$ \\
\hline $\begin{array}{l}\text { Las } \\
\text { públicas, privadas y comunales. }\end{array}$ & $\begin{array}{r}\text { Consideran que el deporte es un medio importante para el desarrollo de la sociedad, en este sentido, es importante la formación de } \\
\text { profesionales que impulsen el desarrollo del deporte no solo en el alto rendimiento, sino también en niveles de promoción de la actividad física y } \\
\text { estilos de vida saludable. }\end{array}$ \\
\hline Las universidades & $\begin{array}{r}\text { Les interesa de sobremanera la aplicación de esta política, de ser el caso estarían dispuestas a crear nuevas carreras profesionales ligadas al } \\
\text { deporte, además que es de su interés albergar a deportistas que los representen con competencias interuniversitarias y de esta manera liderar en el } \\
\text { ámbito deportivo universitario. }\end{array}$ \\
\hline
\end{tabular}


CAPÍTULO VII

CONCLUSIONES Y RECOMENDACIONES 


\section{Conclusiones y recomendaciones}

\subsection{Conclusiones.}

1. El incentivo de Becas permitirá revalorar al deportista, creando un cambio de cultura en nuestra sociedad, permitiendo que los padres de familia vean al deporte como un medio para el desarrollo profesional de sus hijos.

2. El incentivo de las Becas de estudio en carreras relacionadas al deporte, es la base para a mediano plazo contar con profesionales especialistas, que al integrarse al Sistema Deportivo Nacional permitirá fortalecer tanto la preparación como la captación de futuros deportistas de alto rendimiento.

3. Además, con este incentivo se asegura el desarrollo integral de nuestros deportistas, asegurando que desarrollen una actividad profesional al término de ciclo competitivo, lo que le permitirá generar ingresos económicos.

4. Los especialistas del deporte, coinciden en que los estímulos que puedan percibir los deportistas, redundan positivamente en la preparación y en la obtención de resultados deportivos, asimismo, afirman que ante la carencia de profesionales en el deporte, el hecho de otorgar becas de estudio a los deportistas, no solo favorecerá en incrementar la cantidad de deportistas y de los resultados deportivos, sino también en fortalecer el sistema deportivo nacional a través de la formación de profesionales altamente capacitados para dirigir equipos deportivos y/o administrar el deporte nacional.

\subsection{Recomendaciones.}

1. Esta política pública contribuirá en mejorar el nivel competitivo internacional, por ello, es importante que sea elevada al ente rector del sistema deportivo nacional para su evaluación y/o aplicación.

2. Los gobiernos regionales podrán aplicar esta propuesta en sus respectivas 
jurisdicciones para incentivar la promoción del deporte elevar sus resultados deportivos convirtiéndolos en regiones altamente competitivas.

3. A las autoridades competentes, evaluar la viabilidad de la presente propuesta de política pública, a fin de propiciar el despegue deportivo, donde paralelamente se fortalecerá la investigación en el deporte a raves del incremento de deportistas en las universidades. 


\section{REFERENCIAS}

Aguilar, C. \& Lima, M. (s.a.). ¿Qué son y para qué sirven las políticas públicas?, Recuperado el 12 de agosto, 2018 dehttp://secretariageneral.univalle.edu.co/consejoacademico/temasdediscusion/2014/Documentos_de_interes_general/Lecturas_politica_ publica/Que\%20son\%20y\%20para\%20que\%20sirven\%20las\%20politicas\%20publicas_ Aguilar.pdf

Aguilar, L. (1992). La hechura de las políticas. Miguel Angel Arrúa: México D.F.. Recuperado de:http://www.inap.mx/portal/images/RAP/la\%20hechura\%20de\%20las\%20poli ticas.pdf

Aguilar, L. (1993). Antologías de Política Pública. Recuperado dehttp://secretariageneral.univalle.edu.co/consejoacademico/temasdediscusion/2014/Documentos_de_interes_general/Lecturas_p olitica_publica/Que\%20son\%20y\%20para\%20que\%20sirven\%20las\%20politica s\%20publicas_Aguilar.pdf

Aguilar, M. (2018). La competitividad de la industria textil en méxico en un contexto de globalización 1985-2003. Recuperado de http://www.eumed.net/librosgratis/2009b/546/Competitividad\%20sistemica.htm

Arèvalo, G. (2018, 14 de abril). El deporte en el Perú: análisis y propuestas.El caso del fútbol [efdeportes.com].

de:http://www.efdeportes.com/efd49/peru.htm

Recuperado

Asamblea General en su resolución 217 A (1948). Declaración Universal de Derechos Humanos de las Naciones Unidas Adoptada y proclamada por la Asamblea General en su resolución 217 A (III), Recuperado el 14 de abril, 1948 de https:/www.pj.gob.pe/wps/wcm/connect/44d135804954233b8579f5cc4f0b1cf5/ Declaraci\%C3\%B3n+Universal+de+Derechos+Humanos.pdf?MOD=AJPERES

Billat, V. (2002). El rendimiento deportivo, Fisiologia y metodología del entrenamiento deportivo. Barcelona: Paidotribo.

Castro, G. (2016). Creación de Valor Público: Diferentes aproximaciones, un mismo fin [luisgomezcastro.blogspot.pe].

Recuperado de:http://luisgomezcastro.blogspot.pe/2008/03/reflexiones-sobre-lo-publico.html

CEPLAN (2021). Plan Bicentenario: El Perú hacia el 2021. Recuperado de:https://www.mef.gob.pe/contenidos/acerc_mins/doc_gestion/PlanBicentenari oversionfinal.pdf 
Corzo, F. (2014, 01 de octubre). ¿Cuál es el ciclo de vida de las políticas públicas? [iexe.edu.mx]. Recuperado de:https://www.iexe.edu.mx/blog/cual-es-el-ciclo-devida-de-las-politicas-publicas.html

Decreto Supremo No 003-2017 - MINEDU (2017). En Diario Oficial El Peruano. Perú. Recuperado de :http://busquedas.elperuano.pe/normaslegales/aprueban-lapolitica-nacional-del-deporte-decreto-supremo-n-003-2017-minedu-1519268-1/

Decreto Supremo No 003-2017 Política Nacional del deporte (2017). En el diario oficial El Peruano. Perú. Recuperado de: http://busquedas.elperuano.pe/normaslegales/aprueban-la-politica-nacional-del-deportedecreto-supremo-n-003-2017-minedu-1519268-1/

DECRETO SUPREMO Nº 003-2017-MINEDU (2018). Aprueban la Política Nacional del Deporte. Recuperado de https://busquedas.elperuano.pe/normaslegales/apruebanla-politica-nacional-del-deporte-decreto-supremo-n-003-2017-minedu-1519268-1/

Definición ABC (2017). Definición ABC: Tu diccionario hecho fácil [definicionabc.com]. Recuperado de: https://www.definicionabc.com/general/valor.php

Delgado, L. (2009). Las políticas públicas. El ciclo de las políticas públicas. Clases de políticas públicas. Eficacia, legalidad y control. Indicadores de gestión. Documentación sobre gerencia pública, del Subgrupo A2, Cuerpo Técnico, especialidad de Gestión Administrativa, de la Administración de la Junta de Comunidades de Castilla-La Mancha. Recuperado de http://pagina.jccm.es/ear/descarga/A2T3.pdf

Delgado, L.(2009). Tema 3 Las políticas públicas. El ciclo de las políticas públicas. Clases de políticas públicas. Eficacia, legalidad y control. Indicadores de gestión. Recuperado de: http://pagina.jccm.es/ear/descarga/A2T3.pdf

Departamento Nacional de Planeación (2014). Creando valor público: hacia un sistema de medición de la eficiencia y efectividad del gasto público en COlombia [Diapositivas]. Recuperado de: http://slideplayer.es/slide/3374777/

El caso del fútbol [efdeportes.com]. $\quad$ Recuperado de:http://www.efdeportes.com/efd49/peru.htm 
El Comercio (2017, 12 de febrero). Promueven el deporte para alejar a jóvenes de la delincuencia. Recuperado de:http://elcomercio.pe/lima/promueven-deportealejar-jovenes-delincuencia-158534

Escobar, A. (2016, 8 de setiembre). La importancia de generar valor público en las sociedades del siglo XXI [novagob.org]. Recuperado de:https://novagob.org/laimportancia-de-generar-valor-paoblico-en-las-sociedades-del-siglo-xxi/

Esser, K. ; Hillebrand, W.; Messner, D. \& Meyer-Stamer, J. (1996). Competitividad sistémica: Nuevo desafío a las empresas y a la política. Recuperado de: http://www.meyer-stamer.de/1996/cepal.htm

Esser, K; Hillebrand, W. \& Meyer-Stamer, J. (1996). Competitividad sistêmica: nuevo desafío para las empresas y la política. Recuperado dehttp://archivo.cepal.org/pdfs/revistaCepal/Sp/059039052.pdf

García, R. (2015). Gestión pública y valor público. Recuperado de http://aempresarial.com/web/revitem/24_17472_07084.pdf

Gestión (2014, 01 de marzo). Perú invierte en deporte cuatro veces más que Colombia pero no tiene logros. Recuperado de: https://gestion.pe/economia/peru-inviertedeporte-cuatro-veces-colombia-logros-5395?ref=gesr

Gobierno del Estado de Chiapas (2017, 01 de junio). Velasco combate tabaquismo con deporte. Recuperado de:http://www.chiapas.gob.mx/noticias/velasco-combatetabaquismo-con-deporte

http://politicas.typepad.com/files/tamayo_el-analisis.pdf

Instituto para la Democracia y la Asistencia Electoral - IDEA Internacional (2008). ESTADO Y GESTIÓN PÚBLICA. Recuperado de http://www2.congreso.gob.pe/sicr/cendocbib/con4_uibd.nsf/8453BD9D9F57489405257 C0C0014A7FC/\$FILE/Gesti\%C3\%B3n_P\%C3\%BAblica.pdf

Instituto Peruano del Deporte (2016). Memoria anual 2016. Lima: Instituto Peruano del Deporte.

Recuperado

de http://sistemas.ipd.gob.pe:8190/secgral/Transparencia/normativa_interna/memor ia-anual/memoria_anual_ipd_2015.pdf

Instituto Peruano del Deporte (2016). Manual de indicaciones metodológicas 2016. Lima: Instituto 
dehttp://www.ipd.gob.pe/images/documentos/dinadaf/manual/Manual_de_Indic _Metodologicas_2016.pdf

Instituto Peruano del Deporte (2018). Instituto Peruano del Deporte [ipd.gob.pe].

Recuperado de: http://www.ipd.gob.pe/

Instituto Peruano del Deporte (2018). Portal del Instituto Peruano del Deporte. Recuperado de http://www.ipd.gob.pe/34-uncategorised/564-programa-centro-de-altorendimiento

Instituto Peruano del Deporte (2018). Proyecto De Política Nacional Del Deporte [Diapositiva].

Recuperado dewww.ipd.gob.pe/sistemasipd/recursos/formulario1/PND-presentacion.pptx

Instituto Peruano del Deporte (2018, 14 de abril). Programa Apoyo al Deportista - PAD [ipd.gob.pe]. Recuperado de:http://www.ipd.gob.pe/programa-apoyo-al-deportistapad-2

Instituto Peruano del Deporte (2018, 14 de abril). Programa Centro De Alto Rendimiento - Car [ipd.gob.pe]. Recuperado de: http://www.ipd.gob.pe/programa-centro-dealto-rendimiento-car

Instituto Peruano del Deporte (s.a.). Proyecto De Política Nacional Del Deporte. Recuperado de:http://www.ipd.gob.pe/sistemasipd/recursos/formulario1/PND.pdf

Instituto Peruano del Deporte. (2016). Manual de Indicaciones Metodológicas. Recuperado de http://www.ipd.gob.pe/images/documentos/dinadaf/manual/Manual_de_Indic_M etodologicas_2016.pdf

La opinión (2016, 03 de agosto). Medallero histórico de países latinoamericanos en Juegos Olímpicos [laopinion.com]. Recuperado de:https://laopinion.com/2016/08/03/medallero-historico-de-paises-latinoamericanosen-juegos-olimpicos/

Lerda, J.; Acquatella, J. \& Gómez, J. (2003). Integración, coherencia y coordinación de Políticas Públicas Sectoriales (reflexiones para el caso de las políticas fiscal y ambiental). https://www.cepal.org/ilpes/noticias/paginas/8/35988/Lerdaacquatellagomez.pdf 
Ley de promoción y desarrollo del deporte LEY Nº 28036 (2004). En Diario Oficial El Peruano. Perú. Recuperado de :http://www.leyes.congreso.gob.pe/Documentos/Leyes

Ley N 27674 Ley que establece el acceso de deportistas de alto nivel a la administración pública (2004). En Diario Oficial El Peruano. Perú. Recuperado de :http://www.leyes.congreso.gob.pe/Documentos/Leyes/27674.pdf

LEY N ${ }^{\circ}$ 28036. Sobre Congreso De La Republica Ley De Promoción Y Desarrollo del Deporte. En Instituto Peruano del Deporte.Perú. Recuperado de http://www.ipd.gob.pe/images/documentos/normas/sector/Ley\%20N\%2028036. pdf

LEY No 30474 ley que modifica los artículos 26, 37, 44 y 46 e incorpora los artículos 38a y 38-b y los literales r) y s) al numeral 1 del artículo 98 de la ley 28036, ley de promoción y desarrollo del deporte (2018). En Diario Oficial El Peruano. Perú. Recuperado de :http://busquedas.elperuano.pe/normaslegales/ley-que-modificalos-articulos-26-37-44-y-46-e-incorpora-1-ley-n-30474-1398360-2/

LEY N 30476 Ley que regula los programas deportivos de alta competenciaen las universidades (2018). En Diario Oficial El Peruano. Perú. Recuperado de :http://busquedas.elperuano.pe/normaslegales/ley-que-regula-los-programasdeportivos-de-alta-competencia-ley-n-30476-1398360-4/

LEY No 30479 Ley de mecenazgo deportivo (2018). En Diario Oficial El Peruano. Perú. Recuperado de :http://busquedas.elperuano.pe/normaslegales/ley-de-mecenazgodeportivo-ley-n-30479-1398360-7/

Líbero 21 (2017, 01 de febrero). IPD: Crisis en Federaciones impide que puedan recibir dinero del Estado para sus planes deportivos 2017 [libero.pe/deportes]. Recuperado de:http://libero.pe/deportes/174183-ipd-crisis-en-el-deporte-debidoa-que-solo-25-de-56-federaciones-pueden-recibir-dinero-del-estado-para-poneren-marcha-sus-respectivos-planes-deportivos-2017

Ministerio de Economía y Finanzas (2017). Informe de actualización de proyecciones macroeconómicas. Lima: Ministerio de Economía y Finanzashttps://www.mef.gob.pe/contenidos/pol_econ/marco_macro/informe_ac tualizacion_proyecciones.pdf 
Moore, M. (1995). Creating Public Value: Strategic Management in Government. Cambridge: Harvard Univ.

Moore, M. (1995). Gestión estratégica y creación de valor en el sector público. Barcelona : Paidós.

Moreno, M. (2009). Valor Público: un enfoque integral para la gestión de políticas [Diapositiva]. Recuperado de: https://www.cepal.org/ilpes/noticias/paginas/7/35927/C16_Valor_Publico.ppt

Mori, M. (2018). Generación de valor público en el sector turismo (Tesis de licenciatura). Recuperado de: http://repositorio.unsm.edu.pe/bitstream/handle/UNSM/2641/TURISMO\%20$\% 20$ Marilyn\%20Mori\%20Ru\%C3\%ADz.pdf?sequence=1\&isAllowed=y

Navarro, A. (2002). El deporte en el Perú: análisis y propuestas. Revista digital - Buenos Aires. Recuperado de http://www.efdeportes.com/efd49/peru.htm

Oficina de las Naciones Unidad Contra la Droga y el Delito (2018). Usando el poder del deporte para prevenir la delincuencia juvenil y el uso de drogas. Recuperado de:https://www.unodc.org/unodc/es/frontpage/2016/December/using-the-powerof-sports-to-prevent-youth-crime-and-drug-use.html

Osziak, O. \& Odonnell, G. (1981). Estado y políticas estatales en américa latina: hacia una estrategia de investigación. Recuperado de: http://www.oscaroszlak.org.ar/images/articulosespanol/Oszlak\%20y\%200\%20Donnell\%20\%20Estado\%20y\%20Politicas\%20Estatale s.pdf

Ovaciòn corporación deportiva (2017, 15 de marzo). Congresista Noceda: "No sé por qué están en contra de los Juegos" [ovacion.pe]. Recuperado de:http://ovacion.pe/juegos-panamericanos/congresista-noceda-no-se-por-queestan-contra-juegos

Parodi. C. (2017). Economía para todos: Nuevas Proyecciones del MEF, 2017-2019. Recuperado de https://gestion.pe/blog/economiaparatodos/2017/05/nuevasproyecciones-del-mef-2017-2019.html

Perú 21 (2017, 15 de marzo). Luz Salgado sobre Panamericanos: "Deberíamos decir hasta acá no más" [peru21.pe]. Recuperado de:http://peru21.pe/politica/luz-salgadosobre-panamericanos-deberiamos-decir-hasta-aca-no-mas-2274062 
Perú. Ministerio de Educación (20128). Según la Resolución Viceministerial N 0592018-MINEDU, las etapas de desarrollo son las siguientes: 2018:Juegos deportivos escolares nacionales 2018 Daniel kirino Peredo menchola. Recuperado dehttp://www.minedu.gob.pe/jden/pdf/bases-jden-2018.pdf

Perú. Ministerio de Justicia y Derechos Humanos (2018). Ética y valor público [Diapositiva]. www.ipd.gob.pe/sistemasipd/recursos/formulario1/PND-presentacion.pptx

Perú. Ministerio de Economía y Finanzas (2018). Seguimiento de la Ejecución Presupuestal (Consulta amigable). [mef.pe]. Recuperado de: https://www.mef.gob.pe/es/seguimiento-de-la-ejecucion-presupuestal-consultaamigable

Radio Programas del Perú (2016, 14 de julio). Juegos Olímpicos: las únicas medallas ganadas por Perú en la historia [rpp.pe]. Recuperado de:http://rpp.pe/multideportes/juegos-olimpicos/juegos-olimpicos-las-unicas-medallasganadas-por-peru-en-la-historia-noticia-979446

Ravsberg, F. (2008, del 24 de Agosto). El secreto cubano [news.bbc.co.uk]. Recuperado de:

http://news.bbc.co.uk/hi/spanish/deportes/pekin08/newsid_7580000/7580079.st $\underline{\mathrm{m}}$

Real Academia Española (2017). Diccionario [dle.rae.es]. Recuperado de: http://dle.rae.es/

Red Nacional do ESporte (2017, 14 de abril). Beca Atleta Podio [brasil2016.gov.br]. Recuperado de:http://www.brasil2016.gov.br/es/incentivos/bolsa-atleta-podio

Resolución Viceministerial N $\mathrm{N}^{\mathrm{a}}$ 065-2017- MINEDU (2017). En el Ministerio de Educación. Perú. Recuperado de http://www.minedu.gob.pe/jden/pdf/rvm-n-0652017-minedu.pdf

Segeplán (2015). Guía para formulación de políticas públicas. Segeplán: Ciudad de Guatemala. Recuperado de: http://www.segeplan.gob.gt/downloads/2015/Politicas_Publicas/GpFPP.pdf

Tamayo, M. (1997). La nueva Administración Pública. Recuperado de http://politicas.typepad.com/files/tamayo_el-analisis.pdf 
Teoriasadministrativas (2012, 30 de octubre). Modelo burocrático de organización de Max Weber desde un enfoque decidofóbico [teoriasadministrativas.wikispaces.com]. Recuperado de:. https://teoriasadministrativas.wikispaces.com/REPRESENTANTES+Y+APORT ES\%C2\%A0ESPEC\%C3\%8DFICOS\%C2\%A0BUROCRACIA

Torres, C. (2013). Apuntes para una conceptualización de las políticas públicas. Revista científica Avances, Recuperado el 14 de abril del 2017 de https://dialnet.unirioja.es/descarga/articulo/5350844.pdf

Vaquero, P. (2005). Motivación, incentivos y rendimiento estudio de un caso en hockey sobre césped. Revista de psicología del deporte, Recuperado de: https://dialnet.unirioja.es/servlet/articulo? codigo=1355919

Von, Christian (2005). Gobernanza sistémica y desarrollo en América Latina.

Recuperado de: https://repositorio.cepal.org/bitstream/handle/11362/10997/085035052_es.pdf?sequence $=1$

Winchester, L. (2011). La formulación e implementación de las políticas públicas en ALC: Políticas presupuestarias y gestión por resultados en América Latina y el Caribe [Diapositivas]. Recuperado de:https://www.cepal.org/ilpes/noticias/paginas/4/45114/Pol\%C3\%ADticaspubli casenALC_Winchester.pdf

Zuñiga, M. (2012, 16 de setiembre). Red política: ¿estamos creando valor público en nuestras organizaciones? [sieteredes.blogspot.pe]. Recuperado de: http://sieteredes.blogspot.pe/2012/09/red-politica-estamos-creando-valor.html 


\section{ANEXO \\ ENTREVISTA AGENTES DEL DEPORTE}

1. ¿Crees que en el Perú hay suficientes Deportistas Calificados de Alto Nivel? En caso tu respuesta sea $\mathrm{NO}$, ¿cuál crees que sea la causa?

2. ¿Estás de acuerdo que en el Perú todos los deportes tienen el mismo tratamiento e igualdad de oportunidades? ¿Por qué?

3. ¿Cuál crees que es la principal causa de la deserción de Deportistas Calificados de Alto Nivel?

4. ¿Conoces alguna política pública que contribuya a impulsar el desarrollo del deporte de Alto Rendimiento en el Perú? En caso tu respuesta sea SI, describe como contribuye a impulsar el desarrollo del deporte de Alto Rendimiento.

5. ¿Existen suficientes profesionales ligados al rubro deportivo en el Perú?

6. ¿Qué tipo de estímulo consideras que sería relevante otorgar al deportista para impulsar el desarrollo del deporte de alto rendimiento?

7. ¿Consideras importante que los Deportistas Calificados de Alto Nivel - DECAN accedan a becas de estudio? ¿Porque?

8. ¿Cuáles son las carreras ligadas al deporte que se deben potenciar en el Perú? ¿Por qué?

9. ¿Qué apreciación tienes acerca de la administración del deporte nacional?

10. Según tu apreciación, ¿Cómo consideras el nivel deportivo de Perú en comparación con los países suramericanos? 